\title{
Brazilian Fetal Cardiology Guidelines - 2019
}

Direction: Department of Congenital Heart Disease and Pediatric Cardiology (DCC-CP) and the Brazilian Cardiology Society (SBC)

Norms and Guidelines Council: Fernando Bacal, Leandro loschpe Zimerman, Paulo Ricardo Avancini Caramori, and Pedro A. Lemos

Norms and Guidelines Coordinator: Ludhmila Abrahão Hajjar

Coordinators: Simone R. F. Fontes Pedra and Paulo Zielinsky

Authors: Simone R. F. Fontes Pedra, ${ }^{1,2}$ Paulo Zielinsky, ${ }^{3}$ Cristiane Nogueira Binotto, ${ }^{4,5}$ Cristiane Nunes Martins, ${ }^{6}$ Eduardo Sérgio Valério Borges da Fonseca, ${ }^{7}$ Isabel Cristina Britto Guimarães, ${ }^{8,9}$ Izabele Vian da Silveira Corrêa, ${ }^{3}$ Karla Luiza Matos Pedrosa, ${ }^{9}$ Lilian Maria Lopes, ${ }^{10}$ Luiz Henrique Soares Nicoloso, ${ }^{3}$ Marcia Ferreira Alves Barberato, ${ }^{11}$ Marina Maccagnano Zamith ${ }^{12}$

Instituto Dante Pazzanese de Cardiologia, ${ }^{1}$ São Paulo, SP - Brazil

Hospital do Coração (HCor), ${ }^{2}$ São Paulo, SP - Brazil

Instituto de Cardiologia do Rio Grande do Sul, ${ }^{3}$ Porto Alegre, RS - Brazil

Hospital Pequeno Príncipe, ${ }^{4}$ Curitiba, PR - Brazil

Universidade Positivo, ${ }^{5}$ Curitiba, $P R-$ Brazil

Biocor Instituto, ${ }^{6}$ Nova Lima, MG - Brazil

Universidade Federal da Paraíba (UFPB), ${ }^{7}$ João Pessoa, PB - Brazil

Universidade Federal da Bahia (UFBA), ${ }^{8}$ Salvador, BA - Brazil

Hospital Ana Nery, ${ }^{9}$ Salvador, BA - Brazil

Ecokidgrafia Serviços Médicos, ${ }^{10}$ São Paulo, SP - Brazil

Cardioeco Centro de Diagnóstico Cardiovascular, ${ }^{11}$ Curitiba, PR - Brazil

Universidade Federal de São Paulo (UNIFESP), ${ }^{12}$ São Paulo, SP - Brazil

This Guideline should be cited as:

Pedra SRFF, Zielinsky P, Binotto CN, Martins CN, Fonseca ESVB, Guimarães ICB et al. Brazilian Fetal Cardiology Guidelines - 2019. Arq Bras Cardiol. 2019; 112(5):600-648.

Note: These Guidelines are for information purposes and are not to replace the clinical judgment of a physician, who must ultimately determine the appropriate treatment for each patient.

Corresponding Address:

Sociedade Brasileira de Cardiologia - Av. Marechal Câmara, 360/330 - Centro - Rio de Janeiro - Postal Code: 20020-907.

E-mail: sbc@cardiol.br. 


\section{Guideline}

Declaration of potential conflict of interest of authors/collaborators of the Brazilian Fetal Cardiology Guidelines - 2019

If the last three years the author/developer of the Guidelines:

\begin{tabular}{|c|c|c|c|c|c|c|c|}
\hline $\begin{array}{l}\text { Names Members } \\
\text { of the Policy }\end{array}$ & $\begin{array}{l}\text { Participated in clinical studies } \\
\text { and/or experimental trials } \\
\text { supported by pharmaceutical } \\
\text { or equipment related to the } \\
\text { guideline in question }\end{array}$ & $\begin{array}{l}\text { Has spoken at } \\
\text { events or activities } \\
\text { sponsored by } \\
\text { industry related } \\
\text { to the guideline in } \\
\text { question }\end{array}$ & $\begin{array}{l}\text { It was (is) advisory } \\
\text { board member } \\
\text { or director of a } \\
\text { pharmaceutical or } \\
\text { equipment }\end{array}$ & $\begin{array}{l}\text { Committees } \\
\text { participated } \\
\text { in completion } \\
\text { of research } \\
\text { sponsored by } \\
\text { industry }\end{array}$ & $\begin{array}{l}\text { Personal or } \\
\text { institutional aid } \\
\text { received from } \\
\text { industry }\end{array}$ & $\begin{array}{l}\text { Produced } \\
\text { scientific papers } \\
\text { in journals } \\
\text { sponsored by } \\
\text { industry }\end{array}$ & $\begin{array}{l}\text { It shares } \\
\text { the industry }\end{array}$ \\
\hline Cristiane Nogueira Binotto & No & No & No & No & No & No & No \\
\hline Cristiane Nunes Martins & No & No & No & No & No & No & No \\
\hline $\begin{array}{l}\text { Eduardo Sérgio Valério Borges } \\
\text { da Fonseca }\end{array}$ & No & No & No & No & No & No & No \\
\hline Isabel Cristina Britto Guimarãe & No & No & No & No & No & No & No \\
\hline Izabele Vian da Silveira Corrêa & No & No & No & No & No & No & No \\
\hline Karla Luiza Matos Pedrosa & No & No & No & No & No & No & No \\
\hline Lilian Maria Lopes & No & No & No & No & No & No & No \\
\hline Luiz Henrique Soares Nicoloso & No & No & No & No & No & No & No \\
\hline $\begin{array}{l}\text { Marcia Ferreira Alves } \\
\text { Barberato }\end{array}$ & No & No & No & No & No & No & No \\
\hline Marina Maccagnano Zamith & No & No & No & No & No & No & No \\
\hline Paulo Zielinsky & No & No & No & No & No & No & No \\
\hline Simone R. F. Fontes Pedra & No & No & No & No & No & No & No \\
\hline
\end{tabular}




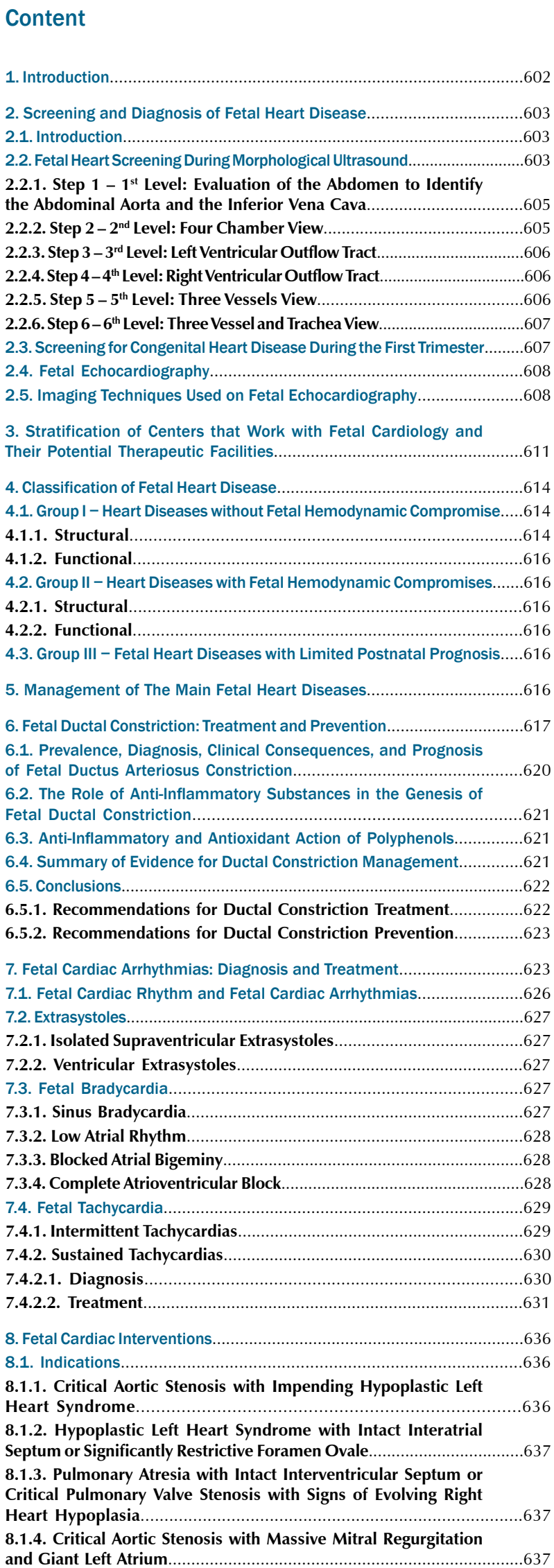

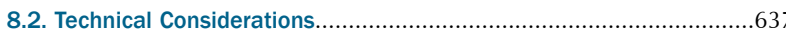

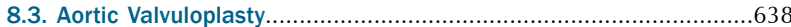

8.4. Critical Aortic Stenosis with Giant Left Atrium.................................638

8.5. Fetal Pulmonary Valvuloplasty...................................................639

8.6. Fetal Atrial Septostomy.............................................................639

8.7. Final Considerations of Fetal Cardiac Interventions........................640

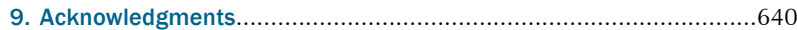

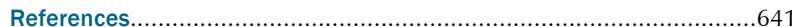

\section{Introduction}

Over the years, Fetal Cardiology have been incorporated into the daily practice of Pediatric Cardiology. What was once restricted to a few fetal heart researchers, has slowly been incorporated into health institutions that deal with congenital heart diseases (CHD). Fetal echocardiography has generated extensive knowledge of the natural and modified history of heart diseases in utero, and normal fetal heart physiology and anatomy. The benefits of fetal diagnosis have become unquestionable over the years. Pioneers in the area succeeded in demystifying the fetal heart examination and proving the importance of screening for cardiac abnormalities during obstetric examinations. Prenatal detection rates have increased, and interest in fetal echocardiography is, thus, no longer merely a diagnostic tool; it has gone on to become a tool of the utmost importance in assisting medical and, progressively, interventional treatment of specific anomalies that occur in fetal life.

A vast body of literature currently supports the practice of Fetal Cardiology. In addition to diagnosis, anatomical and functional particularities may be identified in utero, with implications on the delivery planning and pre and postnatal management. Prenatal diagnosis has certainly led to increase the number of babies with complex heart diseases in Pediatric Cardiology hospital beds. Prior to this, children with complex heart diseases did not survive the immediate neonatal period and died in neonatal intensive care units without being diagnosed. Nowadays, these children require increasingly careful and specific management involving Pediatric Cardiology and thus modifying the practice of Neonatal Cardiology.

Despite the vast literature pertinent to Fetal Cardiology, due to the restricted number of cases, there is a lack of studies with large populations and randomization processes, being the information based on observational studies and description of small samples or cases reports. However, the accumulated knowledge is already enough to develop scientific statements or guidelines.

In April 2014, the American Heart Association (AHA) published the first scientific statement for Fetal 


\section{Guideline}

Cardiology, encompassing all the practical aspects involved in this area, including screening, diagnosis, medical or interventional therapy, counseling, delivery planning, and neonatal treatment. Considering this extremely thorough and highly useful document, we have accepted the challenge of bringing together professionals dedicated to Fetal Cardiology from different regions of Brazil in order to jointly establish guidelines which are adapted to our reality and which also take into consideration knowledge created in Brazil. We believe that the information brought together in this document will be of great use to professionals who face the challenge of dealing with possible abnormalities that affect the fetal heart in their daily practice.

\section{Screening and Diagnosis of Fetal Heart Disease}

\subsection{Introduction}

One of the main aims of prenatal diagnosis is the detection of severe CHD, whose diagnoses, in most cases, depend on delivery planning in a specialized referral center. ${ }^{1-3}$ Although fetal echocardiography, which is traditionally designated for high-risk pregnancies, is quite accurate, the majority of newborns affected by heart diseases in most parts of the world, continue to be born without having been diagnosed. This occur because many cases of CHD affect low-risk groups and are not detected by screening prenatal ultrasound..$^{4,5}$

The concept of prenatal screening for $\mathrm{CHD}$ was first suggested in 1985, with the recommendation of incorporating the four-chamber view into routine obstetric ultrasound. ${ }^{6}$ For more than 25 years, countries such as France, the United Kingdom and Spain have recommended examination of the fetal heart during the routine obstetric ultrasound. Nonetheless, after many years of investment in educational training programs, regional variation in detection rates of prenatal heart diseases continue to be high. The classic study by Garne et al., ${ }^{7}$ conducted in 20 European centers showed that the global detection rate of fetal heart diseases was rather low (25\%), France being the country with the best performance (48\%), followed by Spain (45\%), Germany (40\%), and the United Kingdom (35\%). Many studies have shown that detection rates of prenatal heart diseases significantly improve with the expansion of scanning planes for cardiac analysis, but they remain well below $50 \%$ and continue to lag behind in relation to prenatal detection of other forms of congenital malformation. ${ }^{8,9}$

Faced with this situation, some have argued that fetal echocardiography should be indicated for all pregnancies, given that, in experienced hands, it is able to detect nearly $100 \%$ of all cardiac anomalies in fetal life and is considered the gold standard for fetal cardiac diagnosis. ${ }^{10-13}$

Although it is almost intuitive that prenatal detection of heart diseases would improve perinatal results, it has not been easy to prove this observation scientifically, owing to the difficulty of comparing groups with pre- and postnatal diagnoses, which present rather peculiar and discrepant characteristics. The group with prenatal diagnosis often presents with fetal death or early neonatal death before surgery, as it pertains to the much more severe spectrum of fetal cardiac abnormalities, due to the inability of obstetric ultrasound to screen simpler heart diseases, thus resulting in higher global mortality. On the other hand, the group with postnatal diagnosis, that survives the fetal and early neonatal periods until the baby arrives in a tertiary center, has already demonstrated some constitutional advantages for survival. ${ }^{2}$

A study conducted in France comparing perinatal outcome between babies with transposition of the great arteries, with and without prenatal diagnosis, showed, for the first time, that prenatal diagnosis significantly decreased pre- and postoperative mortality. ${ }^{14}$ Other studies have suggested better results for hypoplastic left heart syndrome (HLHS) and coarctation of the aorta when they are diagnosed during fetal life..$^{15,16}$

Efforts and resources should be directed to teaching and training for prenatal screening of CHD by obstetric ultrasound to achieve a better and more uniform pattern of detection, since performing fetal echocardiography in all pregnancies is unrealistic and has yet to be adopted as a health policy in developed countries. ${ }^{11,13,17}$

Table 2.1 shows the main risk factors for fetal heart diseases, divided into absolute risk of $\geq 2 \%$ and $<2 \%$.

\subsection{Fetal Heart Screening During Morphological Ultrasound}

Considering all these characteristics, we propose a very simple methodology for evaluating the fetal heart, which has been applied in various countries throughout the world. The main advantage of this systematized heart evaluation is that it eliminates the need for complex views and images, avoiding more difficult maneuvers, which is time-consuming and discourage the examiner who neglects this important part of the morphological exam.

With this technique, the fetal heart is evaluated on transverse plane images of the baby only, with no need to rotate the transducer. It starts from the fetal abdomen, from the infradiaphragmatic region to the 
Tabela 2.1 - Clinical conditions that increase the risk of fetal heart disease and are formal indications to perform fetal echocardiogram

\begin{tabular}{|c|c|}
\hline Absolute risk $\geq 2 \%$ & GOR/LOE \\
\hline Pregestational maternal diabetes mellitus & $\mathrm{I} / \mathrm{A}$ \\
\hline Maternal diabetes mellitus diagnosed during the first trimester & $\mathrm{I} / \mathrm{A}$ \\
\hline Poorly controlled maternal phenylketonuria, & $\mathrm{I} / \mathrm{A}$ \\
\hline Maternal anti-RO and anti-LA (SSA/SSB) antibodies & $\| \mathrm{la} / \mathrm{B}$ \\
\hline \multirow{3}{*}{ Maternal medication exposures } & $\| \mathrm{la} / \mathrm{B}$ \\
\hline & $\mathrm{I} / \mathrm{B}$ \\
\hline & $\mathrm{I} / \mathrm{A}$ \\
\hline Maternal rubella during the first semester & $\mathrm{I} / \mathrm{C}$ \\
\hline Maternal infection, with fetal myocarditis suspected & $\mathrm{I} / \mathrm{C}$ \\
\hline Use of assisted reproduction technology & $\| \mathrm{la} / \mathrm{A}$ \\
\hline $\mathrm{CHD}$ in first-degree relative (mother, father, or sibling) & $\mathrm{I} / \mathrm{B}$ \\
\hline Mendelian inheritance associated with $\mathrm{CHD}$ in first- or second-degree relative & $\mathrm{I} / \mathrm{C}$ \\
\hline Suspected CHD on obstetric ultrasound & $\mathrm{I} / \mathrm{B}$ \\
\hline Suspected noncardiac abnormality on obstetric ultrasound & $\mathrm{l} / \mathrm{B}$ \\
\hline Abnormal fetal karyotype & $\mathrm{I} / \mathrm{C}$ \\
\hline Fetal bradycardia, tachycardia, or irregular cardiac rhythm & $\mathrm{I} / \mathrm{C}$ \\
\hline Increased nuchal translucency $>95 \%$ ( $\geq 3 \mathrm{~mm})$ & Ila/A \\
\hline Monochorionic twins & I/A \\
\hline Fetal hydrops or pleural effusion & $\mathrm{l} / \mathrm{B}$ \\
\hline
\end{tabular}

Absolute risk between 1 and $2 \%$

\begin{tabular}{|c|c|c|}
\hline \multirow{5}{*}{ Maternal medication exposures } & Anticonvulsants & $\| \mathrm{lb} / \mathrm{A}$ \\
\hline & Lithium & $\| \mathrm{lb} / \mathrm{B}$ \\
\hline & Vitamin A & $\| \mathrm{lb} / \mathrm{B}$ \\
\hline & Selected serotonin reuptake inhibitor (only paroxetine) & $\| \mathrm{lb} / \mathrm{A}$ \\
\hline & $\begin{array}{l}\text { Nonsteroidal anti-inflammatory drugs during the first and } \\
\text { second trimesters }\end{array}$ & $\| \mathrm{ll} / \mathrm{B}$ \\
\hline $\mathrm{CHD}$ in second-degree relatives & & $\mathrm{Ilb} / \mathrm{B}$ \\
\hline Fetal abnormality of umbilical cord or placenta & & $\mathrm{Ilb} / \mathrm{C}$ \\
\hline Intra-abdominal fetal venous anomaly & & $\mathrm{Ilb} / \mathrm{C}$ \\
\hline \multicolumn{3}{|c|}{ Absolute risk $\leq 1 \%$} \\
\hline Gestational maternal diabetes mellitus with $\mathrm{HbA} 1 \mathrm{C}<6 \%$ & & $\| I / B$ \\
\hline \multirow{2}{*}{ Maternal medication exposures } & Selected serotonin reuptake inhibitor (excepting paroxetine) & $111 / \mathrm{A}$ \\
\hline & Vitamin $\mathrm{K}$ antagonists (warfarin) & $\| I / B$ \\
\hline Maternal infection other than rubella with seroconversion only & & $\| I I / C$ \\
\hline Isolated CHD in a distant relative (not first- or second-degree) & & $\| I / \mathrm{B}$ \\
\hline
\end{tabular}

ACE: angiotensin-converting enzyme; CHD: congenital heart disease; GOR: grade of recommendation; HbA1c: hemoglobin A1c; LOE: level of evidence. Source: Adapted from Donofrio et al. ${ }^{17}$ 


\section{Guideline}

upper mediastinum, obtaining 6 planes, as shown in Figure 2.1.

2.2.1. Step $1-1^{\text {st }}$ Level: Evaluation of the Abdomen to Identify the Abdominal Aorta and the Inferior Vena Cava

This is a transverse view of the fetal abdomen, in the subdiaphragmatic region, and helps to determine the abdominal situs. Before starting, it is necessary to identify the right and left sides of the fetus, according to the fetal presentation; the stomach should be on the fetal left side and the liver on the right. Furthermore, the descending aorta should be seen posterior and to the left, close to the spine, and the inferior vena cava anterior and to the right, within the hepatic parenchyma.

\subsubsection{Step $2-2^{\text {nd }}$ Level: Four Chamber View}

This view is obtained with a transverse scan of the fetal thorax, immediately above the diaphragm. The heart should occupy one third of the thorax, the greater part being in the left hemithorax, with the apex turned to the left. The interventricular septum should be at an angle of approximately $45^{\text {th }}$ with the midline.

The first step for fetal cardiac analysis is the identification of the spine. Opposite to the spine is the anterior wall of the thorax, or sternum. Below is the right ventricle, which is characterized by the moderator band and the tricuspid valve, located a few millimeters displaced to the apex. Returning to the spine, the descending aorta is seen anteriorly as a circle in the mediastinum and, in front of it, is the left atrium. The left atrium is close to the descending aorta and can be identified by the characteristic movement of the foramen ovale flap. Other intracardiac structures, such as the right atrium and the left ventricle, may then be analyzed. They should have dimensions similar to those of the contralateral chambers. The atrioventricular valves should be analyzed in relation to their movement and size of their valve annulus.

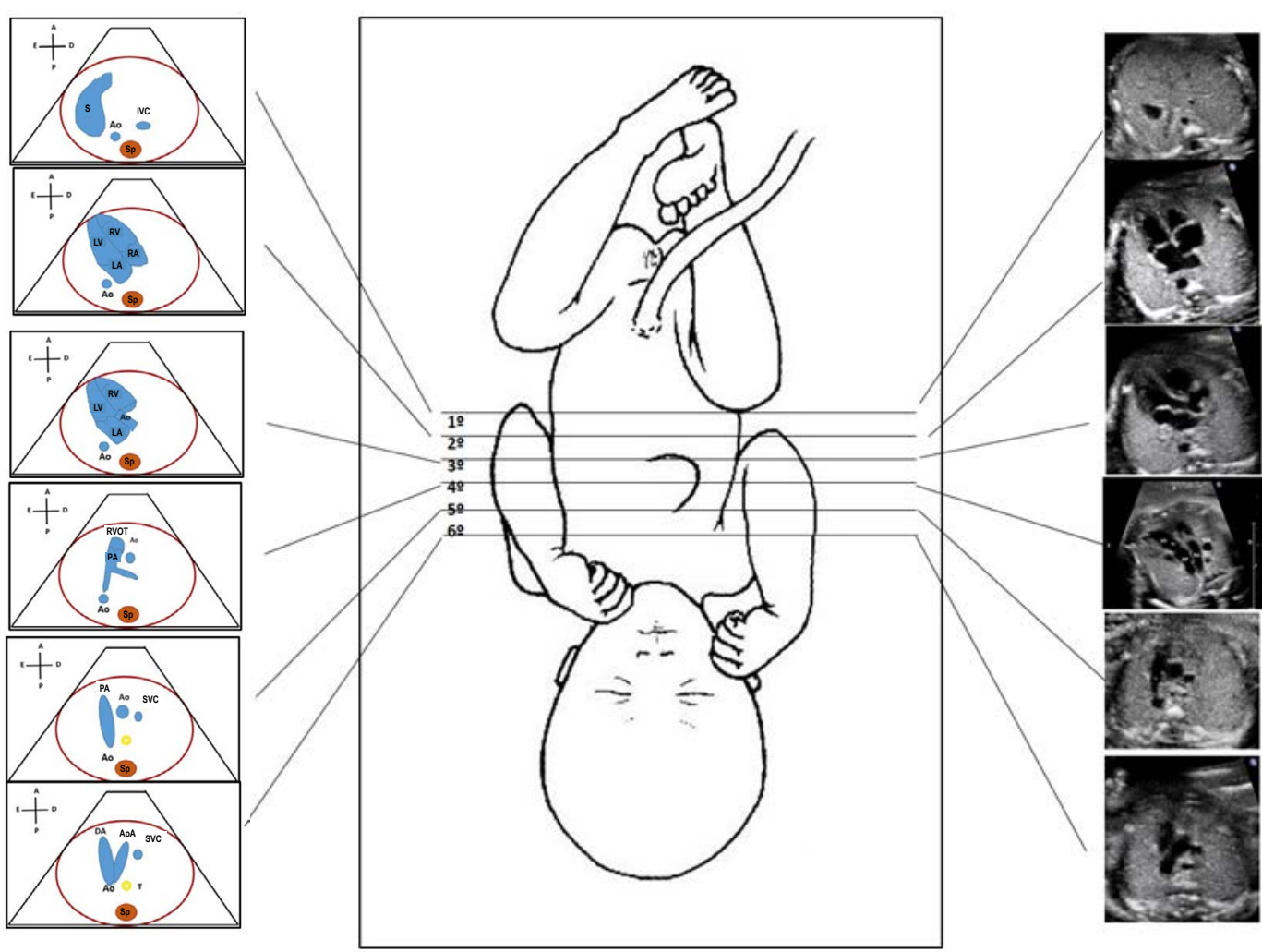

Figure 2.1 - Standardization of fetal heart screening, scanning the fetal vessels and heart from the infradiaphragmatic region towards the cranium. There are 6 levels, being the first exactly below the diaphragm, which allows the identification of the descending aorta and inferior vena cava; second, the four-chamber view; third, left ventricular outflow tract; fourth, right ventricular outflow tract; fifth, three vessel view, and, sixth, three vessel and trachea view.

Ao: Aorta; AoA: aortic arch; Asc: ascending; DA: ductus arteriosus; IVC: inferior vena cava; LA: left atrium; LV: left ventricle; PA: pulmonary artery; RA: right atrium; RV: right ventricle; RVOT: right ventricular outflow tract; S: stomach; Sp: spine; SVC: superior vena cava; T: trachea. 
In summary, the analysis of the four-chamber view should include the following reference points:

- Spine.

- Descending aorta in a transverse plane.

- Left atrium close to the descending aorta and with the foramen ovale flap moving.

- Right ventricle with the apex "filled in" by a piece of muscle called the moderator band.

- Two atria of similar size.

- Two ventricles of similar size, thickness and contractility (the right ventricle may be slightly larger).

- The interatrial and interventricular septum join the atrioventricular valves in the middle of the heart, suggesting the image of a cross, the "crux cordis."

- The interventricular septum should be intact and make an angle of approximately $45^{\circ}$ with the midline of the body.

- Two atrioventricular valves with equal opening orifices. The insertion of the septal leaflet of the tricuspid valve is closer to the cardiac apex, resulting in a minimal difference in the level of implantation of the anterior leaflet of the mitral valve. Sometimes, this difference is quite subtle, resulting in great difficulties in excluding the diagnosis of atrioventricular septal defect and single AV valve junction.

- The interatrial septum may be seen with the foramen ovale and its flap, tilting with the LA.

- The pulmonary veins drainage in the left atrium should be identified in two-dimensional view and confirmed by colored Doppler or power Doppler.

Failure to obtain a normal four chamber view during the obstetric ultrasound scan is an absolute indication for fetal echocardiogram. Because the four-chamber view does not include the examination of the right and left ventricular outflows, important diseases such as transposition of the great arteries, tetralogy of Fallot (TOF), common truncus arteriosus, among others may be missed. Tables 2.2 and 2.3 show the different heart diseases commonly associated with normal and abnormal four chamber views, respectively.

\subsubsection{Step $3-3^{\text {rd }}$ Level: Left Ventricular Outflow Tract}

Starting from the four-chamber views, the left and right outflow tracts and respective arteries can be seen swiping the transducer toward the fetal head. The left ventricular outflow tract is the first identified in the middle of the heart and it directs toward the fetal right shoulder. In this view it is possible to observe the membranous continuity of the septum with the aorta, which rules out a possible overriding aorta or great artery
Table 2.2 - Heart diseases commonly associated with a normal fourchamber view

\begin{tabular}{c}
\hline Tetralogy of Fallot \\
\hline Transposition of the great arteries \\
\hline Common truncus arteriosus \\
\hline Anomalies of the aortic arch \\
\hline Mild aortic and pulmonary valve stenosis \\
\hline Perimembranous ventricular septal defect \\
\hline
\end{tabular}

Table 2.3 - Heart diseases commonly associated with an abnormal four-chamber view

\begin{tabular}{c}
\hline Mitral and/or aortic atresia \\
\hline Tricuspid and/or pulmonary atresia \\
\hline Ebstein's anomaly/tricuspid valve dysplasia \\
\hline Atrioventricular septal defects \\
\hline Large ventricular septal defects \\
\hline Single ventricles \\
\hline Severe aortic and pulmonary valve stenosis \\
\hline Coarctation of the aorta \\
\hline Total anomalous pulmonary venous return \\
Cardiomyopathies \\
Cardiac tumors
\end{tabular}

commonly seen in tetralogy of Fallot, truncus arteriosus, and other complex anomalies.

\subsubsection{Step $4-4^{\text {th }}$ Level: Right Ventricular Outflow Tract}

Swiping slightly the transducer up, the right ventricular outflow tract is reached. It is the most anterior structure of the heart and is exactly below the fetal sternum. It crosses aorta from right towards the left. The great arteries are symmetric at the beginning of gestation, but during the second and the third trimesters the pulmonary trunk is slightly larger than the aorta.

\subsubsection{Step $5-5^{\text {th }}$ Level: Three Vessels View}

This is a special view that allows to analyze the spatial relationship of the pulmonary artery, the aorta and the superior vena cava (SVC). In this view the vessels are seen immediately after their ventricular origins. Important information should be obtained from the 


\section{Guideline}

vessels: number - that should be three; position - SVC on the right, aorta on the middle and pulmonary artery on the left; size - SVC slightly smaller than aorta that should be slightly smaller than the pulmonary artery and finally, alignment - the SVC is more posterior, aorta is in the center and pulmonary artery is anterior. ${ }^{19}$ In this plane, the right and left bronchi are observed.

\subsubsection{Step $6-6^{\text {th }}$ Level: Three Vessel and Trachea View}

Immediately above this plane, i.e., tilting the transducer a bit further in the cephalic direction, a view of two large arches connecting with the descending thoracic aorta is obtained. The one on the left is the ductus arteriosus that originates from the pulmonary artery and the other on the right is the aortic arch, both connecting with the descending aorta. This view makes a figure that suggests the letter $\mathrm{V}$. The trachea appears as an anechoic structure surrounded by a hyperechoic line which corresponds to cartilage, being situated in front of the spine, slightly to the right.

In this view, the aortic arch turns toward the left, which is defined exactly by its relation to the trachea. If the trachea is to the right of the aortic arch, the arch is turned toward the left and vice versa. It is worth highlighting that, the use of color flow mapping should be used during all screening steps and levels, and it is of particular importance during this final view. Both arches should present flow in the same direction, always directed from the heart toward the descending thoracic aorta (Figure 2.2).
2.3. Screening for Congenital Heart Disease During the First Trimester

Because CHD are the most common severe congenital defects and the least diagnosed by routine obstetric ultrasound, the challenge over recent years has been early screening methods for fetal heart disease, considering the fact that the majority of babies affected by heart disease are born to mothers who do not present the classic indications for fetal echocardiography.

Older studies have shown a sensibility of up to $40 \%$ in the detection of $\mathrm{CHD}$ in fetuses with increased nuchal translucency (NT), between weeks 11 and 14 of gestation (above the $99^{\text {th }}$ percentile). Focusing on fetuses with increased NT and normal karyotype, they demonstrated an incidence of heart disease 5 to 7 times greater in this group. ${ }^{20-22}$

The most recent literature shows a sensibility of about $13.5 \%$ for the detection of cardiac abnormalities, being NT $\geq 3.5 \mathrm{~mm}$ considered an indication for fetal echocardiography. ${ }^{23-25}$

Doppler flow analysis of the fetal cardiovascular system is also applied to screen CHD that may or not be associated with chromosome diseases. Several studies have argued that abnormal flow of the ductus venosus, i.e., the appearance of the reverse wave during atrial contraction ("a" wave) in fetuses with NT $\geq 3.5 \mathrm{~mm}$ increases the probability of CHD three-fold, whereas a normal flow pattern decreases the risk of heart disease by half. ${ }^{21}$ The presence of tricuspid regurgitation during the first trimester of pregnancy is highly associated

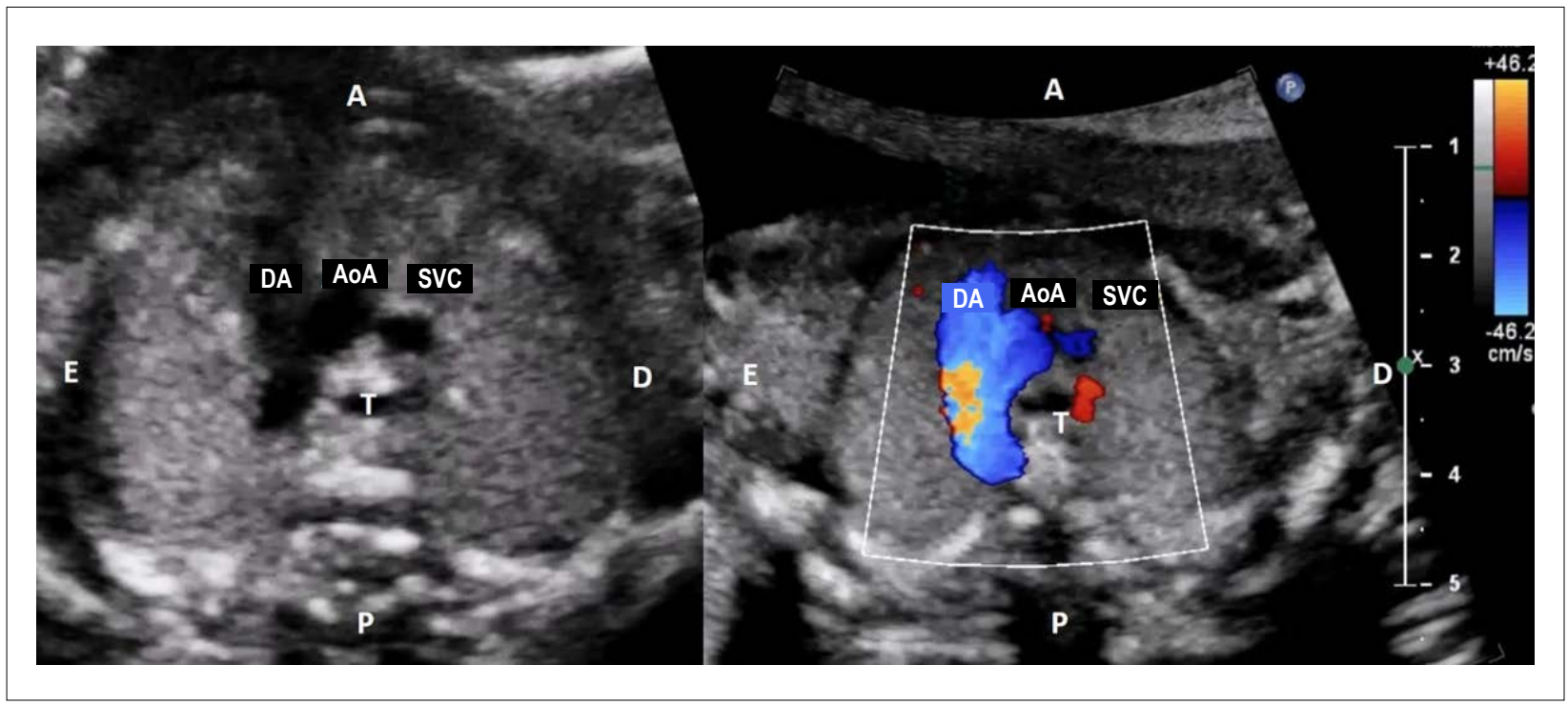

Figure 2.2 - Aorta and pulmonary artery appear elongated, going toward the descending aorta. Both converge to the aorta forming an image similar to a $V$ letter. The trachea is to the right of the aortic arch, demonstrating that the latter descends to the left. During color flow mapping, both arches are observed to have flow in the same direction, i.e., from the heart toward the descending thoracic aorta.

AoA: aortic arch; DA: ductal arch; SVC: superior vena cava; T: trachea. 
with trisomy. When present in chromosomally normal fetuses, the risk of heart disease is observed to increase eight-fold. The etiology of tricuspid regurgitation in the first semester is uncertain; it is known only that it disappears concomitantly with the normalization of nuchal thickness. ${ }^{24}$

\subsection{Fetal Echocardiography}

Before beginning the examination, it is very important to obtain information regarding gestational age, previous obstetric history, possible maternal disease or use of medications that may increase the risk for CHD, and the formal indication for the study. This will provide the cardiologist with the possible risks for cardiac anomalies.

The ultrasound system may be specific for echocardiography or ultrasonography, provided with a preset for fetal heart/echocardiography. Convex (ultrasonography) or phased array (echocardiography) transducers allow to obtain good quality images, with the observation that the majority of convex transducers do not provide continuous Doppler, which may be useful in cases of valvular stenosis or regurgitation.

Volumetric transducers may allow better twodimensional imaging in obese pregnant women and first trimester examination, but they are not essential in daily practice, being considered sophisticated technology not available in the majority of fetal scanning laboratories.

After 18 weeks gestation, all cardiac structures may be securely analyzed by the fetal echocardiogram except in cases of poor acoustic windows like obesity, polyhydramnios, oligohydramnios and others. The best images, however, are obtained between weeks 24 and 28, when the heart is larger in size, the fetus continues moving well, and the bones do not constitute a significant ultrasound barrier. It is worth highlighting that early evaluation of the heart may be performed either by transvaginal or transabdominal ultrasound (after week 14); this is usually indicated in pregnancies with high risks of fetal heart disease, especially when screening at the first trimester is indicative of cardiac anomaly. ${ }^{24}$

It is essential that the fetal cardiologist has a basic understanding of ultrasonography concepts, particularly regarding fetal status and position. Before beginning the evaluation of the heart, the position of the fetus must be determined, identifying right and left sides. The main marker of the fetal left side is the stomach. In the event of situs inversus or situs ambiguous, the stomach may be displaced, and should not be used as a marker of the fetal left side.

The best image of the heart is obtained from the abdomen, sliding the transducer slightly toward the thorax. Although it is also possible to obtain images from the front or the back of the baby, the images obtained from the back may be of inferior quality, especially during the last trimester, when the ossification of the ribs and the spine represents an important barrier to ultrasound passage. In this situation, to improve image quality, one may request patient to lie in left or right lateral decubitus position.

Polyhydramnios is a condition that may pose great difficulties to perform the examination, since the fetus may be too far from the transducer and move constantly. Perform measurements and place the Doppler sample volume in place to obtain the usual traces may be really challenging. In situation like this, the fetus may be brought closer to the transducer, if the patient lies or her knees and elbows. Maternal obesity also poses difficulties to the technical quality of the study and it is often needed a low-frequency transducer, sometimes such as those used for adult echocardiography with more vigorous compression to the maternal abdomen.

Once the fetal heart has been identified, only small movements of the transducer are necessary to analyze all the cardiac structures. Considering that the fetal heart is relatively far from the transducer, small movements mean big changes in angle. Fetal echocardiography is considered complete when the heart has been examined from all possible views and planes, including the projections obtained in a conventional postnatal echocardiogram.

Differently from the recommendations for obstetric screening for cardiac malformations, fetal echocardiography must include transverse and longitudinal views of the fetus, what guarantees different sights of the same structure. ${ }^{18}$ The following images should also be included to the 6 transverse levels: long axis of the aortic and ductal arches (Figures 2.3 and 2.4), bicaval view (Figure 2.5), and short axis of ventricles and great vessels (Figures 2.6 and 2.7).

\subsection{Imaging Techniques Used on Fetal Echocardiography}

Experienced imaging professionals, such as ultrasound specialists, radiologists, or echocardiographers may evaluate the fetal heart with high diagnostic accuracy. However, knowledge of the anatomical, physiological and possible therapeutic algorithms are essential to obtain the most accurate information and counsel the family. To avoid missing information, the international medical societies of echocardiography and ultrasound have established the obligatory contents of a complete fetal echocardiogram.

Based on the AHA guidelines published in 2014, mandatory elements (Class of Recommendation I), elements whose inclusion is reasonable (Class of 


\section{Guideline}

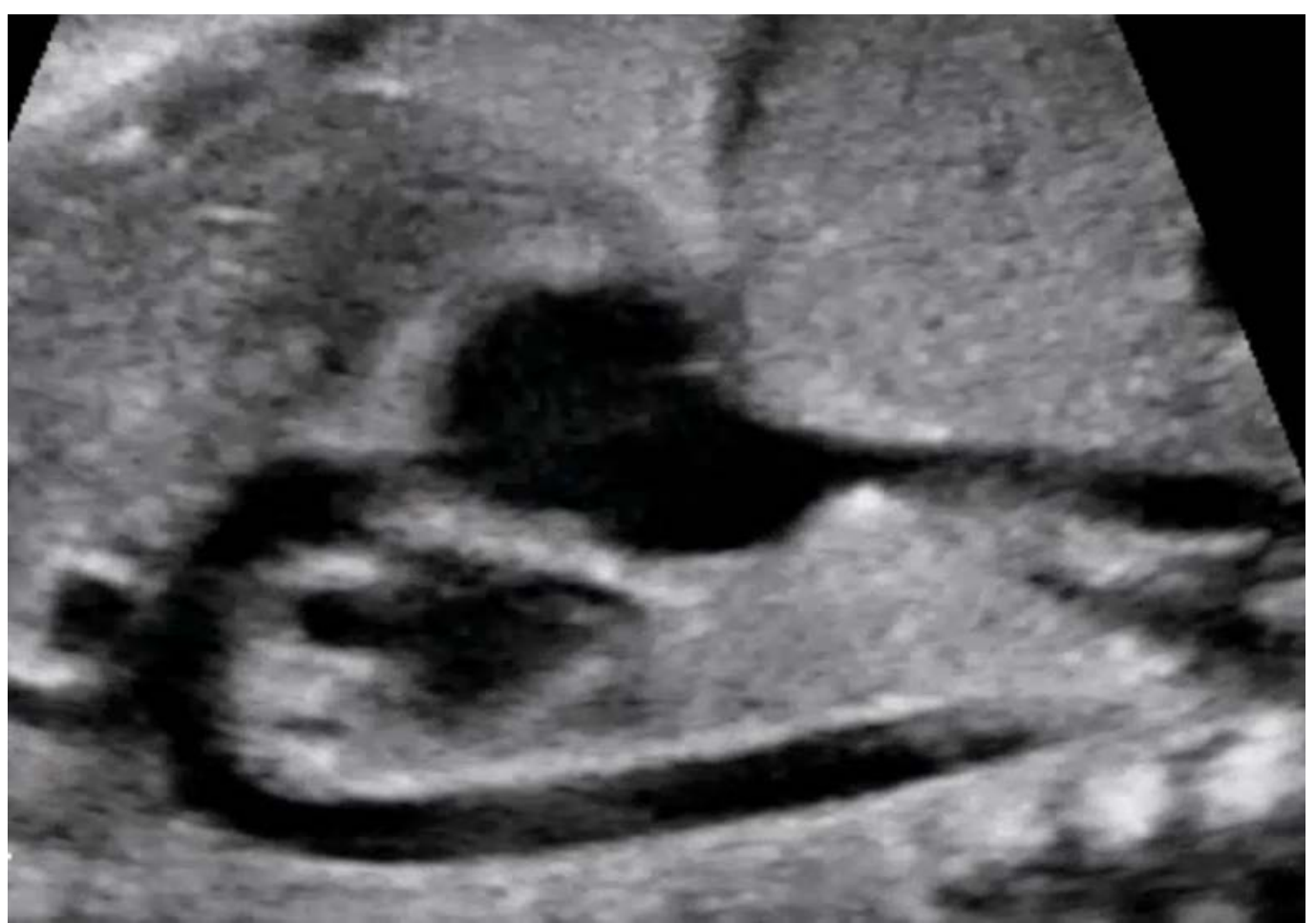

Figure 2.3 - Long axis view of the aortic arch. The shape of the aortic arch is similar to a cane.

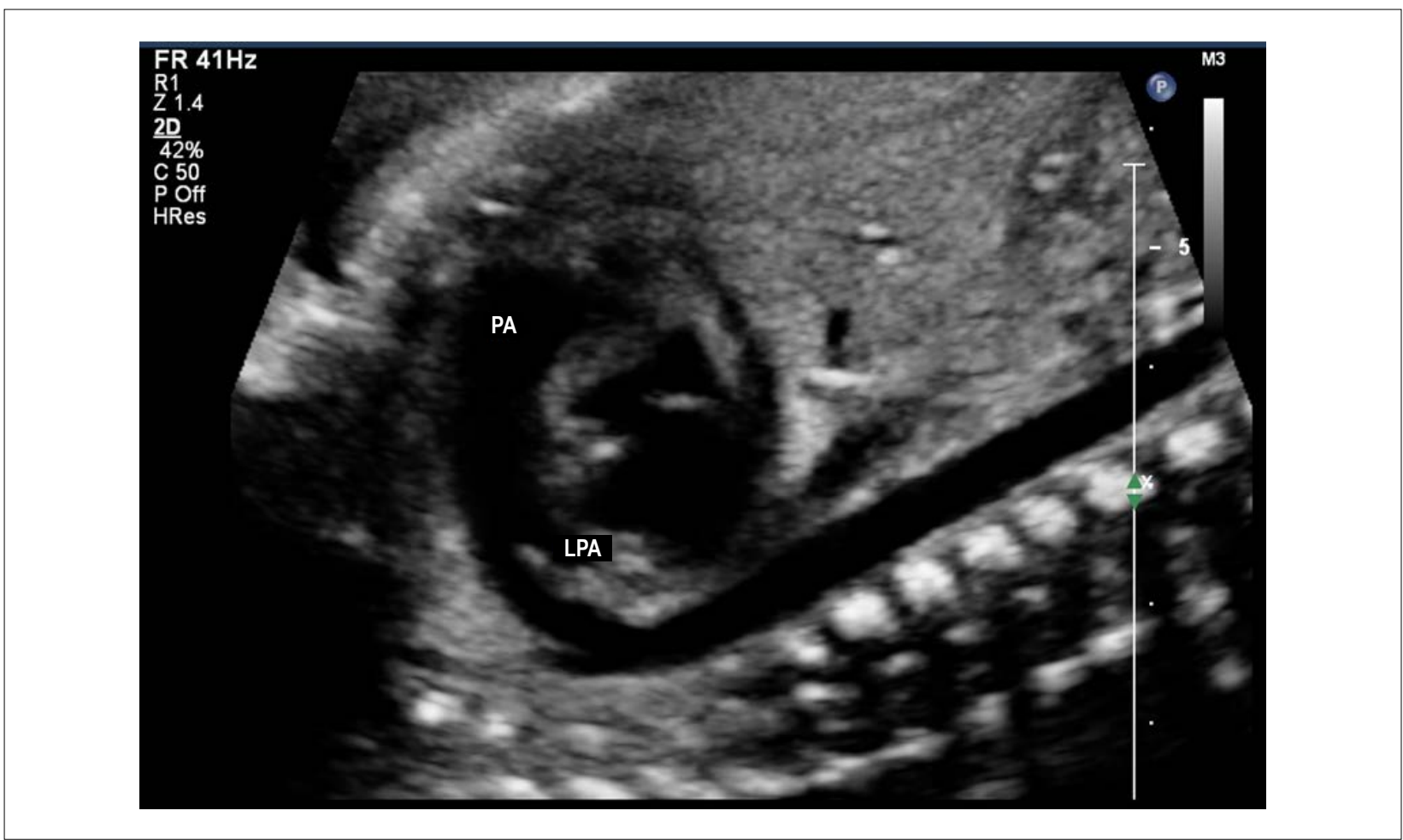

Figure 2.4 - Longitudinal plane slightly anterior and to the left of the fetus, showing the long axis view of the ductal arch. The ductal arch has a different angle than the aortic and looks like a golf club.

LPA: left pulmonary artery; PA: pulmonary artery. 


\section{Guideline}

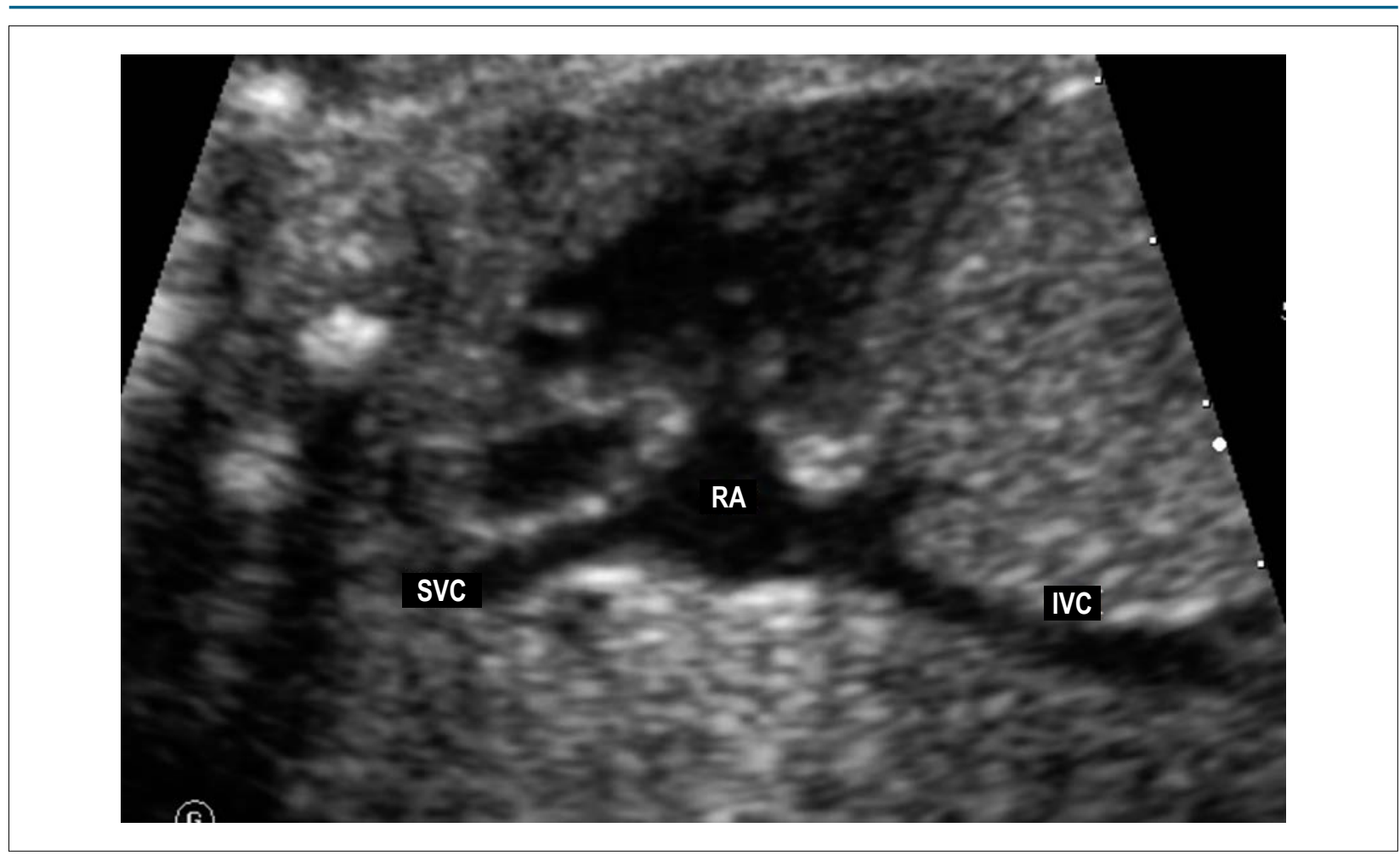

Figure 2.5 - Longitudinal fetal plane tilting posteriorly, showing the bicaval view.

IVC: inferior vena cava; RA: right atrium; SVC: superior vena cava.

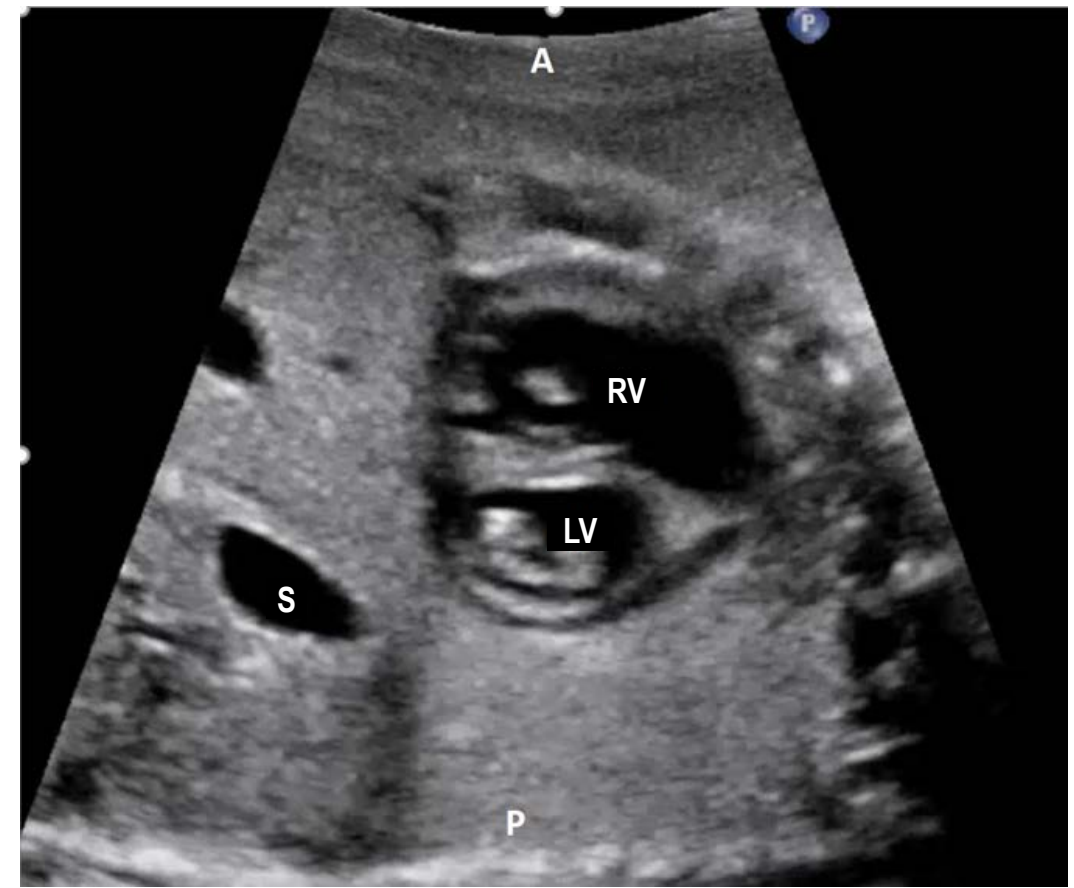

Figure 2.6 - Short-axis of the ventricles. In this plane it is possible to analyze the position of the papillary muscles of the right and left ventricles. It is also of great utility in detecting subtler forms of atrioventricular septal defect when it is presented with two valvular orifices.

A: anterior; P: posterior; LV: left ventricle; RV: right ventricle; S: stomach. 


\section{Guideline}

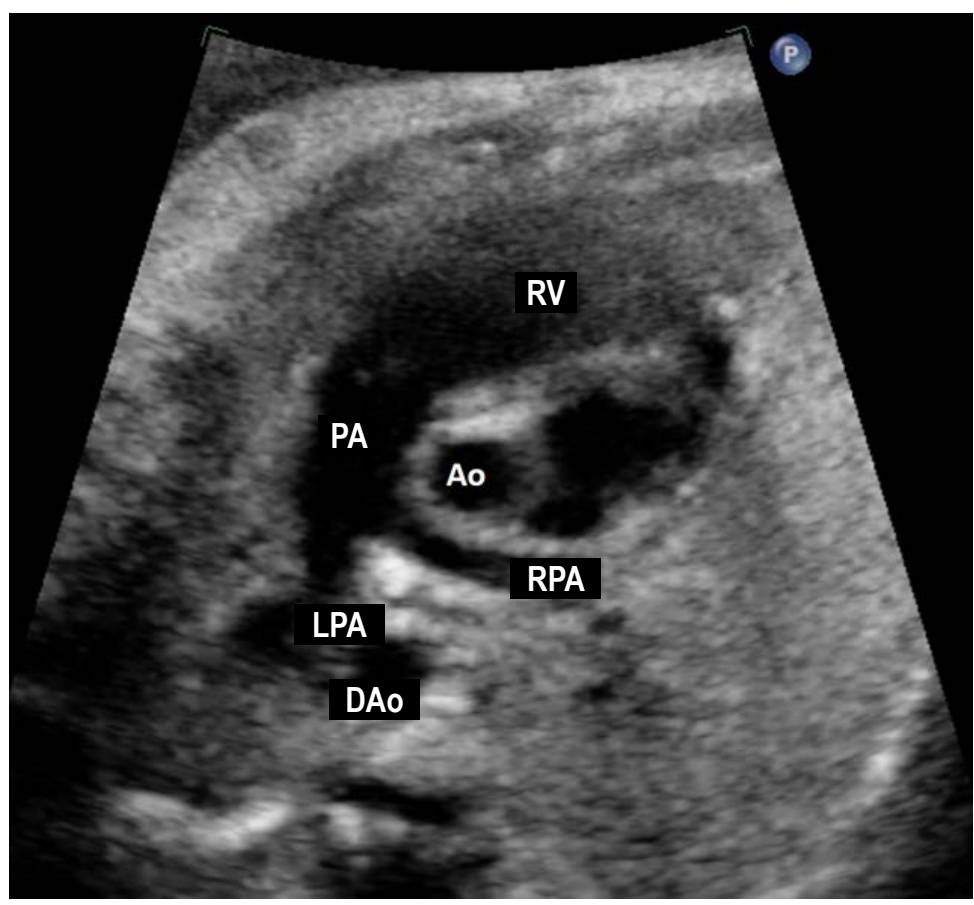

Figure 2.7 - Short axis view of the great vessels. This plane shows the relationship between the great arteries, with the aorta being in the center of the heart and posteriorly and the right ventricular outflow tract surrounding the aorta anteriorly. This is an excellent plane for identifying perimembranous ventricular septal defects and pulmonary obstructions due to the anterior deviation of the infundibular septum observed in the tetralogy of Fallot.

Ao: aorta; DAo: descending aorta; LPA: left pulmonary artery; PA: pulmonary artery; RPA: right pulmonary artery; RV: right ventricle.

Recommendation Ila) or may be reasonable (Class of Recommendation IIb) were distinguished (Table 2.4). ${ }^{17}$

\section{Stratification of Centers that Work with Fetal Cardiology and their Potential Therapeutic Facilities}

Congenital heart diseases are the most frequently malformations related to morbimortality in infancy, especially during the prenatal period. ${ }^{26}$ Its incidence has been estimated as 6 to12 cases per 1,000 live births. During fetal life, it may be up to 5 times higher, being the difference justified by fetal losses. ${ }^{27-29}$ Approximately $50 \%$ of cases have early hemodynamic consequences, requiring catheter or surgical interventions during the first year of life. ${ }^{17}$ Extracardiac malformations may be observed in up to $50 \%$, further increasing pre- and postoperative morbimortality. ${ }^{30}$ It is worth highlighting that, in developed countries, treatment for CHD compared to other congenital anomalies, have the highest hospital costs. ${ }^{31}$

Over the past years, first-trimester ultrasounds and, widespread use of fetal echocardiography have contributed to increase the rates of fetal diagnosis of $\mathrm{CHD}$ and consequently, improve perinatal outcome.

However, fetal echocardiography has not become universally available in Brazil yet, with the majority of professionals trained in Fetal Cardiology being concentrated in the South and Southeast Regions and a more restricted number in the North, Northeast, and Central-West Regions. In the states located in these latter regions, the availability of this tool is mainly restricted to the capital cities and is of low availability in Brazil's public healthcare system (Sistema Único de Saúde, SUS). ${ }^{32-34}$

There is a decreasing tendency of Brazil's infant mortality rates over the last years, with a $77 \%$ decline over 22 years, from 62 deaths per 1,000 live births in 1990 to 14 per 1,000 in 2012. ${ }^{35}$ Deaths during the first year of life represent $90 \%$ of mortality in the $0-4$ age group, with $68 \%$ occurring between 0 and 28 days. Congenital cardiac anomalies have been identified as responsible for a significant part of these rates, especially during the neonatal period. ${ }^{35}$ It is estimated that there are approximately 25,700 new cases of CHD per year in Brazil, which are distributed 
Guideline

Table 2.4 - Fetal echocardiogram mandatory, optional, and recommended elements

\begin{tabular}{|c|c|}
\hline & Essential, mandatory elements (Class I) \\
\hline \multirow{17}{*}{$\begin{array}{l}\text { Two-dimensional echocardiographic } \\
\text { anatomy }\end{array}$} & Cardiovisceral situs \\
\hline & Cardiac position \\
\hline & Pericardial effusion \\
\hline & Systemic and pulmonary venous connections \\
\hline & Atrial morphology \\
\hline & Atrial septal morphology \\
\hline & Atrioventricular connection \\
\hline & Ventricular morphology, size, and comparative analysis of the ventricular sizes \\
\hline & Ventricular-arterial connection \\
\hline & Atrioventricular valves morphology, size, and comparative analysis of the valvular sizes \\
\hline & Semilunar valves morphology, size, comparative analysis of the valvular sizes \\
\hline & Ventricular septal morphology \\
\hline & Great arteries anatomy, size, and comparative analysis of the great arteries sizes \\
\hline & Three vessels and three vessels and trachea views \\
\hline & Aortic arch morphology \\
\hline & Ductal arch morphology \\
\hline & Proximal pulmonary arteries \\
\hline \multirow{10}{*}{ Color doppler } & Superior and inferior vena cavae \\
\hline & Foramen ovale \\
\hline & Atrioventricular valves/ventricular inflows \\
\hline & Interventricular septum \\
\hline & Semilunar valves/ventricular outflows \\
\hline & Ductus venosus \\
\hline & Pulmonary veins \\
\hline & Great arteries \\
\hline & Left and right pulmonary arteries \\
\hline & Aortic and ductal arches \\
\hline \multirow{8}{*}{ Pulsed-wave doppler } & Atrioventricular valves/ventricular inflows \\
\hline & Semilunar valves/ventricular outflows \\
\hline & Ductus venosus \\
\hline & Umbilical vein \\
\hline & Umbilical artery \\
\hline & Pulmonary veins \\
\hline & Great arteries \\
\hline & Ductal arch \\
\hline
\end{tabular}

Heart rate and rhythm assessment 


\begin{tabular}{|c|c|}
\hline & Optional elements (classes Ila and IIb) \\
\hline \multirow{9}{*}{ Cardiac and general biometry } & Cardiothoracic ratio \\
\hline & Atrial dimensions \\
\hline & Ventricular dimension \\
\hline & Atrioventricular valve diameters \\
\hline & Semilunar valve diameters \\
\hline & Ascending aortic and main pulmonary artery diameters \\
\hline & Aortic and ductal arch diameters \\
\hline & Branch pulmonary artery diameters \\
\hline & Fetal biometry \\
\hline \multirow[t]{2}{*}{ Color doppler } & Umbilical vein and arteries \\
\hline & Superior and inferior vena cavae \\
\hline \multirow[t]{2}{*}{ Pulsed-wave doppler } & Right and left pulmonary arteries \\
\hline & Middle cerebral artery \\
\hline \multirow{2}{*}{ Other doppler modalities } & Continuous-wave doppler \\
\hline & Tissue doppler \\
\hline \multirow{3}{*}{ Additional cardiac function indexes } & Ventricular shortening fraction \\
\hline & Myocardial performance index \\
\hline & Calculation of cardiac output \\
\hline
\end{tabular}

regionally as follows: 2,758 cases in the North Region; 7,570 in the Northeast; 10,112 in the Southeast; 3,329 in the South, and 1,987 in the Central West. ${ }^{36}$ In 2010, the Live Births Information System (Sistema de Informação sobre Nascidos Vivos, SINASC) of the Ministry of Health, had 1,377 cases of live births with CHD notified. This represents only $5.3 \%$ of the estimated number. ${ }^{36}$

There are currently approximately 40 services accredited by the Ministry of Health to perform pediatric cardiac surgery, with a rather heterogeneous distribution, concentrated mainly in the South and Southeast Regions (62\%). In accordance with 2002 data from the Brazilian Unified Health System's Department of Informatics (Departamento de Informática do Sistema Único de Saúde, DATASUS), the deficit in cardiac surgery for CHD in the North and Northeast Regions was $93.5 \%$ and $77.4 \%$, respectively. ${ }^{32,33}$ As the implantation of Fetal Cardiology is directly related to pediatric cardiac surgery services, the current situation in Brazil, with respect to fetal diagnosis, continues to be considerably heterogeneous. ${ }^{34}$
According to their potential therapeutic facilities, Fetal Cardiology centers were stratified on three specific levels:

- Level 1: Centers that can diagnose structural and functional fetal cardiac anomalies, make the followup of the affected fetuses and, stablishe the delivery planning according to the fetal heart disease.

- Level 2: Centers where, in addition to the fetal diagnoses of structural and functional fetal cardiac anomalies, have a multidisciplinary team with obstetricians, pediatric cardiologists, interventional cardiologists, and pediatric cardiac surgeons, and can provide the postnatal therapy.

- Level 3: Centers where, in addition to diagnosis and follow-up of the affected fetuses, have a multidisciplinary team with obstetricians, pediatric cardiologists, interventional cardiologists, and pediatric cardiac surgeons and provide invasive intrauterine interventions.

Currently, in Brazil, the majority of Pediatric Cardiology centers are considered levels 1 or 2 . Intrauterine interventions are restricted to a very small number of fetuses with very specific pathologies and 
particularities that benefit from fetal therapy. For this reason, the existence of more than 1 or 2 centers with these characteristics in Brazil is not justified.

It is clear that Brazil needs more Pediatric and Fetal Cardiology centers as well as increase the number of cardiac surgeries and percutaneous interventions. Nevertheless, due to various political and environmental issues, these changes will only occur in medium to long term.

Aiming to maximize referrals of fetuses with $\mathrm{CHD}$ to the existing centers, it is mandatory that all professionals involved in the screening of CHD know how to refer the patient to the appropriate care centers. ${ }^{37,38}$ When fetuses with $\mathrm{CHD}$ are identified in places where there is no appropriate care, the doctor should promptly look for help to refer the patient to a specialized center according to the regulatory flow of the state. If the state has no specific hospital do refer the patient, the local health system should ask for outside treatment (tratamento for a de domicílio -TFD) which will look for the closest specialized center to take care of the mother and the fetus. This process is nowadays regulated by CNRAC (central nacional de regulação da alta complexidade) since directive instructions of the Ministry of Health to organize the health care for highrisk pregnancies were published. It is emphasized here that the high-risk pregnancies are "those in which the life or health of the mother, the fetus, or the newborn has higher chances of being affected when compared to the general population." ${ }^{\prime 39}$

When fetal cardiologist is dealing with a case of fetal heart disease, he or she needs to define whether there is any need of prenatal intervention or whether the treatment has to be started immediately after birth and if the patient needs to be referred to center levels 2 or 3 available in our country, reminding that not all the centers considered level 2 can treat all types of neonatal anomalies. It is known that HLHS and its variations, for example, have an extremely high fetal incidence, whereas few centers in our country have satisfactory operative results for this anomaly.

The Figure 3.1 is a flowchart that standardizes the specific care according to the fetal heart disease.

\section{Classification of Fetal Heart Disease}

With the development of fetal medicine as a medical subspecialty and with the recent advances in the ultrasound imaging, the detection of fetuses with congenital malformations has become increasingly frequent, making earlier treatment possible with significant reduction of fetal and neonatal mortality. ${ }^{40}$
With prenatal diagnosis, diseases with potential risk to have hemodynamic compromise in utero and/or in the neonatal period can be followed up and have the specific pre and postnatal care planned. Taking into account the characteristics of the fetal circulation, it is particularly important to recognize the behavior of the different heart diseases in utero and after birth, identifying those that will require any kind of treatment (use of medications or invasive procedures) or anticipation of the childbirth. ${ }^{41}$

Fetal cardiac disease may be classified as structural or functional. The majority of the structural heart diseases do not have hemodynamic compromise in utero due to the fetal circulation physiology. Clinical manifestations will occur after birth, when the physiological intracardiac shunts close. Cardiomyopathies, conditions like high output fistulas, significant abnormalities of the cardiac rhythm and restricted foramen ovale, ductal constriction or absent ductus venosus may also occur in utero and compromise the fetal hemodynamic requiring prenatal treatment.

It is important to highlight the importance of a multidisciplinary team involved in the care of fetuses affected by heart diseases, since genetic syndromes or severe extracardiac malformations may be associated and significantly increase postnatal mortality.

For these reasons, fetal heart diseases were classified into 3 groups according to possible clinical presentation and in utero hemodynamic manifestations and were separated in groups A - structural and B - functional (Table 4.1).

4.1. Group I - Heart Diseases without Fetal Hemodynamic Compromise

\subsubsection{Structural}

This group includes simple or complex cardiac defects that do not usually present progression or hemodynamic decompensation during the fetal period and, thus, do not require treatment during pregnancy and do not change obstetric management. The main example of this group are diseases with left-to-right shunt, including atrial, ventricular and atrioventricular septal defects, and aortic to pulmonary window; heart diseases with mild obstruction of right or left outflow tracts, such as pulmonary valve stenosis, aortic stenosis, and localized coarctation of the aorta; and complex CHD such as TOF with mild pulmonary flow obstruction, corrected transposition of great arteries, double outlet right ventricle, and univentricular hearts without obstructions or with mild obstructions to systemic and pulmonary outflow tract flows. 


\section{Guideline}

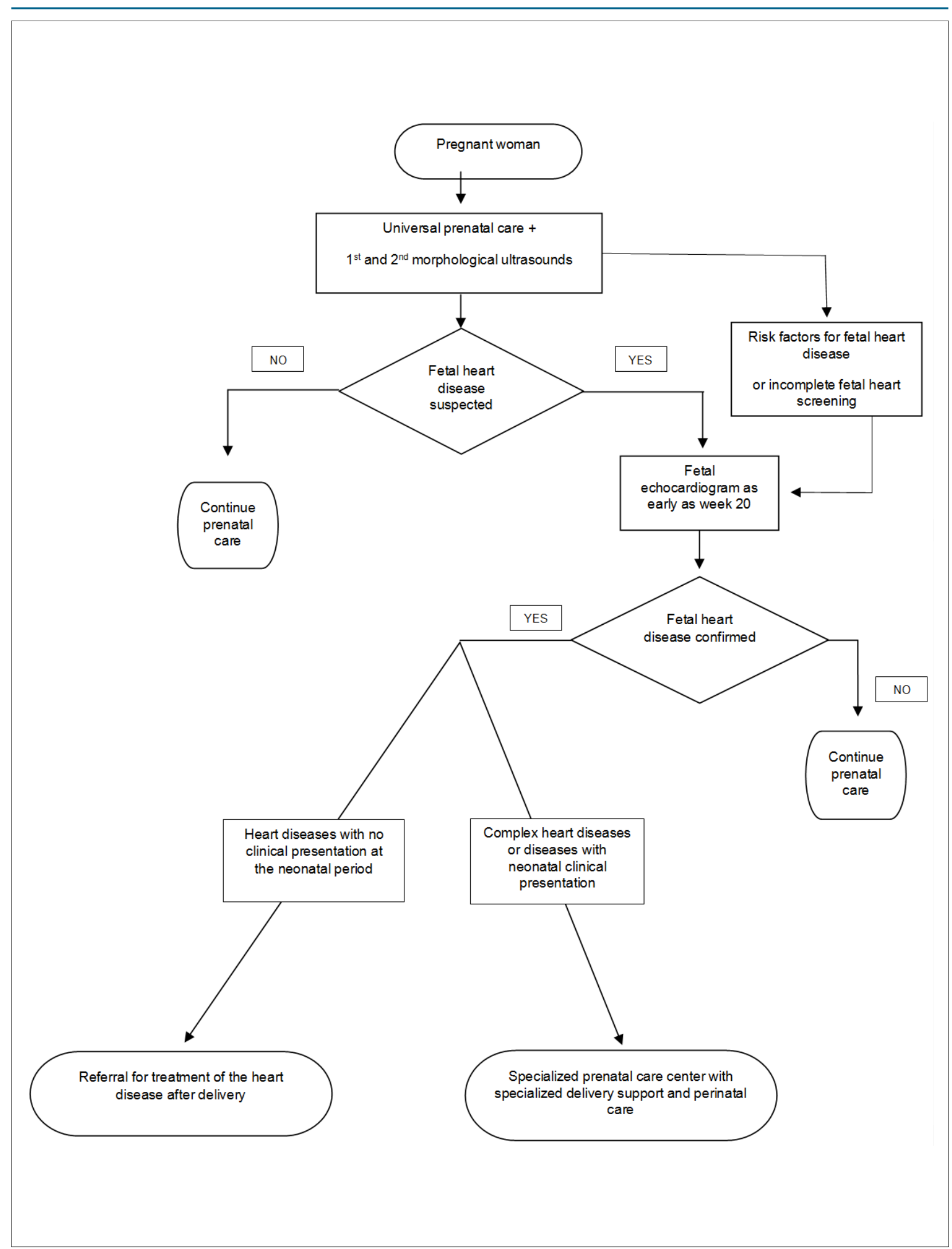

Figure 3.1 - Fetal care flowchart according to the specific fetal heart condition. USG: ultrasound. 
Table 4.1 - Classification of fetal anomalies according to fetal outcome

\begin{tabular}{cc}
\hline Group & Fetal outcome \\
\hline I & Heart diseases without fetal hemodynamic compromise \\
& A. Structural \\
& B. Functional \\
\hline II & Heart diseases with fetal hemodynamic compromise \\
& A. Structural \\
\hline III & B. Functional \\
\hline
\end{tabular}

\subsubsection{Functional}

This group includes cardiac rhythm abnormalities such as isolated supraventricular extra beats and mild isolated tricuspid regurgitation.

\subsection{Group II - Heart Diseases with Fetal Hemodynamic Compromises}

\subsubsection{Structural}

This group includes cardiac defects that may compromise the development of cardiac structures throughout gestation, such as critical or total obstruction of the ventricular outflows, ${ }^{42,43}$ defects that potentially trigger heart failure due to the presence of severe valvular insufficiency, ${ }^{44}$ and anomalies that require patent foramen ovale to divert flow from one chamber to the other (atrioventricular valves atresia or stenosis), being the main examples HLHS and tricuspid atresia. ${ }^{45}$ This group requires special attention, and some of the cases may benefit from a fetal cardiac intervention to increase the blood mixture at the atrial level (see the Fetal Interventions Chapter). ${ }^{44}$

\subsubsection{Functional}

Primary fetal myocardial dysfunctions have various etiologies. They may be caused by myocarditis (usually viral), structural changes in myocardial fibers (noncompacted myocardium, deposit diseases such as mucopolysaccharidoses or glycogenoses), and they may be related to maternal diabetes and genetic conditions. ${ }^{46,47}$ Severe cardiac arrhythmias, such as sustained tachyarrhythmias and complete atrioventricular block (CAVB) lead to cardiac chambers dilation, atrioventricular valves regurgitation, and myocardial dysfunction. ${ }^{48}$ Tachyarrhythmias are considered emergencies in Fetal Cardiology due to the risk of hydrops and fetal death; being the majority of cases possible to be treated with antiarrhythmic medication. ${ }^{49}$
Cardiac tumors are rare. The most prevalent in fetal life is rhabdomyoma. They may be single or multiple and their dimensions increase during fetal life. ${ }^{50}$ Serial echocardiograms are indicated because of the risk of arrhythmias, ventricular outflow obstructions, or cardiac structures compression. Functional abnormalities of the intracardiac shunts may imbalance the distribution of fetal blood flow. Ductal arteriosus constriction, the most frequent, will be detailed discussed in a subsequent chapter. ${ }^{51}$ Restrictions of blood flow through the foramen ovale and agenesis of the ductus venosus are rare conditions. Both evolve with right chamber dilation and may lead to fetal heart failure. ${ }^{52,53}$ High-output fistulas may lead to cardiac chambers dilation and dysfunction and fetal hydrops. The most frequent are Galen's vein aneurysm, hemangioma, hepatoblastoma, pulmonary arteriovenous malformation, vascularized tumors such as sacrococcygeal or cervical teratoma, and the twintwin transfusion syndrome. ${ }^{54,55}$ Severe anemia resulting from viral infection or blood type incompatibilities may lead to heart failure. Fetal hemodynamics may also be compromised by extrinsic fetal heart compressions, such as diaphragmatic hernia, pulmonary cystic adenomatoid malformation, and pericardial tumors. This group needs serial fetal echocardiograms, ideally biweekly, and this interval may be reduced if needed. The cardiovascular profile score, published by Huhta et al should be employed to establish the outcome. ${ }^{56}$

\subsection{Group III - Fetal Heart Diseases with Limited Postnatal Prognosis}

This group corresponds to very severe heart diseases in which, any therapeutic measurements will result in nearly $100 \%$ chance of death. It includes severe forms of left atrial isomerism associated with CAVB, obstruction of both ventricular outflows tracts and myocardial disease, critical obstructive malformations associated with noncompacted myocardium, the worst spectra of Ebstein's anomaly or tricuspid valve dysplasia associated with lung hypoplasia, left ventricular aneurysms with fetal congestive heart failure, and heart diseases associated with chromosomal disorders with limited prognosis (trisomies of 13 and 18). In this group, multidisciplinary follow-up, including psychological support for parents must be prioritized, but delivery may be in a hospital with basic support (Table 4.2).

\section{Management of the Main Fetal Heart Diseases}

One of the main challenges for the ultrasound specialist and pediatric cardiologist is to know exactly 


\section{Guideline}

Table 4.2 - Distribution of fetal heart diseases according to their classification

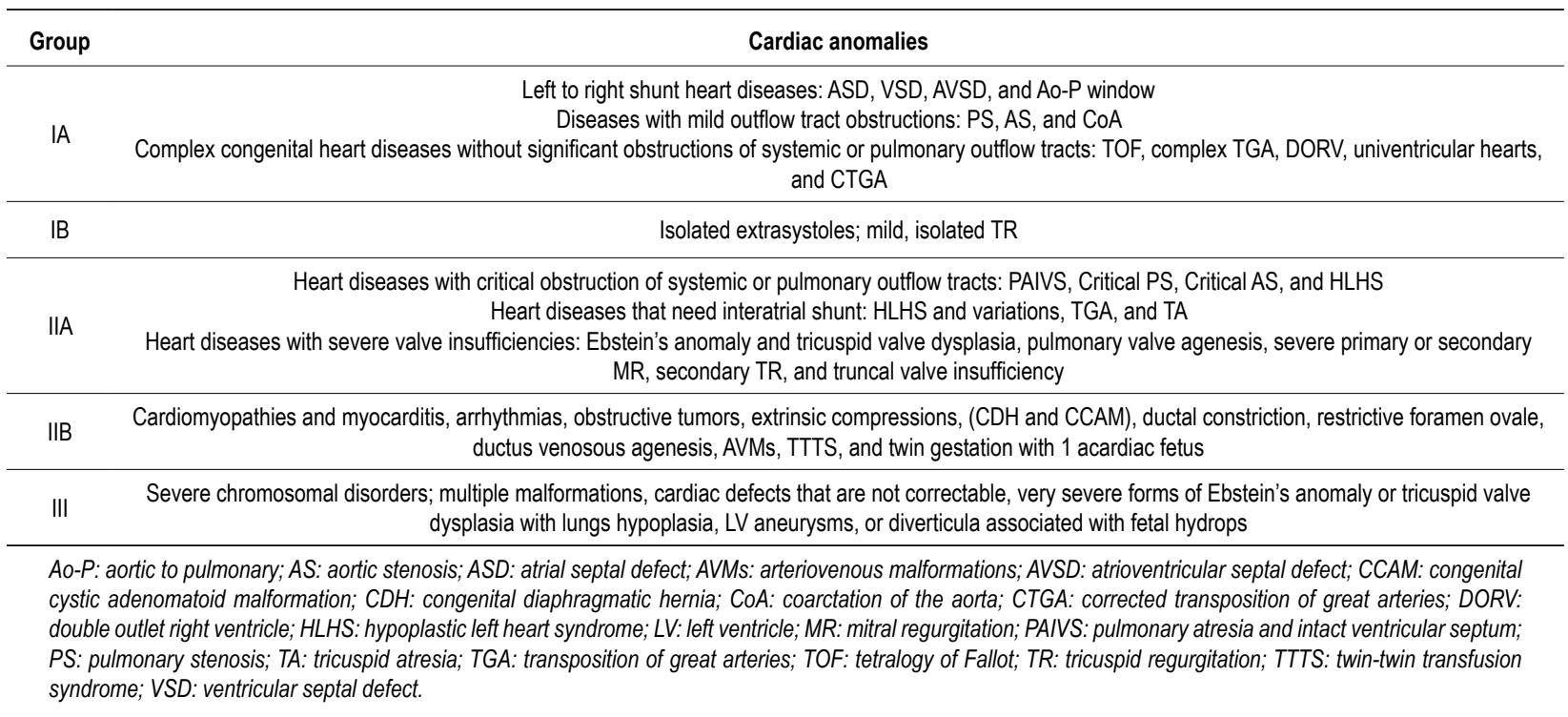

what to do when they face a fetus with CHD. Because of the fetal physiology characteristics, the majority of cardiac anomalies have a benign outcome in utero. However, at birth, they may become devastating, and require specific treatment immediately after the umbilical cord clamping. On the other hand, mild fetal cardiac abnormalities may be overvalued and lead unnecessary attitudes regarding gestation and delivery conduction, just because of the lack of knowledge of the real impact of the anomalies to the baby's health after birth. Although prenatal diagnosis has been possible for more than 40 years, understanding the behavior of $\mathrm{CHD}$ during the pre- and postnatal periods has become clearer over the past last years, thanks to the diagnostic accuracy improvements and to the introduction of fetal therapy that lead to progressive understanding of their natural and modified history. For these reasons, in order to guide the need of delivery and/or treatment in specialized centers, cardiac anomalies were separated into several groups according to their perinatal outcome: with and without hemodynamic compromise, with and without in utero progression, and possible postnatal outcome (Tables 5.1 to 5.8).

\section{Fetal Ductal Constriction: Treatment and Prevention}

Fetal circulation has specific characteristics, differing morphologically and functionally from extrauterine circulation. Anatomically, the ductus arteriosus is part of the right ventricular outflow tract, playing a essential role in directing blood flow to lower portions of the fetus. Basically, the ductus arteriosus carries $80-85 \%$ of right ventricular output to the descending

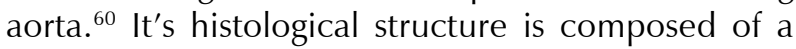
thick muscle layer, which increases with gestational age. Its constrictive mechanism is facilitated by the circumferential orientation of muscular fibers, especially those of the external layer. ${ }^{61}$ Due to these histological characteristics, its patency is measured by multiple factors. Luminal abnormalities may cause severe fetal and neonatal complications, such as heart failure, hydrops, persistent neonatal pulmonary hypertension, and death. ${ }^{62-64}$

Typically, maternal use of indomethacin and/or other anti-inflammatory medications interferes with the metabolism of prostaglandins (PG), causing ductal constriction. ${ }^{65-67}$ Many causes of ductal constriction and neonatal pulmonary hypertension, however, are not related to the use of these substances and are classified as idiopathic. ${ }^{68}$

A growing amount of evidence has recently shown that herbs, fruits, nuts, and a wide variety of substances commonly consumed as part of a daily diet affect the inflammatory cascade, culminating in reduced PG synthesis. ${ }^{69,70}$ This anti-inflammatory action, especially of polyphenols, when ingested during the third trimester of gestation, influences the dynamics of the fetal ductus arteriosus. ${ }^{71-78}$ 
Table 5.1 - Group IA. Structural fetal heart diseases without in utero hemodynamic compromise, which do not require immediate neonatal care. Class of recommendation/level of evidence: IB. . $^{17,41,57-59}$

\begin{tabular}{cccc}
\hline Heart disease & In utero outcome & In utero follow up & Delivery \\
\hline VSD & & Postnatal assessment & Delivery type according to \\
AVSD & Stable & $\begin{array}{c}\text { Repeat the study a few weeks } \\
\text { before birth is recommended } \\
\text { LSD }\end{array}$ & $\begin{array}{c}\text { Maternity ward or outpatient } 1 \text { center } \\
\text { clinic }\end{array}$ \\
Ao-P window & & & \\
\hline
\end{tabular}

Ao-P: aortopulmonary; ASD: atrial septal defect; AVSD: atrioventricular septal defect; VSD: ventricular septal defect.

Table 5.2 - Group IA. Structural fetal heart diseases without in utero hemodynamic compromise that may progress during fetal life and may or may not require immediate neonatal care. Class of recommendation/level of evidence: IB. . $^{17,41,57-59}$

\begin{tabular}{|c|c|c|c|c|}
\hline Heart disease & In utero outcome & In utero follow up & Delivery & Postnatal assessment \\
\hline $\begin{array}{c}\text { TOF } \\
\text { DORV } \\
\text { Complex TGA } \\
\text { CTGA } \\
\text { TA }\end{array}$ & $\begin{array}{l}\text { May progress to significant } \\
\text { obstruction to systemic or } \\
\text { pulmonary outflow tracts }\end{array}$ & $\begin{array}{l}\text { After diagnosis, repeat the } \\
\text { study every 4-6 weeks } \\
\text { A new study a few weeks } \\
\text { before birth is highly } \\
\text { recommended }\end{array}$ & $\begin{array}{l}\text { Delivery type according to obstetric } \\
\text { indication } \\
\text { Level } 1 \text {; Level } 2 \text { or } 3 \text { centers in case } \\
\text { the in utero hemodynamic condition } \\
\text { worsens or precipitates immediate } \\
\text { neonatal decompensation (significant } \\
\text { obstruction of the systemic or } \\
\text { pulmonary outflow tracts) }\end{array}$ & $\begin{array}{c}\text { In all cases, before hospital } \\
\text { discharge, cardiac assessment } \\
\text { with echocardiogram is } \\
\text { required }\end{array}$ \\
\hline
\end{tabular}

CTGA: corrected transposition of great arteries; DORV: double outlet right ventricle; TA: tricuspid atresia; TOF: tetralogy of Fallot; TGA: transposition of great arteries.

Table 5.3 - Group IB. Functional fetal heart diseases without in utero hemodynamic compromise, that not require immediate neonatal care. Class of recommendation/level of evidence: IB. . $7,41,57-59^{2}$

\begin{tabular}{cccc}
\hline Heart disease & In utero outcome & In utero follow-up & Delivery \\
\hline $\begin{array}{c}\text { Atrial or ventricular } \\
\text { extrasystoles } \\
\text { Mild TR }\end{array}$ & Stable & $\begin{array}{c}\text { Repeat the study a few weeks } \\
\text { before birth is recommended }\end{array}$ & $\begin{array}{c}\text { Delivery type according to } \\
\text { obstetric indication } \\
\text { Level 1 center }\end{array}$ \\
\hline
\end{tabular}

TR: tricuspid regurgitation.

Table 5.4 - Group IIA. Structural fetal heart diseases with possible in utero hemodynamic compromise and chance of fetal treatment, which require immediate neonatal care. Class of recommendation/level of evidence: IB. 17,41,57-59

\begin{tabular}{|c|c|c|c|c|}
\hline $\begin{array}{c}\text { Heart } \\
\text { disease }\end{array}$ & In utero outcome & In utero follow-up & Delivery & Postnatal assessment \\
\hline $\begin{array}{l}\text { PS } \\
\text { PAIVS } \\
\text { AS } \\
\text { Ebstein's } \\
\text { anomaly }\end{array}$ & $\begin{array}{l}\text { Risk of ventricular hypoplasia } \\
\text { Risk of ventricular dysfunction or } \\
\text { fetal hydrops } \\
\text { Risk of circular shunt } \\
\text { Risk of fetal arrhythmia }\end{array}$ & $\begin{array}{c}\text { Repeat the study every } 2 \text { to } 4 \\
\text { weeks is recommended } \\
\text { If signs of in utero progression, } \\
\text { consider fetal intervention between } \\
22 \text { and } 32 \text { weeks } \\
\text { If circular shunt, consider induced } \\
\text { ductal constriction }\end{array}$ & $\begin{array}{l}\text { Without hydrops, induced vaginal } \\
\text { delivery or programmed C-section } \\
\text { With hydrops, programmed } \\
\text { C-section } \\
\text { Level } 2 \text { or } 3 \text { center }\end{array}$ & $\begin{array}{l}\text { Immediate neonatal cardiac } \\
\text { assessment } \\
\text { PAIVS requires neonatal treatment } \\
\text { Severe or critical PS and AS, may } \\
\text { require neonatal treatment } \\
\text { Ebstein's anomaly needs treatment } \\
\text { if pulmonary atresia and lung } \\
\text { hypoplasia }\end{array}$ \\
\hline
\end{tabular}

AS: aortic stenosis; PAIVS: pulmonary atresia with intact interventricular septum; PS: pulmonary stenosis. 


\section{Guideline}

Table 5.5 - Group IIA. Structural fetal heart diseases that inevitably require neonatal care. Class of recommendation/level of evidence: IB. 17,41,57-59

\begin{tabular}{|c|c|c|c|c|}
\hline Heart disease & In utero outcome & In utero follow-up & Delivery & Postnatal assessment \\
\hline $\begin{array}{c}\text { Simple TGA } \\
\text { HLHS } \\
\text { IAA } \\
\text { Severe CoA } \\
\text { TAPVR } \\
\text { Truncus } \\
\text { Complex heart } \\
\text { diseases with severely } \\
\text { restricted systemic } \\
\text { or pulmonary outflow } \\
\text { tracts }\end{array}$ & $\begin{array}{l}\text { FO may be restrictive during } \\
\text { gestation } \\
\text { Although they are complex } \\
\text { heart diseases, they tend } \\
\text { to remain stable, without } \\
\text { hemodynamic compromise } \\
\text { during gestation }\end{array}$ & $\begin{array}{l}\text { Repeat study every } 4 \text { to } 6 \\
\text { weeks is recommended } \\
\text { In HLHS or anatomical } \\
\text { variations with restrictive ASD, } \\
\text { consider fetal intervention } \\
\text { Perform a new evaluation a } \\
\text { few weeks before delivery }\end{array}$ & $\begin{array}{l}\text { Induced vaginal } \\
\text { delivery or } \\
\text { programmed } \\
\text { C-section } \\
\text { Level } 2 \text { or } 3 \\
\text { center }\end{array}$ & $\begin{array}{l}\text { Immediate neonatal cardiac evaluation } \\
\text { The majority are duct dependent } \mathrm{CHD} \text { and require } \\
\text { prostaglandin infusion + interventional or surgical } \\
\text { treatment during the first week of life } \\
\text { TAPVR and Truncus are diseases with early } \\
\text { presentation of HF and } \mathrm{PH} \text {, and thus require } \\
\text { treatment during the first weeks of life, even when } \\
\text { they are not duct dependent }\end{array}$ \\
\hline
\end{tabular}

COA: coarctation of the aorta; FO: foramen ovale; HF: heart failure; HLHS: hypoplastic left heart syndrome; IAA: interrupted aortic arch; PH: pulmonary hypertension;

TAPVR: total anomalous pulmonary venous return; TGA: transposition of great arteries.

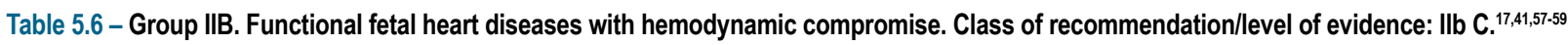

\begin{tabular}{|c|c|c|c|c|}
\hline Heart disease & In utero outcome & In utero follow up & Delivery & Postnatal assessment \\
\hline $\begin{array}{c}\text { Restricted FO } \\
\text { Ductal constriction } \\
\text { Pericardial effusion } \\
\text { Extrinsic compressions } \\
\text { Anemia } \\
\text { High-output AV fistulas } \\
\text { TTTS }\end{array}$ & $\begin{array}{l}\text { May evolve with ventricular } \\
\text { dysfunction or fetal hydrops }\end{array}$ & $\begin{array}{c}\text { Serial echocardiogram every } 4 \\
\text { to } 6 \text { weeks is recommended } \\
\text { May need fetal treatment }\end{array}$ & $\begin{array}{c}\text { With hydrops, programmed } \\
\text { C-section; } \\
\text { Without hydrops, induced } \\
\text { vaginal delivery or } \\
\text { programmed C-section } \\
\text { Level } 2 \text { or } 3 \text { centers } \\
\text { Evaluate the need for preterm } \\
\text { delivery }\end{array}$ & $\begin{array}{l}\text { Immediate neonatal cardiac } \\
\text { evaluation } \\
\text { May require clinical, } \\
\text { interventional or surgical } \\
\text { treatment immediately after } \\
\text { birth }\end{array}$ \\
\hline
\end{tabular}

AV: arteriovenous; FO: foramen ovale; TTTS: twin-twin transfusion syndrome.

Table 5.7 - Group IIB. Nonstructural fetal heart diseases which may evolve with hemodynamic compromise. Class of recommendation/level of evidence: | C. 17,41,57-59

\begin{tabular}{|c|c|c|c|c|}
\hline Heart disease & In utero outcome & In utero follow up & Delivery & Postnatal assessment \\
\hline $\begin{array}{c}\text { Cardiomyopathies } \\
\text { Arrhythmias } \\
\text { Tumors }\end{array}$ & $\begin{array}{l}\text { May evolve with } \\
\text { fetal hydrops } \\
\text { May require } \\
\text { medical treatment }\end{array}$ & $\begin{array}{l}\text { Frequent follow-up (weekly } \\
\text { or biweekly), depending on } \\
\text { diagnosis and hemodynamic } \\
\text { compromise }\end{array}$ & $\begin{array}{l}\text { Vaginal delivery in a level } 1 \text { center if well controlled } \\
\text { tachyarrhythmias or cardiomyopathies without fetal } \\
\text { hemodynamic compromise; } \\
\text { Programmed C-section in a level } 2 \text { or } 3 \text { center in } \\
\text { cases of arrhythmia or hydrops which have not been } \\
\text { resolved in utero }\end{array}$ & $\begin{array}{l}\text { Cardiac management } \\
\text { according to diagnosis } \\
\text { Treatment is usually with } \\
\text { medication, with the exception } \\
\text { of some tumors which } \\
\text { need to be removed due to } \\
\text { obstructive or compressive } \\
\text { character, which compromises } \\
\text { hemodynamics }\end{array}$ \\
\hline
\end{tabular}

Table 5.8 - Group III. Fetal heart diseases associated with genetic syndromes or extracardiac malformations. Class of recommendation/level of evidence: Illb C. ${ }^{17,41,57-59}$

\begin{tabular}{|c|c|c|c|c|}
\hline Heart disease & In utero outcome & In utero follow up & Delivery & Postnatal assessment \\
\hline $\begin{array}{c}\text { Multiple malformations } \\
\text { Associative syndromes } \\
\text { Trisomies } \\
\text { Triploidy } \\
\text { Other genetic anomalies }\end{array}$ & $\begin{array}{l}\text { May evolve with fetal } \\
\text { hydrops depending } \\
\text { on the genetic of } \\
\text { extracardiac anomaly }\end{array}$ & $\begin{array}{c}\text { Depends on fetal or } \\
\text { neonatal viability and } \\
\text { extracardiac anomalies } \\
\text { prognosis }\end{array}$ & $\begin{array}{c}\text { For non-viable fetuses or newborns, } \\
\text { delivery may be in a level } 1 \text { center, } \\
\text { preferably by spontaneous vaginal } \\
\text { birth. } \\
\text { For viable fetuses or newborns, } \\
\text { delivery may be vaginal or } \\
\text { programmed C-section in a level } 2 \text { or } \\
\quad 3 \text { center } \\
\text { Consider palliative care team support }\end{array}$ & $\begin{array}{l}\text { Cardiac management according } \\
\text { to prognosis of associated } \\
\text { anomalies or chromosome } \\
\text { diseases }\end{array}$ \\
\hline
\end{tabular}


6.1. Prevalence, Diagnosis, Clinical Consequences, and Prognosis of Fetal Ductus Arteriosus Constriction

The prevalence of ductal constriction detected in a convenience sample of 16,079 records of fetal echocardiograms performed during the third trimester of gestation, over a period of 11 years, excluding all other concomitant anomalies, in Porto Alegre, Rio Grande do Sul, Brazil was 2.7\% (435 cases). During this period, there were 207,323 live births; the sample thus represented $7.75 \%$ of births. ${ }^{79}$

Experimental studies have shown that fetal ductal constriction results in an increase in the medial layer of the pulmonary artery, which leads to a secondary increase in pulmonary vascular resistance in utero. ${ }^{80}$ Thus, the majority of studies on persistent pulmonary hypertension are based on the experimental model of fetal ductal constriction induced by the administration of indomethacin. ${ }^{81}$ Moderate or chronic ductal constrictions lead to pulmonary hypertension due to the increase in the medial layer and consequent increase in pulmonary artery constriction. This sustained increase in right ventricular afterload may lead to morphological, functional, and histological modifications in the right ventricular myocardium. ${ }^{82}$ Ventricular dysfunction in cases related to maternal medication ingestion may be completely reverted following its interruption. The persistence of the dysfunction, however, may even lead to myocardial ischemia with papillary dysfunction. ${ }^{80,83,84}$ Fetal cardiac dysfunction is described as one of the characteristics of fetal ductal closure and, in severe cases, the possibility of anticipation the childbirth should be considered, once fetal pulmonary maturity is reached..$^{85}$ Postnatal clinical outcome depends on the severity of in utero right ventricular failure and response to the increased pulmonary vascular resistance. ${ }^{86}$

Long-term prognosis is uncertain; however, in cases with favorable initial outcome, there usually are no chronic complications. Nevertheless, after fetal heart failure, functional modifications may persist during the neonatal period, even in those with benign outcome.

Echocardiographic diagnosis of fetal ductal constriction is based on the presence of turbulent flow in the ductus, with an increase in systolic velocity $(>1.4 \mathrm{~m} / \mathrm{s})$, increase in diastolic velocity $(>0.3 \mathrm{~m} / \mathrm{s})$, and decrease in pulsatility index $(\mathrm{PI})(<2.2)$. In the first publication, the cutoff point for $\mathrm{PI}$ was $1.9 .^{87}$ Recent studies, however, have considered a higher threshold. ${ }^{78,88}$ With the increased afterload secondary to ductal constriction, the heart shows symptoms of growth in earlier stages, hypertrophic response, with hyperplasia (substituted by apoptosis), increased right chamber proportions, increased pulmonary artery to aorta ratio, and interventricular septum bulging into the left ventricle. ${ }^{89,90}$ It is important to highlight that the diagnosis of ductal constriction and the evaluation of its severity cannot be established solely in terms of categorical variables of the "yes/no" sort, but are based rather on continuous variables, with a spectrum of circulation compromise (mild, moderate, or severe) which has been summarized in Table 6.1.

The scores are classified as followed:

Mild constriction: 3-7 points, the first 3 criteria being required

Moderate constriction: 8-14 points, the first 3 criteria being required

Severe constriction: $>15$ points, the first 3 criteria being required.

As the vasoconstrictor effect in the ductus arteriosus is dose-dependent, ${ }^{91}$ the disappearance of hemodynamic abnormalities and non-development of fetal/neonatal cardiac dysfunction are common after the use interruption of constrictor substances. ${ }^{89,92-95}$ Even in severe cases of ductal constriction following use of substances that

Table 6.1 - Diagnostic criteria and classification according to the severity of ductal constriction

\begin{tabular}{cccc}
\hline Criteria & 1 point each & 2 points each & 3 points each \\
\hline Systolic velocity, $\mathrm{m} / \mathrm{s}$ & $1.40-1.69$ & $1.70-1.99$ & $\geq 2.00$ \\
\hline Diastolic velocity, $\mathrm{m} / \mathrm{s}$ & $0.30-0.34$ & $0.35-0.39$ & $\leq 0.40$ \\
\hline Pulsatility index & $2.2-2.1$ & $2.0-1.9$ & $\geq 1.8$ \\
\hline RV:LV ratio & $1.30-1.59$ & $1.60-1.79$ & $\geq 1.80$ \\
\hline PA:Ao ratio & $1.30-1.59$ & $1.60-1.79$ & $+++/ 4-++++/ 4$ \\
\hline Septal bulging to the left & $0-+/ 4$ & $++/ 4$ & $+++/ 4-++++/ 4$ \\
\hline Tricuspid regurgitation & $0-+/ 4$ & $++/ 4$ & \\
\hline
\end{tabular}

Ao: aorta; LV: left ventricle; PA: pulmonary artery; RV: right ventricle. 


\section{Guideline}

inhibit PG, their use interruption reduces systolic and diastolic ductal velocities, with improvements of the abnormal hemodynamics. ${ }^{89}$ There are no reports of important spontaneous reversal of ductal constriction without the removal of the causal factor.

In more severe cases, preterm delivery may be necessary, with immediate neonatal cardiopulmonary resuscitation measures. Although the relationship between the duration of the prenatal condition of ductal constriction and the prevalence and severity of neonatal pulmonary hypertension has yet to be defined, ideally it should be as short as possible. The moment of preterm delivery, thus, takes into account fetal pulmonary maturity, the severity of the of ductal constriction presentation and its progressive nature. ${ }^{62}$ To allow for recovery and early resolution of the process, it is obviously crucial to remove the cause immediately.

\subsection{The Role of Anti-Inflammatory Substances in the Genesis of Fetal Ductal Constriction}

The action of non-steroidal anti-inflammatory drugs (NSAID) results from PG synthesis inhibition caused by the inactivation of the cyclooxygenase $1(\mathrm{COX}-1)$ and 2 (COX-2) enzymes. ${ }^{96}$ This inhibitory effect reduces the formation of PGG2 and PGF2. ${ }^{97,98}$ The use of this class of medication for treating premature birth, preeclampsia, and restricted growth in utero has made it possible to evaluate its effects on COX and ductal constriction.

Indomethacin is the most studied NSAID medication. Its effect on COX is reversible after excretion. ${ }^{99,100}$ It crosses the placental barrier freely, as early as in the second gestational trimester. ${ }^{101}$ Fetal response to indomethacin, however, is individual, varying in studies with twin fetuses. ${ }^{102}$ Reports of constrictions before 27 weeks gestation are rare; however, they have occurred as early as week $22^{\text {nd }} .{ }^{83}$ Other PG synthesis inhibitors are involved in fetal ductal constriction, with well documented dose-dependent effects, for example, in dipyrone, paracetamol, scopolamine, fluoxetine, paroxetine and sertraline. ${ }^{66,91,103-111}$

Glucocorticoids also affect ductal patency. Their effects occur through the reduction of PG formation and ductal sensitivity to PGE2, with dose-dependent effects. ${ }^{12,113}$ Concomitant use with indomethacin has a synergetic effect that duplicates the incidence of fetal ductal constriction. ${ }^{114}$

\subsection{Anti-Inflammatory and Antioxidant Action of Polyphenols}

The main action of phenolic compounds or polyphenols is described in the literature as antiinflammatory and antioxidant, demonstrating positive effects on cardiovascular health, cancer, diabetes, and neurodegenerative diseases. ${ }^{115-117}$

The antioxidant capacity of these compounds is essential to the organism in neutralizing the action of oxygen-reactive species, ${ }^{118}$ which, when produced excessively and not destroyed by endogenous defense, may interact with DNA, proteins, and lipids, culminating in the development of diseases such as cancer. ${ }^{119,120}$

Polyphenols play an important role in inhibiting the inflammatory cascade, with actions similar to that of NSAID, and are able to interfere with PG synthesis. The inflammatory cascade is initiated by the activation of phospholipase A2 (PLA2), stimulated, for example, by compounds such as thrombin, bradykinin, or epinephrine, upon membrane receptor binding. Activated PLA2 hydrolizes arachidonic acid (AA), or other similar polyunsaturated fatty acids, from membrane phospholipids. AA, in its turn, through the action of the COX-2 enzyme, initiates the formation cascade of PG and thromboxane (TX). Some NSAID, such as indomethacin, for example, inhibit the inflammatory cascade via inhibitory action of COX-2, a mechanism that has been studied in order to explain the similar effect of polyphenols in this process.

Polyphenols have their anti-inflammatory effects through a variety of molecular targets, which may be divided into 2 pathways: AA-dependent and AAindependent. COX, lipoxigenase, and PLA2 are AAdependent inflammatory mediators. The activation of these proteins leads to the release of AA (a starting point for general inflammatory response) which promotes the release of pro-inflammatory molecules. ${ }^{114}$ On the other hand, nitric oxide synthase (NOS) nuclear factorkappa B (NF-kB), and peroxisome proliferator activated receptor (PPAR) promote inflammation through AAindependent pathways.

\subsection{Summary of Evidence for Ductal Constriction Management}

A cornerstone of treating and preventing ductal constriction during fetal life is the reduction of fetal exposure to agents that interfere with the biosynthesis of PGE1, and PGE2.

The metabolic chain of PG production can be inhibited on different levels, such as in the decrease of AA production from phospholipids, by PLA2 inhibition, as is the case with corticosteroids, in the reduction of the transformation of AA to PGG2, measured by inhibition of COX-1 and COX-2, by maternal use of NSAID or consumption of polyphenol-rich foods, and by the inhibition of isomerase, which is responsible for the synthesis of PG, TX, and prostacyclin. 
The inhibitory effect of NSAID on PG biosynthesis has been broadly demonstrated. Meta-analysis conducted in a systematic review of 25 randomized clinical trials, which evaluated the risk of fetal ductal constriction in pregnant women exposed and not exposed to NSAID, concluded that the risk of ductal constriction is 15 times greater in acutely exposed fetuses. ${ }^{66}$

Multiple randomized clinical trials, systematic reviews, and meta-analyses have established that polyphenols, in the various forms in which they are present in food, have a definite anti-inflammatory and antioxidant action, which culminates in the inhibition of circulating PG, with diversified clinical outcomes.

In 2015, the International Federation of Gynecology and Obstetrics (FIGO) published its official recommendations for gestational nutrition. One point in the section, "Exposures to avoid" reads:

"In late pregnancy, women should avoid high intakes of herbal teas and polyphenol-rich foods, which have been associated with effects on the fetal ductus arteriosus brought about by inhibition of prostaglandin synthesis." (italics ours) ${ }^{106}$

Specifically regarding the results of "abnormal ductal flow and ductal constriction" in fetuses exposed to a maternal diet rich in polyphenols, studies developed in Brazil, on all levels of the evidence pyramid, from experimental to case control studies, have unequivocally demonstrated the following:

- Consumption of green tea, yerba mate, and grape juice, which are sources of high concentrations of polyphenols, causes ductal constriction in experimental models of sheep fetuses in the final trimester of gestation. ${ }^{121}$

- There is a cause-effect relationship between maternal consumption of green tea and ductal constriction during the third trimester of gestation in experimental models of sheep fetuses. ${ }^{74}$

- High maternal consumption of polyphenols induces fetal ductal constriction in sheep, with increased urinary excretion of total polyphenols and abnormalities in oxidative stress biomarkers, which characterize the antiinflammatory and antioxidant actions of polyphenols. ${ }^{122}$

- An experimental single-dose of cocoa administered to rats during the third trimester of gestation caused ductal constriction equivalent to that caused by indomethacin. ${ }^{123}$

- Normal human fetuses during the third trimester, when exposed to maternal consumption of polyphenols above the $75^{\text {th }}$ percentile of the average population, exhibit worse ductus arteriosus flow dynamics and increased right-to-left ventricular diameter ratios (higher ductal flow velocities and larger right ventricular diameters), in comparison with those exposed to maternal consumption of polyphenols below the $25^{\text {th }}$ percentile. ${ }^{76}$

- Normal human fetuses submitted to guided nutritional intervention (restriction of polyphenol-rich foods) in the third trimester showed, after 2 weeks, decreased ductal systolic and diastolic velocities, increased pulsatility index, and decreased right-toleft ventricular and pulmonary artery to aorta ratios, whereas these parameters did not change during the same period in control fetuses who were not submitted to the intervention. ${ }^{77}$

- Human fetuses with ductal constriction during the third trimester showed, in more than $95 \%$ of cases, reversion of the echocardiographic signs of this condition, as well as its hemodynamic compromise, after 3 weeks of a restricted in polyphenols diet, whereas there were no changes in the parameters evaluated in fetuses controls of the same gestational age, who did not receive a nutritional intervention with restricted maternal intake of polyphenols. ${ }^{78}$

- Polyphenol supplementation capsules inhibit physiological increase of PGE2 and other markers of inflammation and oxidative stress in women of childbearing age using combined hormonal contraceptives. ${ }^{124}$

- Dietary intervention to restrict maternal consumption of polyphenol-rich foods in the third trimester in cases of fetuses with ductal constriction is accompanied by an increase in plasma levels of PGE2, with improvements in the condition. ${ }^{125}$

- A 52-item food frequency questionnaire for quantifying consumption of polyphenol-rich foods in pregnant women, whose validity and reproducibility were evaluated in the South of Brazil, may be used in clinical practice. ${ }^{71}$

\subsection{Conclusions}

\subsubsection{Recommendations for Ductal Constriction} Treatment

When ductal constriction is diagnosed in the fetal echocardiogram, the complete use interruption of NSAID should be recommended, in addition to the restriction of polyphenol-rich foods, made up of products with a concentration $\geq 30 \mathrm{mg} / 100 \mathrm{~g}$ of food, in accordance with the recommendations in table 6.2, intending to maintain balanced diet that includes all necessary micronutrients during this gestational period, reducing, however, the concentration of total polyphenols below $125 \mathrm{mg}$ per day, or to the $25^{\text {th }}$ consumption percentile ${ }^{78}$ (Class of recommendation: I; level of evidence: A). If possible, consumption of other medications with 
potential anti-inflammatory actions (corticosteroids, ${ }^{108}$ aspirin, ${ }^{107}$ dipyrone, ${ }^{105,110}$ fluoxetine, ${ }^{109,126}$ paroxitine, sertraline, ${ }^{109,111}$ isoxsuprine, ${ }^{107}$ and naphazoline),$^{107}$ their use interruption may be considered (Class of recommendation: Ila; level of evidence: C). In cases in which there is no reversal of ductal constriction and its consequences after initiation of treatment, preterm delivery may be considered, provided that fetal pulmonary maturity has been established (Class of recommendation: Ilb; level of evidence: C).

\subsubsection{Recommendations for Ductal Constriction Prevention}

In order to prevent fetal ductal constriction, pregnant women should be recommended not to use NSAID during the third trimester of gestation, regardless of the route of administration (Class of recommendation: I; level of evidence: A). It is also considered to recommend that they avoid using other medications with possible anti-inflammatory effects (corticosteroids, ${ }^{108}$ aspirin, ${ }^{107}$ dipyrone, fluoxetine, ${ }^{109,126}$ paroxetine, sertraline, ${ }^{109,111}$ isoxsuprine, ${ }^{107}$ and naphazoline) ${ }^{107}$ (Class of recommendation: Ila; level of evidence: C). It is sufficient to recommend moderate maternal polyphenol-rich foods consumption during the third trimester of gestation, i.e., below the $75^{\text {th }}$ percentile of consumption, ${ }^{76}$ or limiting consumption of foods with concentrations above $30 \mathrm{mg}$ per $100 \mathrm{~g}$, in accordance with the food pyramid shown in Figure 6.1. Reduced daily consumption of polyphenols below 1,089 $\mathrm{mg}$ $\left(75^{\text {th }}\right.$ percentile) maintains an acceptable diet for nutritional needs during this period of gestation (Class of recommendation: Ila; level of evidence: C). Figures 6.2 and 6.3 , respectively, show recommendations for treatment and prevention of fetal ductal constriction.

\section{Fetal Cardiac Arrhythmias: Diagnosis and Treatment}

Screening programs for detecting prenatal cardiac abnormalities developed over the past 3 decades,

Table 6.2 - Recommendations for polyphenol-rich foods restriction after 28 weeks gestation for ductal constriction treatment

\begin{tabular}{|c|c|}
\hline Restricted foods & Alternatives options \\
\hline Raw beets: consume no more than 2 tablespoons/day & Cooked beets or carrots \\
\hline Lettuce: consume no more than 10 medium-sized leaves/day & It is ideal to consume less \\
\hline Red/purple plums, unpeeled: consume no more than 1 small unit/day & Pineapples, pears, and peeled red apples \\
\hline Blackberries/mulberries: consume no more than $1 / 2$ cup/day & Pineapples, acerolas, and limes \\
\hline Red apples, unpeeled: do not eat the peel & Green apples or peeled red apples \\
\hline Oranges/orange juice: do not consume & Pineapples, acerolas, limes, and tangerines* \\
\hline Papaya: consume no more than 1 slice/day (formosa variety) & Guavas, acerolas, limes, and tangerines* \\
\hline Strawberries: consume no more than 2 larges units/day & Pineapple, acerolas, limes, and tangerines* \\
\hline Red/purple/pink grapes/grape juice: do not consume & White grapes, pears, and peeled apples \\
\hline Green tea: do not consume & Fruit teas (teabags) \\
\hline Black tea: do not consume & Fruit teas (teabags) \\
\hline Boldo tea: do not consume & Fruit teas (teabags) \\
\hline Coffee: do not consume & --- \\
\hline Yerba mate: do not consume & -- \\
\hline Dark/milk/bittersweet chocolate: do not consume & White chocolate \\
\hline \multicolumn{2}{|l|}{ Cocoa powder: do not consume } \\
\hline Olive oil: do not consume & Canola oil \\
\hline Green herbs: consume no more than 12 teaspoons/day & Other natural spices \\
\hline
\end{tabular}

* Consume in moderation. When consuming a restricted food, consume no more than once daily, and do not exceed the quantities described in the table. Source: Adapted from Arnt et al. ${ }^{127}$ 


\section{FOOD PYRAMID}

\section{GUIDELINES FOR CONSUMPTION OF POLYPHENOL-RICH FOODS DURING THE THIRD TRIMESTER OF} PREGNANCY, IN ORDER TO AVOID DUCTAL CONSTRICTION

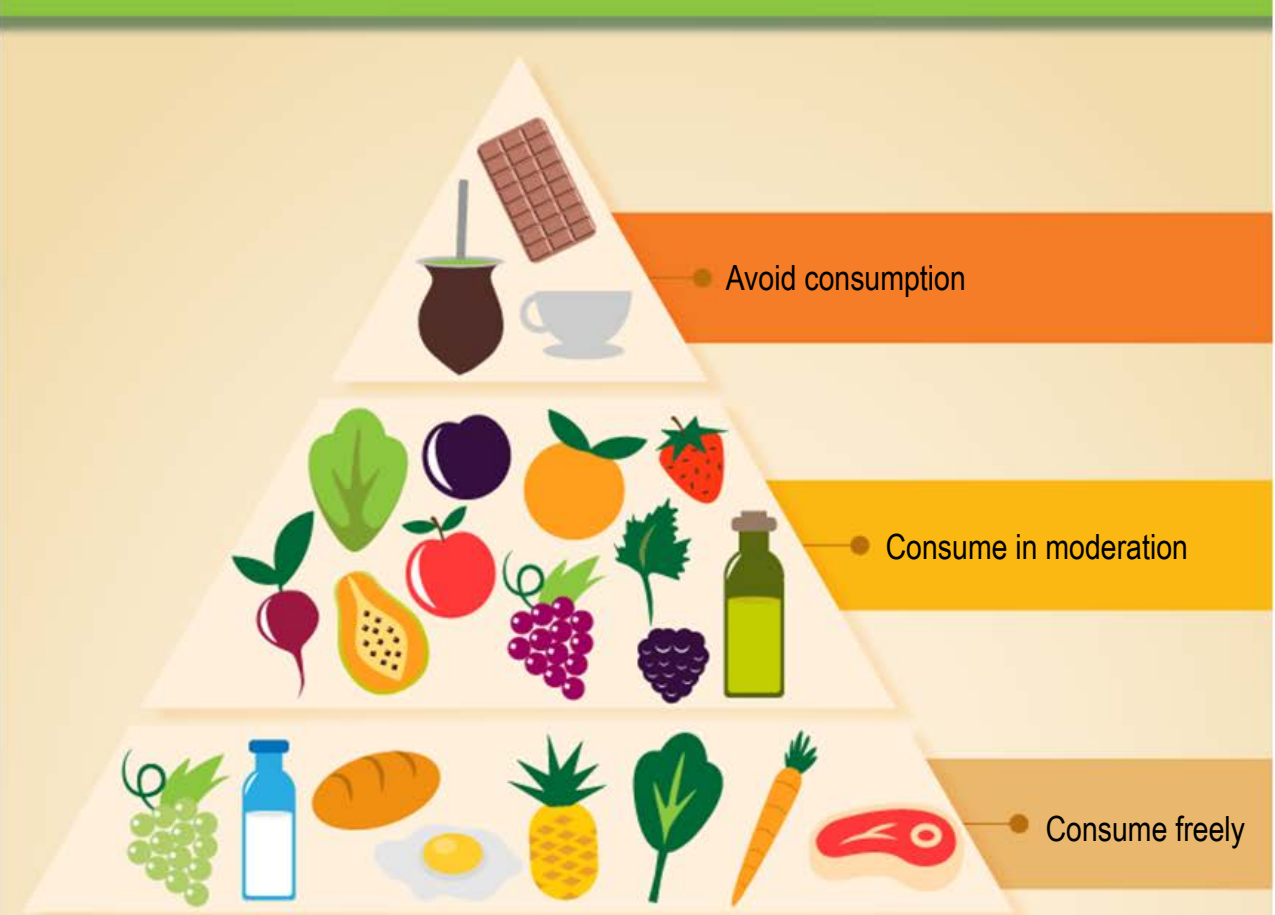

\section{AVOID CONSUMPTION}

Foods with high concentrations of total polyphenols per $100 \mathrm{~g}$ or per $100 \mathrm{ml}$, which are contraindicated or which do not have nutritional benefits during pregnancy $=$ dark chocolate, coffee, yerba mate, and tea.

\section{CONSUME IN MODERATION}

Foods with concentrations over $30 \mathrm{mg}$, which may be consumed in moderation, in accordance with the portions established below:

- Lettuce: consume no more than 10 medium-sized leaves/day

- Red/purple plums, unpeeled: consume no more than 1 small unit/day

- Blackberries/mulberries: consume no more than 1/2 cup/day

- Red apples, unpeeled: do not eat the peel

- Oranges/orange juice: do not consume

- Papaya: consume no more than 1 slice/day (formosa variety)

- Strawberries: consume no more than 2 larges units/day

- Red/purple/pink grapes/grape juice: do not consume

- Olive oil: consume no more than 1 teaspoon/day

- Raw beets: consume no more than 2 tablespoons/day

- Green herbs: consume no more than 12 teaspoons/day

\section{CONSUME FREELY}

Foods with concentrations below $30 \mathrm{mg}$ per $100 \mathrm{~g}=$ other fruits and vegetables which are not mentioned in the middle of the pyramid, bread and starches in general, cereals, dairy products, meat, and eggs. 


\section{Guideline}

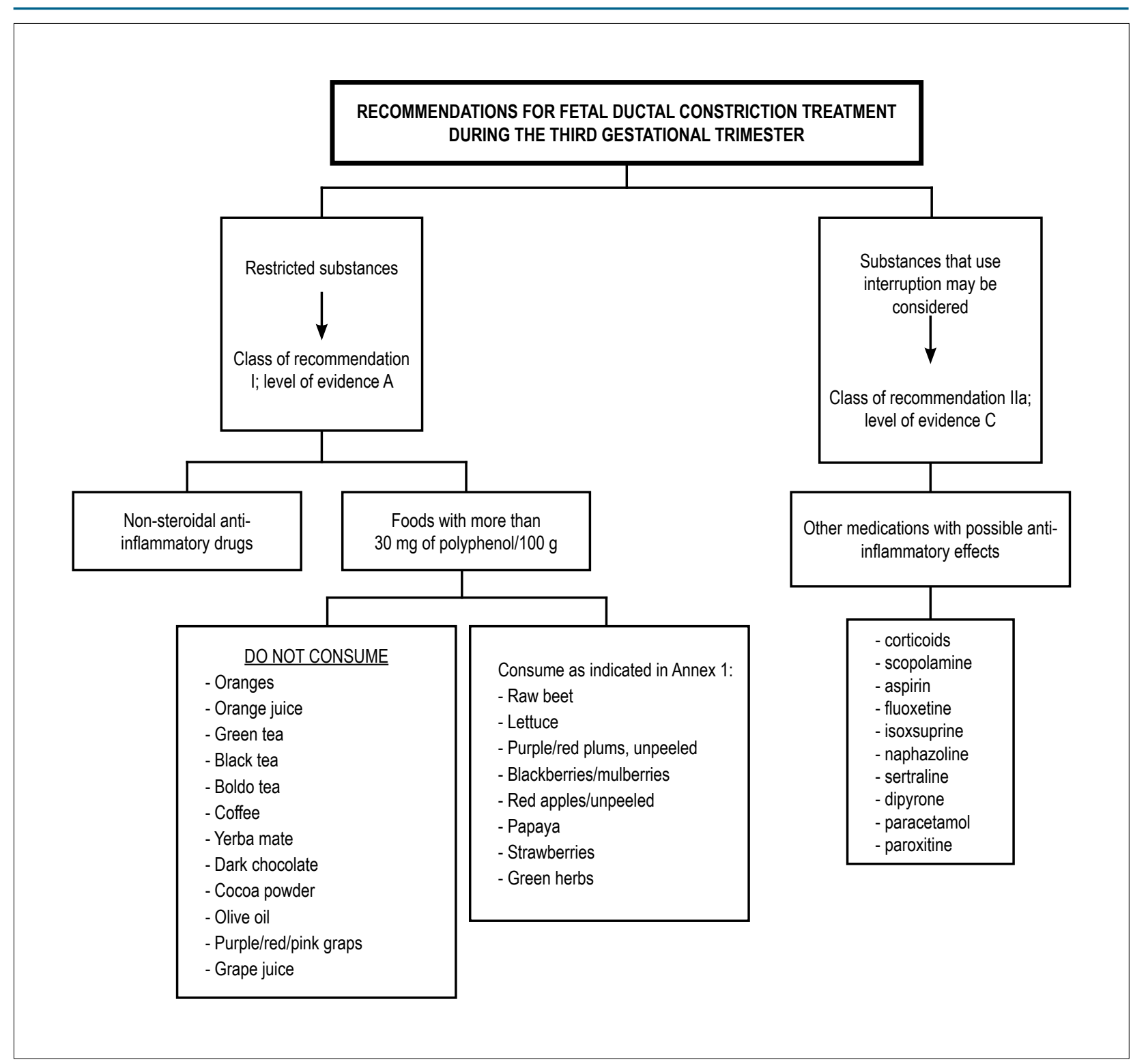

Figure 6.2 - Recommendations for fetal ductal constriction treatment during the third gestational trimester. In cases in which there is no reversal of the ductal constriction and its consequences after initiation of treatment, preterm delivery may be considered, since fetal pulmonary maturity has been established. Class of recommendation: Ilb; Level of evidence: $C$.

improved the understanding of fetal cardiac rhythm abnormalities. Since fetal arrhythmias may severely compromise the gestation outcome, it is very important to diagnose, recognize the mechanisms, hemodynamic consequences, and the fetal cardiac morphology for perinatal therapy planning.

Fetal cardiac rhythm abnormalities affect approximately $0.5-2 \%$ of pregnancies, and are responsible for $10-20 \%$ of referrals for in utero cardiac examination. The ectopic beats are the most prevalent rhythm irregularities seen during fetal heart. They are usually benign however, may potentially trigger a sustained supraventricular tachycardia (SVT) especially when they are blocked. Some fetal cardiac arrhythmias, however, are considered emergencies in Fetal Cardiology, requiring early diagnosis and treatment and have determinant impact on perinatal morbidity and mortality. Complete heart block (CAVB), atrial flutter $(\mathrm{AF})$, and SVT may have severe consequences for the fetus clinical status. ${ }^{128}$ 


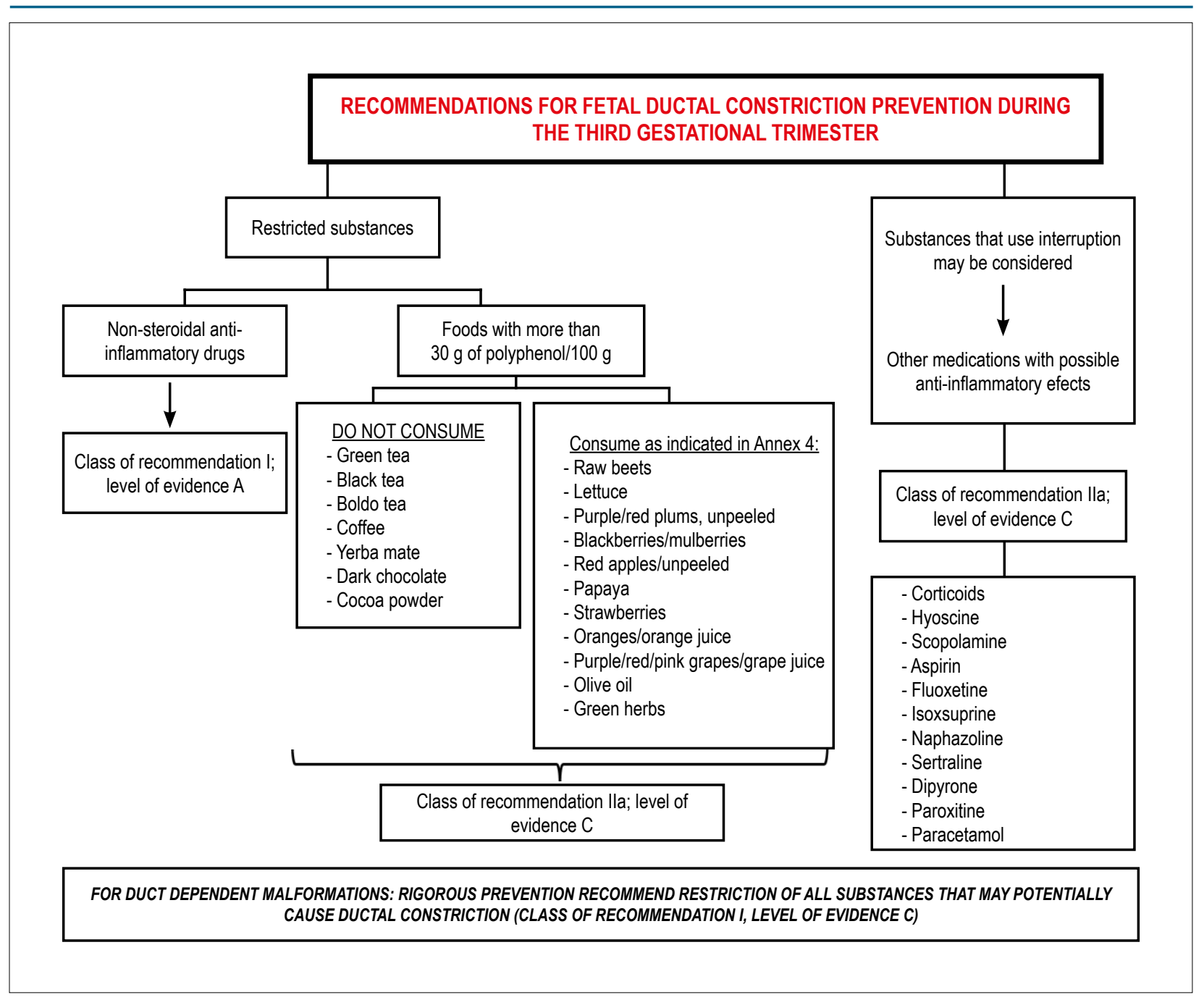

Figure 6.3 - Recommendations for fetal ductal constriction prevention during the third gestational trimester.

\subsection{Fetal Cardiac Rhythm and Fetal Cardiac Arrhythmias}

During fetal echocardiography, heart rate and rhythm are assessed with simultaneous examination of the atrial and ventricular systoles employing M-mode, two-dimensional echocardiography and pulsed-wave Doppler with or without color flow mapping. Cardiac rhythm is considered normal when the ratio of atrial and ventricular contractions is $1: 1$, with heart rate ranging from 120 to 180 bpm. ${ }^{48,129-131}$

M-mode allows to evaluate the movement of the posterior atrial wall (atrial systole or A wave), concomitantly with aortic valve opening (ventricular systole or $\mathrm{V}$ wave). This trace is obtained from the longitudinal two-dimensional image of the heart, with the cursor positioned crossing the right ventricle, the aortic valve and the LA. Sinus rhythm is identified when, for each movement of the left atrial wall (A wave), there is a corresponding opening movement of the aortic valve ( $\mathrm{V}$ wave), i.e., 1:1 atrioventricular $(\mathrm{A}: \mathrm{V})$ conduction. Positioning the cursor simultaneously across the atrial (A wave) and ventricular ( $\mathrm{V}$ wave) wall may also be employed. Color M-mode facilitates the identification of aortic flow during ventricular systole and may also be used to identify left atrial activity from mitral flow.

The atrioventricular sequence may also be assessed positioning the pulsed Doppler sample volume between the left ventricular inflow and outflow tracts, thus recording the mitral (A wave) and aortic ( $V$ wave) flows. Additionally, the sample volume may be placed between the SVC and the aorta in the 3 vessels view. The SVC " $A$ " wave reversal flow represents the atrial contraction (A wave), and the aortic flow represents ventricular systole ( $\mathrm{V}$ wave). The same concept can be used with 


\section{Guideline}

the Doppler sample volume placed at the same time reaching the pulmonary artery and vein flows. ${ }^{48,129-138}$

\subsection{Extrasystoles}

Extrasystoles occur in $1-3 \%$ of pregnancies. They are, usually, benign, with no consequences for the fetus. In the setting of bigeminy, trigeminy, or very frequent extrasystoles ( 1 for every 3-5 fetal heartbeats), differential diagnosis with ventricular extrasystoles, long QT syndrome, and second-degree atrioventricular block may be difficult. The presence of blocked bigeminy increases the risk of SVT triggering. ${ }^{139-141}$

\subsubsection{Isolated Supraventricular Extrasystoles}

Correspond to premature atrial contractions (A wave), that may or may not be followed by ventricular activity (conducted or blocked, respectively). They may occur with bi- or trigeminy, compensatory pauses, or in series. They are considered benign arrhythmias, and do not require treatment. About $1 \%$ of conducted ectopic beats may trigger tachyarrhythmias. ${ }^{48}$

\subsubsection{Ventricular Extrasystoles}

Ventricular extrassystoles are ventricular ectopic beats that are not related to atrial activity.

Table 7.1 shows the summary of in utero management of irregular rhythms.

\subsection{Fetal Bradycardia}

Fetal bradycardia is considered when the fetal heart rate of $<110 \mathrm{bpm}$. When treatment is necessary, it is important to identify its cause and mechanism.

\subsubsection{Sinus Bradycardia}

Sinus bradycardia is diagnosed when the heart rate is $<110 \mathrm{bpm}$ with a 1:1 A:V conduction. It is usually a vagal response secondary to hypoxia or umbilical cord

Table 7.1 - In utero management of irregular rhythm

\begin{tabular}{|c|c|c|c|c|}
\hline Diagnosis & Cause & In utero management & GOR/LOE & Comments \\
\hline \multirow[t]{3}{*}{ Second-degree AVB } & Autoimmune & Dexamethasone & $\mathrm{llb} / \mathrm{B}$ & This may stop progression to CAVB \\
\hline & Structural CHD & Weekly follow-up & I/C & $\begin{array}{l}\text { If possible, perform FMCG to rule } \\
\text { out LQTS }\end{array}$ \\
\hline & Channelopathy & Weekly follow-up & $\mathrm{I} / \mathrm{C}$ & \\
\hline \multirow[t]{5}{*}{ VPC or frequent APC } & Idiopathic & $\begin{array}{l}\text { Observation with obstetric evaluation of fetal HR } \\
\text { weekly until the arrhythmia is resolved (bigeminy, } \\
\text { trigeminy, or } 1 \mathrm{ES} \text { at every } 3-5 \text { beats) }\end{array}$ & $\mathrm{I} / \mathrm{A}$ & $\begin{array}{l}2 \% \text { also have first- or second-degree } \\
\text { AVB }\end{array}$ \\
\hline & Oval fossa aneurysm & & & $\begin{array}{c}\text { For APC, there is a } 0.5-1 \% \text { risk of } \\
\text { developing SVT }\end{array}$ \\
\hline & & & & $\begin{array}{c}\text { For VPC, the risk of developing VT is } \\
\text { unknown }\end{array}$ \\
\hline & & & & $\begin{array}{l}\text { Most episodes are benign and of } \\
\text { short duration }\end{array}$ \\
\hline & & & & Evaluate secondary causes \\
\hline \multicolumn{5}{|l|}{ Secondary causes } \\
\hline VPC or frequent $\mathrm{APC}$ & Myocarditis & $\begin{array}{l}\text { Observation with evaluation of FHR at weekly } \\
\text { intervals }\end{array}$ & I/C & \\
\hline \multicolumn{5}{|c|}{$\begin{array}{l}\text { Frequent evaluation (every 1-2 week) of heart } \\
\text { function and other parameters of fetal CHF }\end{array}$} \\
\hline & Cardiac tumors & $\begin{array}{l}\text { Observation with obstetric evaluation of FHR } \\
\text { weekly }\end{array}$ & $\mathrm{I} / \mathrm{C}$ & \\
\hline & $\begin{array}{l}\text { Ventricular or atrial } \\
\text { diverticula or aneurysm }\end{array}$ & Observation with FHR assessment by OB weekly & $\mathrm{I} / \mathrm{C}$ & \\
\hline & Maternal stimulants & Observation with FHR assessment by OB & $\mathrm{I} / \mathrm{C}$ & \\
\hline
\end{tabular}

APC: atrial premature contractions; AVB: atrioventricular block; CAVB: complete atrioventricular block; CHD: congenital heart disease; CHF: congestive heart failure; FHR: fetal heart rate; FMCG: fetal magnetocardiography; GOR: grade of recommendation; LOE: level of evidence; LQTS: Iong QT syndrome; SVT: supraventricular tachycardia; VPC: ventricular premature contraction; VT: ventricular tachycardia. Source: adapted from Donofrio et al. ${ }^{17}$ 
compression by the transducer. It also may occur due to maternal illnesses. When transitory, they are commonly benign and do not require treatment. However, persistent bradycardia indicates fetal abnormality and its causes should be treated. ${ }^{48,129,134,137,141}$

\subsubsection{Low Atrial Rhythm}

The main mechanisms of low atrial rhythm include congenital displacement of atrial activation, acquired damage of the sinoatrial node, channelopathy, and secondary suppression of sinus node rate. Left and right atrial isomerism can occur, with fetal heart rate varying from 80 to $130 \mathrm{bpm}$. Situations that may cause sinus node fibrosis, such as maternal anti-Ro/ anti-LA antibodies or viral myocarditis, may occur with progression to fetal death. Additionally, maternal use of medications, such as sedatives or betablockers, may reduce the sinus node rate. Low atrial rhythm does not require treatment. ${ }^{137}$

\subsubsection{Blocked Atrial Bigeminy}

Blocked atrial bigeminy occur with a heart rate ranging from 75 to110 bpm in a 2:1 atrioventricular conduction. They do not require treatment. It is known, however, that approximately $10-13 \%$ may evolve to SVT; weekly evaluation of fetal heartbeats is thus recommended by echocardiogram or sonar. ${ }^{137,142}$

\subsubsection{Complete Atrioventricular Block}

CAVB results in complete dissociation between atrial and ventricular activity, with heart rates usually below 60 bpm. In $50-55 \%$ of cases, malformation of the conduction system occurs, as a consequence of structural heart diseases, such as congenitally corrected transposition of great arteries and left atrial isomerism. ${ }^{141,143-146}$ In about $40 \%$ of the cases, it occurs due to maternal autoimmune diseases that present with anti-SSA/SSB (anti-Ro/LA antibodies). ${ }^{142-147}$

The risk increases in the presence of anti-Ro 52-kd (sequence p200) antibodies, that cannot be tested in Brazil yet. ${ }^{147-153}$ In a minority of cases, no etiology is identified. Fetuses without hydrops and with heart rate above $55 \mathrm{bpm}$ have good prognoses. In immature fetuses, with very early hydrops and heart rates below 50 bpm, prognosis is more limited. Fetuses with CAVB and structural heart diseases, such as left atrial isomerism, have a poor prognoses. ${ }^{145}$

In mothers with autoimmune diseases, it is recommended to test maternal anti-SSA/RO antibodies. If positive, and the fetus is in sinus heart rhythm, weekly measurements of the AV interval (mechanical
PR interval) are recommended, from weeks 18 to 26 . This measurement should be taken employing pulsedwave Doppler, evaluating mitral and aortic flows simultaneously, from the beginning of the mitral A wave (" $\mathrm{A}$ ") to the beginning of the ventricular systole ("V"). ${ }^{142}$ Myocardial function should be monitored every 4 weeks up to delivery (grade of recommendation: I; level of evidence: C) (Figure 7.1). ${ }^{154}$

Although controversial, treatment with dexamethasone at a dose of 4-8 mg orally can be started to cases where the AV interval is > 150 milliseconds or when it increases progressively. Some groups have shown to be beneficial the treatment of immune CAVB with maternal dexamethasone (4-8 mg orally) and/or intravenous gammaglobulin infusion, ${ }^{149-158}$ observing reduced inflammatory response, stabilization of firstand second-degree $A V B$, regression of endocardial fibroelastosis and hydrops improvement. ${ }^{145-151}$

However, the use of corticosteroids may be associated with complications, such as ductal constriction, maternal diabetes, restricted growth, and oligohydramnios. ${ }^{149-161}$

Dexamethasone may be used to treat first- and second-degree AVB associated with signs of myocardial inflammation (myocardial hyperechogenicity, valve regurgitation, cardiac dysfunction, and pericardial effusion) to prevent progressing to CAVB, however the efficiency of corticosteroids has not been completely established and one may consider its possible side effects. ${ }^{140}$ In fetuses with CAVB without functional consequences, dexamethasone may also be used to reduce the prevalence of dilated cardiomyopathy. ${ }^{152,162}$ Whenever significant side effects occur in the mother or the fetus, the use of the medication should be interrupted. Intravenous immunoglobulin associated with dexamethasone may improve survival in fetuses with endocardial fibroelastosis or systolic dysfunction. ${ }^{149}$ It is not yet known, however, when is the ideal moment for administration and the ideal intervals between doses. There is no recommendation regarding the prophylactic use of immunoglobulin at the beginning of gestation for mothers with positive antibodies. ${ }^{160}$

The use of salbutamol, terbutaline, or isoprenaline is indicated when heart rate is $<55 \mathrm{bpm}$ and/or in the presence of fetal heart failure and hydrops. ${ }^{142,146,157}$ These medications are usually well tolerated. Maternal extrasystole and sinus tachycardia may appear. ${ }^{161}$ There is an increase in fetal heart rate of approximately 10 to $15 \%$ of the basal frequency, and, although small, it may prolong the gestation to or close to term. There are no studies demonstrating that these medications modify fetal survival in these cases. In immature fetuses with hydrops, with very low heart rate, in utero implantation of a pacemaker may be considered. This procedure 


\section{Guideline}

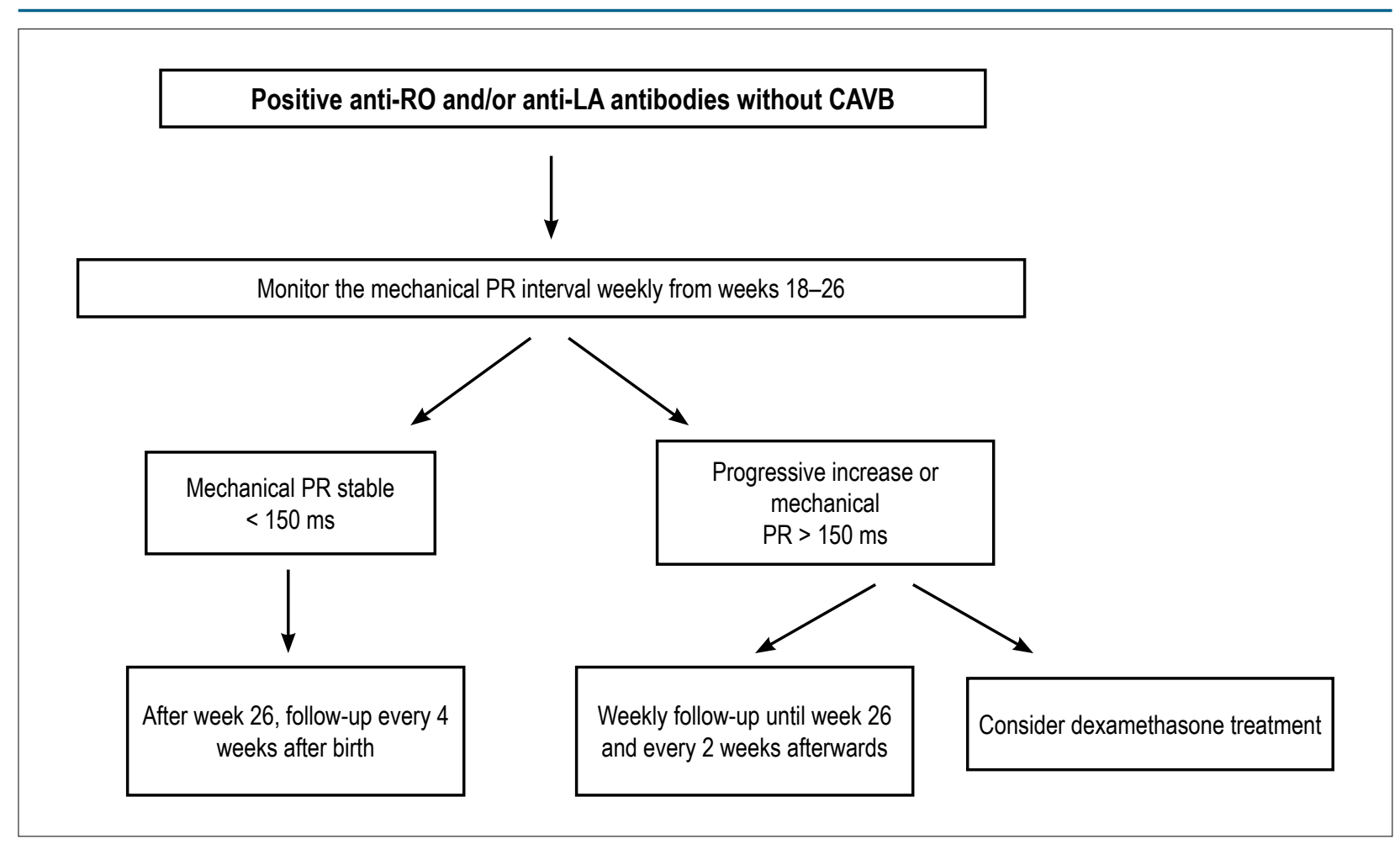

Figure 7.1 - Suggested approach for pregnant women with positive antibodies, without fetal CAVB.

CAVB: complete atrioventricular block; ms: miliseconds.

continues to have technical limitations and is still undergoing experimental studies.

Indications for delivery should be analyzed based on the degree of fetal manifestations. In fetuses with significant hydrops, with ventricular rate $<50 \mathrm{bpm}$ and pulmonary maturity (after week 34 of gestation), delivery should be considered, with immediate postnatal pacemaker implant. ${ }^{163}$ In fetuses before week 26 of gestation, with heart rate $<45 \mathrm{bpm}$ and hydrops, in utero pacemaker implant, still in experimental phase, may be a therapeutic option. ${ }^{164-168}$ In fetuses between weeks 26 and 34 of gestation, the risks of prematurity and the manifestations of CAVB should be weighed together. The in utero suggested manaegment of fetal bradycardia is summarized in figure 7.2.

\subsection{Fetal Tachycardia}

Fetal tachycardia is diagnosed when fetal heart rate is $>180 \mathrm{bpm}$. In utero treatment depends on gestational age, etiology, degree of hemodynamic compromise (presence of hydrops), mother's clinical condition, and potential maternal risks of fetal treatment. The therapeutic decision should be based on fetal vs. maternal risks. Medical treatment is indicated for fetuses with sustained or intermittent tachycardias with hydrops and/or ventricular dysfunction, unless gestation is close to term, with fetal pulmonary maturity, thus minimizing the risks of preterm birth. ${ }^{17,129,131-133,136,140,142,169,170}$

Tables 7.3 and 7.4 , respectively, demonstrate the management of tachyarrhythmias and antiarrhythmic drugs. ${ }^{17}$ The suggested management approaches for fetal tachycardias are shown in Figures 7.3, 7.4, and 7.5.

\subsubsection{Intermittent Tachycardias}

Intermittent tachycardia is defined when it is present for less than $50 \%$ of the exam period, the minimum observation time being 30 minutes. Sinus tachycardia is determined by atrial and ventricular activation with 1:1 A: $\mathrm{V}$ conduction and heart rate over $160 \mathrm{bpm}$ and, usually, below $180 \mathrm{bpm}$. It is frequently associated with an underlying fetal or maternal abnormal condition, such as fever, stress, or use of medication. Its cause should be treated. As an isolated finding, it does not have clinical significance and does not require treatment. ${ }^{137,138,141}$

Intermittent ventricular tachycardia, with ventricular rate over $200 \mathrm{bpm}$ is extremely rare and may evolve to important hemodynamic impairment and hydrops; for this reason, treatment is indicated. 


\section{Guideline}

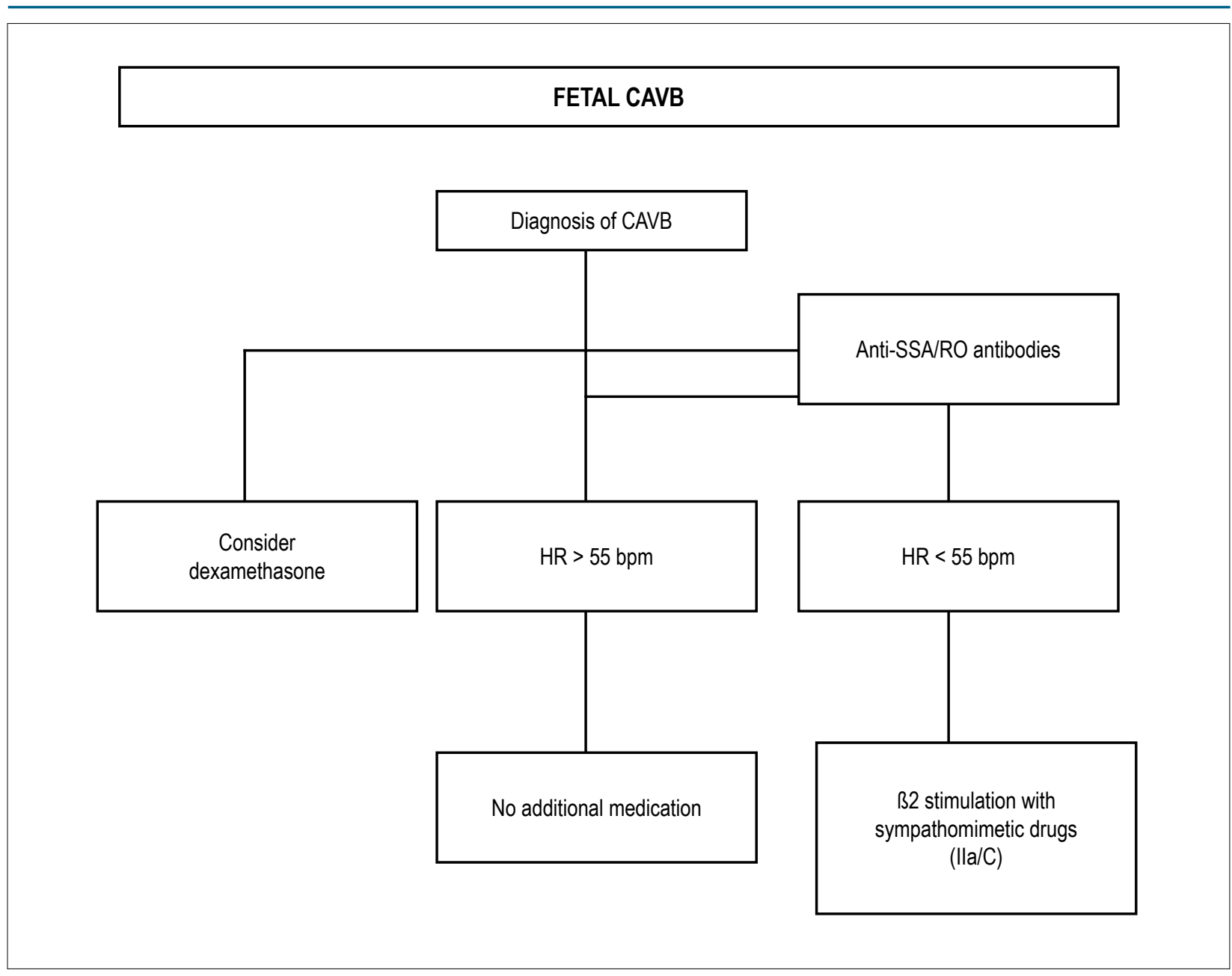

Figure 7.2 - Suggested approach for fetuses who have CAVB.

CAVB: complete atrioventricular block; HR: heart rate.

Other intermittent tachycardias usually do not have signs of cardiac hemodynamic impairment, and there is no indication for treatment. ${ }^{171}$ However, in isolated cases, it may evolve to sustained tachycardia, justifying its follow up.

\subsubsection{Sustained Tachycardias}

This group of fetal arrhythmias, identified by a period of more than $50 \%$ of exam duration, includes supraventricular tachycardias, AF, and ventricular tachycardias. The therapeutic goal is to bring the gestation to term, while improving secondary manifestations. Prognosis is good when they are reversed in utero and limited for immature fetuses with hydrops and cases of arrhythmia which were not successfully reversed. Prognosis should be considered favorable when fetuses continue with tachyarrhythmia, but with lower heart rates and improvement in hydrops.

\subsubsection{Diagnosis}

Sustained atrial tachycardia is characterized by a cardiac rhythm with 1:1 A: $\mathrm{V}$ conduction and heart rate above 180 bpm, usually above 220 bpm. 17,137,138,141 It is important to understand the underlying mechanism of the arrhythmia, assessing simultaneously the atrial and ventricular activity. Using Doppler flow tracing, it is possible to measure the AV (atrium $\rightarrow$ ventricle) and VA (ventricle $<$ atrium) intervals, which correspond, analogously and respectively, to PR and RP intervals in an electrocardiogram. When the VA interval is greater than the $\mathrm{AV}$, the most possible diagnosis is reentrant tachycardia (95\%); when the VA interval is greater 


\section{Guideline}

Table 7.2 - In utero management of bradycardias

\begin{tabular}{|c|c|c|c|c|}
\hline Diagnosis & Primary causes & In utero management & GOR/LOE & Comments \\
\hline \multirow[t]{3}{*}{ Sinus bradycardia } & Ectopic atrial pacemaker & $\begin{array}{l}\text { Rule out fetal distress as the cause of } \\
\text { bradycardia }\end{array}$ & $\mathrm{I} / \mathrm{A}$ & Can be seen in atrial isomerism \\
\hline & $\begin{array}{l}\text { Sinus node dysfunction } \\
\text { (including immune } \\
\text { mediated or infection) }\end{array}$ & Observation until bradycardia resolves & $\mathrm{I} / \mathrm{A}$ & $\begin{array}{l}\text { Test for anti-Ro/LA antibodies } \\
\text { Maternal IgG/lgM for TORCH } \\
\text { diseases and parvovirus }\end{array}$ \\
\hline & $\begin{array}{c}\text { Secondary causes: } \\
\text { maternal medications, } \\
\text { maternal hypothyroidism, } \\
\text { fetal distress or fetal CNS } \\
\text { abnormalities }\end{array}$ & Treat underlying cause of bradycardia & $\mathrm{I} / \mathrm{A}$ & \\
\hline Blocked atrial bigeminy & Atrial extrasystoles & Observe / reduce maternal stimulants & $\mathrm{I} / \mathrm{A}$ & $\begin{array}{l}10 \% \text { risk of fetal SVT } \\
\text { Weekly auscultation of fetal HR until } \\
\text { arrhythmia resolves }\end{array}$ \\
\hline \multirow[t]{7}{*}{ AVB } & $\begin{array}{l}\text { Maternal anti-Ro/La } \\
\text { antibodies }\end{array}$ & Observation & $1 / A$ & Structurally normal heart \\
\hline & & $\begin{array}{l}\text { Dexamethasone for second-degree block } \\
\text { or first-degree block with findings of cardiac } \\
\text { inflammation }\end{array}$ & $\| \mathrm{llb} / \mathrm{B}$ & $\begin{array}{l}\text { Endocardial fibroelastosis, associated } \\
\text { valvular or myocardial dysfunctions }\end{array}$ \\
\hline & & $\begin{array}{l}\text { For CAVB to prevent death or } \\
\text { cardiomyopathy }\end{array}$ & $\mathrm{llb} / \mathrm{B}$ & $4-8 \mathrm{mg}$ day \\
\hline & & $\begin{array}{l}\text { IVIG (note: IVIG as prophylaxis is not } \\
\text { recommended) }\end{array}$ & $\mathrm{Ila} / \mathrm{C}$ & \\
\hline & & $\begin{array}{l}\text { Sympathomimetics for } \mathrm{HR}<55 \mathrm{bpm} \text { or higher } \\
\text { rates associated with fetal hydrops }\end{array}$ & $\mathrm{Ib} / \mathrm{C}$ & \\
\hline & $\begin{array}{l}\text { CAVB not related to } \\
\text { antibodies }\end{array}$ & Observation & $\mathrm{I} / \mathrm{A}$ & $\begin{array}{l}\text { Associated with structural defects } \\
\text { such as CTGA, left atrial isomerism }\end{array}$ \\
\hline & $\begin{array}{l}\text { CAVB related to } \\
\text { channelopathies }\end{array}$ & Observation & $\mathrm{I} / \mathrm{A}$ & \\
\hline
\end{tabular}

Avoid QT-prolonging drugs

AVB: atrioventricular block; CAVB: complete atrioventricular block; CNS: central nervous system; CTGA: corrected transposition of great arteries; GOR: grade of recommendation; HR: heart rate; IVIG: intravenous infusion of gammaglobulin; LOE: level of evidence; mg: milligrams; SVT: supraventricular tachycardia; TORCH: toxoplasma IgG, Rubella IgG, Cytomegalovirus IgG, and Herpes. Source: adapted from Donofrio et al.17

than the $\mathrm{AV}$, tachycardia due to ectopic atrial focus or junctional reciprocating tachycardia are the most frequent diagnosis. ${ }^{132,133,136}$

Atrial flutter presents with atrial rates above $400 \mathrm{bpm}$, with variable atrioventricular conduction $(2: 1,3: 1,4: 1)$ and ventricular rates (200-250 bpm). ${ }^{17,137,138,141,169}$

Ventricular tachycardia is identified as atrioventricular dissociation, with atrial rate lower than ventricular, varying from 100 to $400 \mathrm{bpm}$. When it coexists with bradycardia periods, the possible diagnosis is long QT syndrome, which may manifest as monomorphic ventricular tachycardia, torsade de pointes, ventricular dysfunction, atrioventricular valve regurgitation, and fetal hydrops. ${ }^{138,172}$

\subsubsection{Treatment}

The first choice for medical treatment of supraventricular tachycardias in most centers continues to be transplacental digoxin, given that it is safe and widely used during gestation. ${ }^{17,137,138,141,173,174}$ The doses should be high, since only $50-70 \%$ crosses the placental barrier. The recommended loading dose is $3.0 \mathrm{mg}$ during the first 48 hours of treatment, i.e., $0.50 \mathrm{mg}$ every 8 hours. The maintenance dose is $0.25-0.75 \mathrm{mg} /$ day, varying in accordance with isolated experience of each service and maternal serum level. Daily control of digoxin level is mandatory, and it should be kept between 1 and $2 \mathrm{ng} / \mathrm{mL}$. If it is not possible to administer it orally, intravenous lanatoside $\mathrm{C}$ may be used as an alternative. If the arrhythmia has not reversed 
Guideline

Table 7.3 - In utero management of tachycardias

\begin{tabular}{|c|c|c|c|}
\hline Diagnosis & In utero management & GOR/LOE & Comments \\
\hline \multicolumn{4}{|c|}{ Intermittent tachycardia } \\
\hline SVT or AF & Observation & $\mathrm{I} / \mathrm{B}$ & Frequent fetal HR auscultation \\
\hline$V T \geq 200 \mathrm{bpm}$ & Antiarrhythmic medication & $\| \mathrm{la} / \mathrm{C}$ & \\
\hline \multicolumn{4}{|c|}{ Sustained tachycardia } \\
\hline \multirow{3}{*}{$\begin{array}{l}\text { SVT or AF with hydrops or ventricular } \\
\text { dysfunction }\end{array}$} & Digoxin & $\mathrm{I} / \mathrm{B}$ & \\
\hline & Sotalol & $\mathrm{I} / \mathrm{B}$ & \\
\hline & Combination of drugs (transplacental) & $\mathrm{llb} / \mathrm{B}$ & $\begin{array}{c}\text { Combination treatments are used for severe } \\
\text { drug-refractory cases. Consider preterm } \\
\text { delivery if near term }\end{array}$ \\
\hline & Amiodarone & $\mathrm{I} / \mathrm{B}$ & \\
\hline & Contraindicated: verapamil & $\| I I / A$ & \\
\hline & Contraindicated: procainamide & III/B & \\
\hline \multicolumn{4}{|c|}{ Direct fetal treatment: } \\
\hline & IM digoxin & $\| \mathrm{la} / \mathrm{B}$ & \\
\hline & Intracordal digoxin & $\mathrm{llb} / \mathrm{B}$ & \\
\hline & $\begin{array}{l}\text { Contraindicated: } \\
\text { Intracordal adenosine }\end{array}$ & III/B & \\
\hline
\end{tabular}

First or second line:

SVT $\geq 200$ bpm, without hydrops or ventricular dysfunction (usually SVT has $H R \geq 220$ bpm; consider other causes if $\mathrm{HR}<220 \mathrm{bpm}$ ).

\begin{tabular}{|c|c|c|}
\hline Digoxin & $\mathrm{l} / \mathrm{B}$ & $\begin{array}{l}\text { See Table } 7.4 \text {, for doses and monitoring } \\
\text { recommendations }\end{array}$ \\
\hline Sotalol & I/B & $\begin{array}{l}\text { Frequent monitoring of fetal well-being and } \\
\text { maternal/fetal drug toxicity. Consider preterm } \\
\text { delivery if near term. }\end{array}$ \\
\hline \multicolumn{3}{|l|}{ Third line: } \\
\hline Amiodarone & $\mathrm{llb} / \mathrm{B}$ & \\
\hline Contraindicated: verapamil & $\mathrm{Ilb} / \mathrm{A}$ & \\
\hline Contraindicated: procainamide & III/B & \\
\hline Observation & I/B & \\
\hline Sotalol & I/B & \multirow{2}{*}{$\begin{array}{l}\text { Digoxin increases AVB and decreases } \\
\text { ventricular response. Consider preterm delivery } \\
\text { if near term }\end{array}$} \\
\hline Digoxin & $\mathrm{l} / \mathrm{B}$ & \\
\hline Amiodarone & $\mathrm{llb} / \mathrm{B}$ & \\
\hline \multirow[t]{2}{*}{ Contraindicated: procainamide } & III/B & \\
\hline & I/C & \\
\hline $\begin{array}{l}\text { Magnesium IV } \\
\text { Lidocaine IV } \\
\text { Propranolol (oral) }\end{array}$ & $\mathrm{I} / \mathrm{C}$ & $\begin{array}{l}\text { FMCG (if available) to measure QTc interval. } \\
\text { Start with magnesium IV, then lidocaine, load + } \\
\text { maintenance. } \\
\text { Note: maternal intravenous magnesium should } \\
\text { not be used for }>48 \mathrm{~h} \text {. } \\
\text { Consider preterm delivery if near term. }\end{array}$ \\
\hline $\begin{array}{l}\text { Mexiletina (oral) } \\
\text { Sotalol }\end{array}$ & I/C & \\
\hline
\end{tabular}

AF: atrial flutter; GOR: grade of recommendation; IV: intravenous; HR: heart rate; IM: intramuscular; FMCG: fetal magnetocardiography; LOE: level of evidence; SVT: supraventricular tachycardia; VT: ventricular tachycardia. Source: adapted from Donofrio MT et al. ${ }^{17}$ 


\section{Guideline}

Table 7.4 - Antiarrhythmic drugs

\begin{tabular}{|c|c|c|c|}
\hline Drug & Therapeutic dose & Therapeutic serum level and effect & Toxicity \\
\hline \multirow[t]{2}{*}{ Digoxin } & $\begin{array}{c}\text { LD: } 0.5 \mathrm{mg} \text { (2 capsules) every } 8 \mathrm{~h} \text { for } 48 \mathrm{~h}- \\
1.5 \mathrm{mg} / \mathrm{d} \text { for } 2 \text { days }\end{array}$ & $0.7-2.0 \mathrm{ng} / \mathrm{mL}$ & $\begin{array}{l}\text { Maternal nausea/vomiting, sinus } \\
\text { bradyarrhythmia or AVB, proarrhythmia }\end{array}$ \\
\hline & $\begin{array}{c}\text { MD: } 0.25-0.75 \mathrm{mg} / \mathrm{day} \\
\text { Fetal IM dose: } 88 \mu \mathrm{g} / \mathrm{kg} \text { every } 12 \mathrm{~h} \text {, repeat } \\
\text { twice }\end{array}$ & $\begin{array}{c}\text { Nausea, fatigue, loss of appetite, sinus } \\
\text { bradycardia, first-degree AV block, nocturnal } \\
\text { Wenckebach AV block (rare) }\end{array}$ & $\begin{array}{l}\text { Fetal IM: sciatic nerve injury or skin } \\
\text { laceration from injection }\end{array}$ \\
\hline \multirow[t]{2}{*}{ Sotalol } & $160-480$ mg/day every 8-12 h PO & Levels not monitored & $\begin{array}{l}\text { Nausea/vomiting, dizziness, QTc } \geq 0.48 \mathrm{~s} \text {, } \\
\text { fatigue, BBB, maternal/fetal proarrhythmia }\end{array}$ \\
\hline & & $\begin{array}{c}\text { Bradycardia, first-degree AVB, P and QRS } \\
\text { widening, QTc } \leq 0.48 \mathrm{~s}\end{array}$ & \\
\hline \multirow[t]{2}{*}{ Amiodarone } & LD: $1800-2400$ mg/d divided every 6 h PO & $0.7-2.0 \mu \mathrm{g} / \mathrm{mL}$ & $\begin{array}{l}\text { Nausea/vomiting, thyroid dysfunction, } \\
\text { photosensitivity rash, thrombocytopenia, } \\
\text { BBB, QTc } \geq 0.48 \mathrm{~s} \text {, maternal/fetal } \\
\text { proarrhythmia, fetal torsades with LQTS, } \\
\text { fetal goiter, neurodevelopmental concerns }\end{array}$ \\
\hline & MD: $200-600 \mathrm{mg} / \mathrm{d}$ PO & $\begin{array}{c}\text { Maternal/fetal sinus bradycardia, decreased } \\
\text { appetite, first-degree AVB, P and QRS } \\
\text { widening, QTc } \leq 0.48 \mathrm{~s}\end{array}$ & \\
\hline
\end{tabular}

Consider discontinuation of drug and transition to another agent once normal rhythm is reestablished or hydrops has resolved.

\begin{tabular}{|c|c|c|c|}
\hline Propranolol & $60-320 \mathrm{mg} / \mathrm{d}$ divided every $6 \mathrm{~h}$ PO & $25-140 \mathrm{ng} / \mathrm{mL}$ & $\begin{array}{c}\text { Fatigue, bradycardia, hypotension, AV } \\
\text { block, fetal growth restriction, increased } \\
\text { uterine tone }\end{array}$ \\
\hline & & $\begin{array}{l}\text { First-degree AVB, bradycardia, } \\
\text { increased uterine tone }\end{array}$ & \\
\hline Lidocaine & $\begin{array}{l}\text { LD: } 1-1.5 \mathrm{mg} / \mathrm{kg} \text { followed by infusion of } 1-4 \\
\mathrm{mg} / \mathrm{min} \text { continuous IV }\end{array}$ & $1.5-5 \mu \mathrm{g} / \mathrm{mL}$ & $\begin{array}{c}\text { Nausea/vomiting, neurological symptoms, } \\
\text { proarrhythmia }\end{array}$ \\
\hline Mexiletine & 600-900 mg/d divided every $8 \mathrm{~h}$ PO & $0.5-2 \mu \mathrm{g} / \mathrm{mL}$ & $\begin{array}{c}\text { Nausea/vomiting, neurological symptoms, } \\
\text { proarrhythmia }\end{array}$ \\
\hline \multirow[t]{2}{*}{ Magnesium sulfate } & LD: 2-6 g IV over 20 min followed by $1-2 \mathrm{~g} / \mathrm{h}$ & $<6 \mathrm{mEq} / \mathrm{L}$ & $\begin{array}{l}\text { Fatigue, neurological symptoms } \\
\text { If there is loss of patellar reflex and/or } \\
\text { levels of }>6 \mathrm{mEq} / \mathrm{L} \text { STOP infusion }\end{array}$ \\
\hline & $\begin{array}{l}\text { Treatment for }>48 \mathrm{~h} \text { is not recommended but } \\
\text { redosing may be considered if VT recurs }\end{array}$ & Monitor patellar reflex & $\begin{array}{c}\text { Levels }>5 \mathrm{mEq} / \mathrm{L} \text { associated with maternal } \\
\text { changes on ECG and proarrhythmia }\end{array}$ \\
\hline
\end{tabular}

AV: atrioventricular; AVB: atrioventricular block; BBB: bundle-branch block; ECG: electrocardiogram; IM: intramuscular; IV: intravenous; LD: Ioading dose; LOE: level of evidence; LQTS: long QT syndrome; MD: maintenance dose; PO: orally; VT: ventricular tachycardia. Source: afapted from Donofrio et al. ${ }^{17}$

after 5 days, oral sotalol is initiated as second-choice drug. ${ }^{175-177}$ This may be used with an initial dose of 80 mg every 12 hours, gradually increasing $40-80$ mg every $3-5$ day, until the arrhythmia is reversed or the maximum dose of $480 \mathrm{mg} /$ day has been reached. In this case, the mother must remain in hospital for monitorization, with daily ECG control to measure the QTC interval, as well as serum levels of digoxin. In fetuses with significant hydrops and sustained tachycardia with elevated heart rate, sotalol may be initiated concomitantly with digoxin. Combined therapy has greater risks of maternal and fetal complications. If there is no therapeutic response in fetuses who are severely affected, the third-choice drug, amiodarone, may be used at a dose of $800-1,200 \mathrm{mg} /$ day. ${ }^{178-179}$ This drug, however, has a significant toxicity for both mother and fetus. ${ }^{180}$

If the fetal tachyarrhythmia continues, with important hemodynamic impairment and severe hydrops, direct fetal therapy may be necessary, via cordocentesis or direct intramuscular injection, given that, in this situation, there is a significant decrease in the transplacental passage of medications. ${ }^{171,181,182}$ The risks and benefits of every situation must be weighed individually. Digitalis (dose of $0.03 \mathrm{mg} / \mathrm{kg}$ ) or amiodarone (dose of $15 \mathrm{mg} / \mathrm{kg}$ ) may be administered. Adenosine has not shown any effect in maintaining sinus rhythm, and it is not recommended for atrial flutter. 


\section{Guideline}

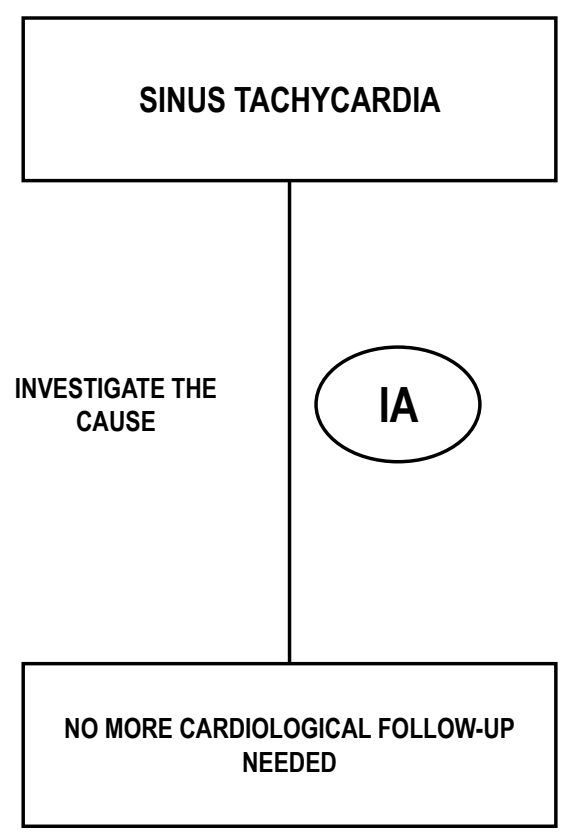

Figure 7.3 - Sinus tachycardia clinical management.

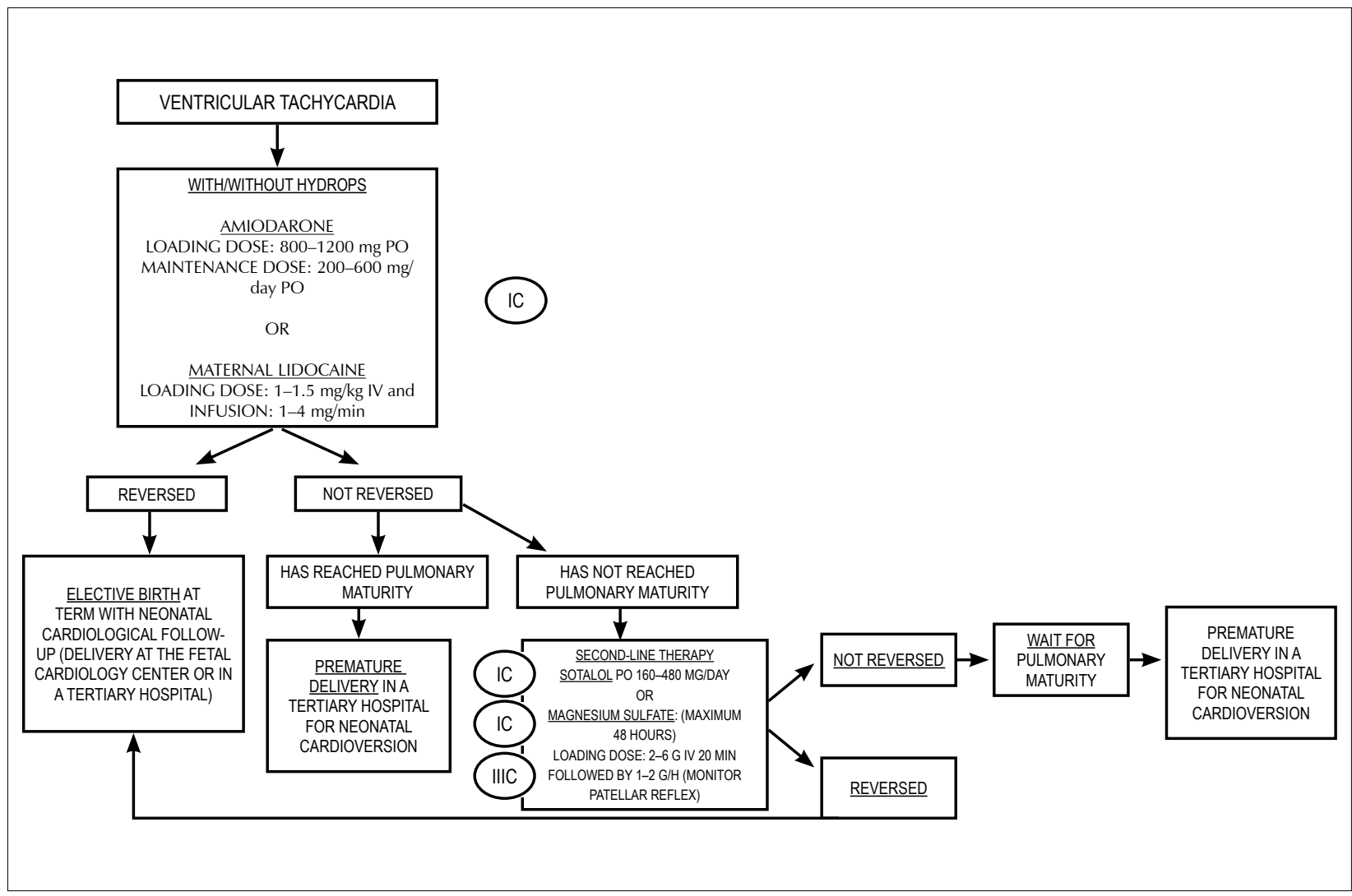

Figure 7.4 - Treatment flowchart for ventricular tachycardia. IV: intravenous; $P O$ : orally. 


\section{Guideline}

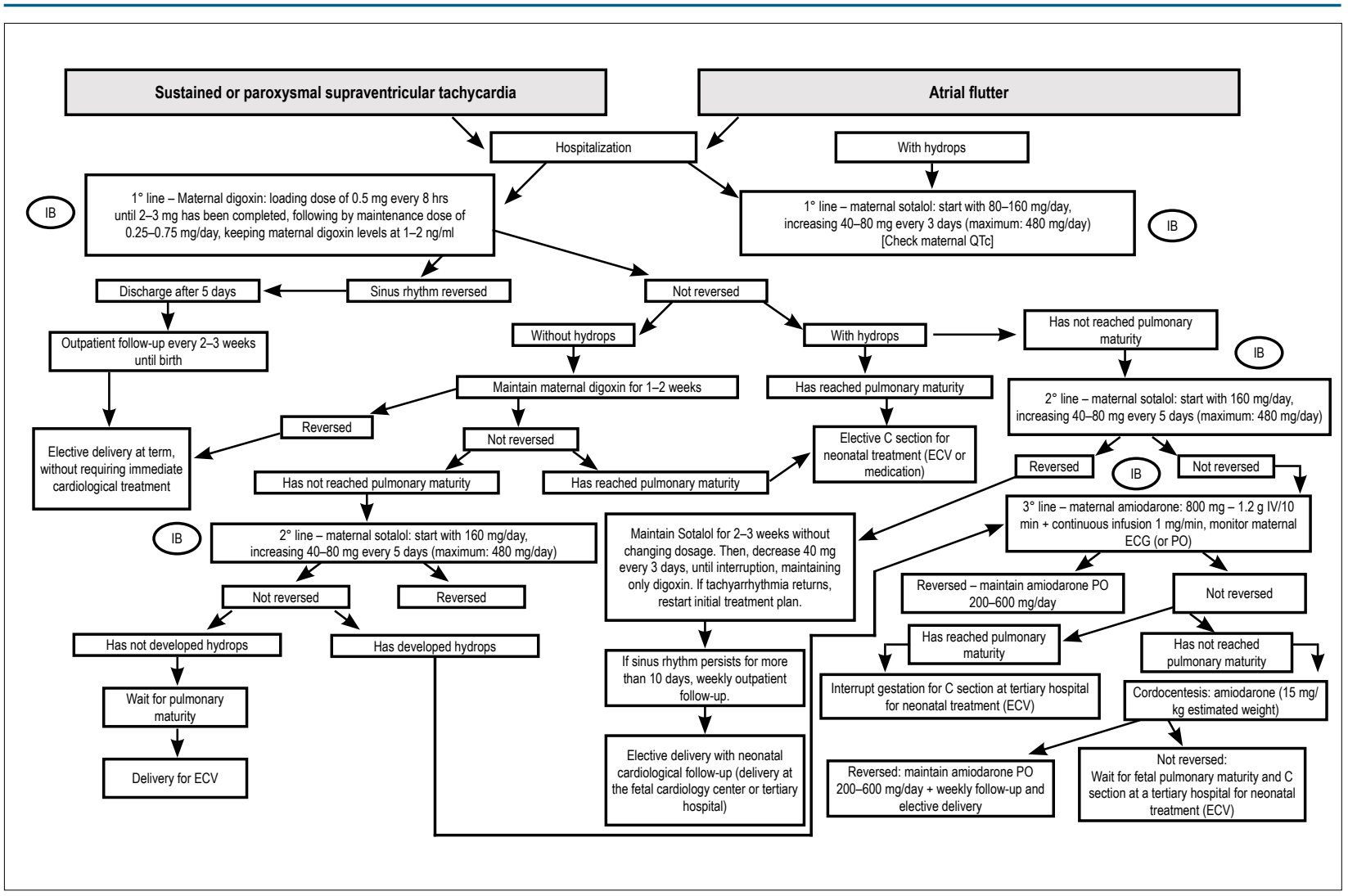

Figure 7.5 - Flowchart treatment for supraventricular tachycardias.

ECV: electric cardioversion; IV: intravenous; PO: orally.

Some centers use flecainide (not commercially available in Brazil) or sotalol as first-choice drugs. ${ }^{130,177,183,184}$ After birth, treatment should be based on the therapy used in utero and on the tachycardia mechanism. It is recommended to maintain therapy for 6 months to 1 year, in accordance with the outcome. About $50 \%$ of cases of fetal SVT do not recur after birth. ${ }^{185}$

For $\mathrm{AF}$, recommended medication for initial treatment may be either digoxin and/or sotalol. ${ }^{185}$ Sotalol is also safe and efficient with a reversal rate to sinus rhythm of $50-80 \%$, without mortality. ${ }^{177}$

Doses and forms of administration for $\mathrm{AF}$ are as previously described for SVT. Following delivery, synchronized cardioversion is indicated when there is no in utero reversal. After birth, AF does not usually recur once it has been reversed and maintenance of medical treatment is not recommended.

Sustained ventricular tachycardia with ventricular rate $<200$ bpm is usually well tolerated; when it exceeds this rate, transplacental magnesium is recommended. This infusion should not be administered for more than 48 hours. ${ }^{172,186,187}$ If ventricular tachycardia recurs, a new dose of magnesium may be used, provided that maternal serum levels are $<6 \mathrm{mEq} / \mathrm{L}$ and there are no signs of toxicity. Therapeutic options for pharmacological treatment of sustained ventricular tachycardias include oral administration of amiodarone, propranolol, and mexiletine or maternal intravenous lidocaine. Amiodarone, sotalol, and flecainide cannot be used when there is long QT syndrome. ${ }^{186,187}$ When ventricular tachycardia is secondary to myocarditis or maternal antibodies, intravenous dexamethasone and immunoglobulin may be administered to the mother. This treatment should be continued after birth.

One should consider that treatment of fetal sustained tachycardias is slow and its goal is to bring gestation to term. Total reversal of arrhythmia and hydrops may occur several weeks after initiation of medical treatment. A concomitant Doppler ultrasound, performed by the obstetrician, is essential to decide if the delivery should be anticipated. Delivery anticipation should be limited to fetuses with imminent risk of in utero death. If sustained tachycardia persists in fetuses with severe hydrops and proven pulmonary maturity (after week 34 of gestation), it 
is recommendable to deliver the baby and begin postnatal treatment immediately.

\section{Fetal Cardiac Interventions}

The potential benefits of fetal cardiac interventions have been emphasized for many years. In the year 2000, Kohl et al. ${ }^{188}$ published the worldwide experience of fetal aortic valvuloplasty, which, at that time, consisted of 12 cases, with 7 technically well-succeeded but only 1 survival. Since that time, the Boston Children's Hospital group has initiated an invasive intrauterine cardiac therapy program, stimulating vast progress in the field and disseminating technical application throughout various other centers around the world. ${ }^{189,190}$

The main reason for invasive procedures during fetal life is to improve outcome and postnatal prognosis, either because the fetus is at a risk of not surviving or because postnatal outcome is strongly unfavorable. Early therapy for CHD may improve the chances of myocardial and vascular remodeling and offer better chances of adapting the blood supply to the developing myocardium. Thus, provided that the technique is well established, the equipment is appropriate, and, above all, the medical team is trained in fetal surgery, pediatric interventions, and Fetal Cardiology, fetal percutaneous interventions represent another form of therapy in the field of Pediatric Cardiology. ${ }^{189}$

The main heart diseases that benefit from intervention in utero are HLHS with severe flow restriction through the interatrial septum, critical aortic valve stenosis with impending left ventricular hypoplasia, and pulmonary atresia with intact interventricular septum (PAIVS), or critical pulmonary stenosis with right ventricular hypoplasia. ${ }^{191}$

\subsection{Indications}

The main indications for fetal cardiac interventions are summarized in Table 8.1 and subsequently described.

\subsubsection{Critical Aortic Stenosis with Impending Hypoplastic Left Heart Syndrome}

Aortic stenosis is defined as the following morphological and functional characteristics: thick valve, little mobility, and turbulent or no antegrade

Table 8.1 - Main indications for fetal cardiac interventions

\begin{tabular}{|c|c|}
\hline Aortic valvuloplasty & Gestational age between 22 and 30 weeks \\
\hline \multirow[t]{6}{*}{ Critical aortic stenosis with impending HLHS } & Thick aortic valve with little mobility \\
\hline & Minimal or no aortic anterograde flow \\
\hline & Reverse flow in the transverse arch \\
\hline & Reverse shunt at the atrial level $(L \rightarrow R)$ \\
\hline & Monophasic LV inflow (single E wave of short duration) \\
\hline & Moderate or severe LV systolic dysfunction (subjective analysis) \\
\hline \multirow[t]{3}{*}{ Critical aortic stenosis with giant LA } & Same criteria as previously described \\
\hline & LV function may not be very abnormal due to the presence of massive mitral regurgitation \\
\hline & Giant LA \\
\hline Pulmonary valvuloplasty & Gestational age between 22 and 30 weeks \\
\hline \multirow[t]{5}{*}{$\begin{array}{l}\text { Pulmonary atresia with intact interventricular septum/ } \\
\text { critical pulmonary stenosis }\end{array}$} & Thick pulmonary valve with little or no mobility \\
\hline & Minimal or no pulmonary anterograde flow \\
\hline & Inverted flow in the ductus arteriosus, i.e., aorta $\rightarrow$ pulmonary \\
\hline & Monophasic RV inflow (single E wave of short duration) \\
\hline & Some degree of RV hypoplasia or no growth during $2-4$ weeks of observation \\
\hline Balloon atrial septostomy & Gestational age between 28 and 33 weeks \\
\hline \multirow[t]{3}{*}{$\begin{array}{l}\text { HLHS or variants with intact interatrial septum or } \\
\text { minimal foramen ovale }\end{array}$} & Minimal or no flow at the atrial level \\
\hline & Dilated LA and pulmonic veins \\
\hline & Biphasic and bidirectional pulmonary vein Doppler tracing \\
\hline
\end{tabular}

HLHS: hypoplastic left heart syndrome; L: left; LA: left atrium; LV: left ventricle; $R$ : right; $R$ V: right ventricle. 
flow across the valve assessed by Doppler techniques. Left ventricular to aorta Doppler gradient should not be used to classify the severity of the stenosis since, there is a frequent association of endocardial fibroelastosis and severe myocardial dysfunction in critical aortic stenosis. Reverse flow in the transverse arch, i.e., coming from the descending aorta to the ascending aorta; inverted flow at the atrial level (from left to right); monophasic left ventricular inflow (Doppler tracing across the mitral valve showing single A wave due to high filling pressures), and moderate or severe left ventricular dysfunction are the main functional parameters that suggest impending HLHS. ${ }^{192-195}$ Ideally, when fetal intervention is considered to avoid left heart hypoplasia, left ventricular length Z score (long axis) should be $>-2$, meaning that the left ventricle is not hypoplastic yet. Occasionally, aortic valvuloplasty is performed in cases where the left ventricle has already some degree of hypoplasia (Z-score $>-4$ and $<-2$ ), and the main aim in these cases is to promote some anterograde aortic flow, which may improve coronary and encephalic perfusion and allow ascending aorta growth, knowing that the chances of left ventricular complete recovery are low. ${ }^{192-195}$

\subsubsection{Hypoplastic Left Heart Syndrome with Intact} Interatrial Septum or Significantly Restrictive Foramen Ovale

This situation is characterized by absent or minimal high velocity flow across the interatrial septum and bidirectional flow in the pulmonary vein with prominent reverse flow, with disappearance of the classic triphasic pattern. ${ }^{196,197}$

8.1.3. Pulmonary Atresia with Intact Interventricular Septum or Critical Pulmonary Valve Stenosis with Signs of Evolving Right Heart Hypoplasia

This disease is defined as membranous pulmonary atresia with identifiable pulmonary valve leaflets with intact interventricular septum, associated with minimal or no anterograde pulmonary blood flow; reverse flow in the ductus arteriosus, i.e., coming from the aorta to the pulmonary artery; some degree of right heart hypoplasia, with hypoplastic tricuspid valve annular diameter ( $Z$ score $<-2)$, or evidence that the right ventricle has not grown during 2-4 weeks of observation. Cases with significant coronary to right ventricle fistulas are excluded. ${ }^{198-200}$

\subsubsection{Critical Aortic Stenosis with Massive Mitral} Regurgitation and Giant Left Atrium

This is a specific group of fetuses that has only recently been characterized as a subgroup of critical aortic stenosis. These cases present with left ventricular dilation, reverse flow in the transverse arch, and some degree of left ventricular dysfunction. Most of them are associated with fetal hydrops and may benefit from aortic valvuloplasty associated or not with atrial septostomy to reduce the risk of fetal or neonatal death. ${ }^{44,201}$

\subsection{Technical Considerations}

Pre-anesthesia fasting and tocolytic prophylaxis consist the main preparation for the procedure. Nifidipine, $20 \mathrm{mg}$ orally, started $4-8$ hours before the procedure, is the medication of choice for this purpose, since it has few side effects and is highly effective. ${ }^{189}$ The intervention is performed under maternal regional block, preferably via spinal anesthesia. General anesthesia may also be used, but this has the disadvantage of hindering proper fetal positioning, given that maternal general anesthesia also anesthetizes the fetus.

The fetal positioning is obtained with manual maneuvers allowing the fetal specialist to reach the target cardiac structure percutaneously. The ideal fetal position is pelvic with the spine downwards, leading to proceed the puncture as close as possible to the uterine fundus. ${ }^{189}$

Fetal anesthesia may be intramuscular or intravenous via the umbilical cord. It is performed with a mixture of opioid (fentanyl), muscle blocker (pancuronium), and atropine at doses of $15 \mu \mathrm{g}, 0.2 \mathrm{mg}$, and $0.02 \mathrm{mg}$ per kilogram of fetal weight, respectively. A 20-G Chiba needle is used to administer this medication. ${ }^{189,190,194}$

The heart is also accessed with a Chiba needle, $15 \mathrm{~cm}$ in length ranging from 17 to 19 Gauge. The entire procedure is monitored by ultrasound, which may be operated by either the fetal specialist or the fetal cardiologist. Once the abdominal wall is crossed, the needle reaches the amniotic cavity and the fetal thorax. ${ }^{194}$ The target structure (aortic valve, pulmonary valve, or interatrial septum) is reached by direct heart puncture.

Once the distal end of the needle has reached the target cardiac structure, a pre-assembled coronary angioplasty balloon catheter is advanced through the needle until the balloon is positioned across the structure to be dilated. The pressure with which the balloon is inflated varies, considering the diameter and the target structure. For semilunar valve dilation, the ideal balloon:annulus ratio is from 1.1 to $1.2 .{ }^{193}$ After the balloon is completely deflated, the entire set (balloon, catheter, and puncture needle) is removed all together, at once. After the system is complete removed from the fetal heart, bradycardia and hemopericardium frequently occur. ${ }^{190}$ Voluminous effusions should promptly be emptied via a new puncture with a 
20-G needle. ${ }^{194}$ Removal of $1-2 \mathrm{ml}$ of blood from the pericardium is usually enough to treat the condition. In most cases, this does not cause fetal anemia.

These procedures are not exempt from risks involving the mother and/or the fetus. Maternal risks are currently extremely low and minimized, thanks to the increased experience in fetal surgery for noncardiac diseases. These complications include premature rupture of membranes, infection, hemorrhage, placental abruption, preterm labor, anemia, bradycardia, and fetal death. ${ }^{202}$

There are still some doubts regarding the ideal moment to perform fetal cardiac intervention. Due to the reduced number of candidates and the morphological variability that every pathology may present, it is difficult to establish when it should be considered too late for intervention. ${ }^{203}$ It seems reasonable to perform intervention as early as possible, soon after the diagnosis. From the technical point of view, however, it is very difficult to act before gestational week 20, due to the small dimensions of the fetal heart. Interventions performed very early may result in orifice and valve closure before the fetus has reached term. ${ }^{203}$ On the other hand, late interventions do not prevent ventricular hypoplasia or avoid vascular damage of the pulmonary circulation. It appears to be consensual that the adequate period would be between gestational weeks 22 and $30 .{ }^{190}$

\subsection{Aortic Valvuloplasty}

The goal of aortic valvuloplasty is to change the natural history of critical aortic stenosis, maintaining left ventricular size and function adequate for biventricular physiology at birth or after a rehabilitation process. Alleviating left ventricular outflow obstruction reduces the left ventricular myocardial damage, thus facilitating chamber growth and myocardial function improvement. This hypothesis is based on animal models studies, which demonstrated the impact of load and flow conditions abnormalities on the developing myocardium, which leads to abnormal cardiovascular growth and function conditions. ${ }^{204-209}$ According to the study published by McElhinney et al., ${ }^{195}$ there are anatomical and functional characteristics that are predictive of technical success and progression to postnatal biventricular circulation, based on the experience of 70 fetal aortic valvuloplasty procedures performed by their group. ${ }^{8}$ These criteria are shown in Table 8.2.

There is evidence that the transition from normal left ventricle to HLHS in fetuses with critical aortic stenosis almost always occurs during the second or third trimester of gestation. ${ }^{210}$

An interesting aspect observed by the authors is that the progressive growth of left structures during fetal life and early infancy may eventually result in biventricular correction during the first year of life. Applying the strategy initiated with fetal aortic valvuloplasty, treatment continues with neonatal hybrid procedure, which may or may not be associated with a new aortic valvuloplasty or Norwood procedure, with the maintenance of partially restrictive foramen ovale and aortic commissurotomy. This management is a bridge to biventricular correction following the process known as left ventricular rehabilitation. ${ }^{189,201,211,212}$ Although diastolic dysfunction may be a problem in this group of patients, it is believed that this is better than the morbidity and mortality inherent in medium- and longterm of the univentricular pathways. ${ }^{213}$

\subsection{Critical Aortic Stenosis with Giant Left Atrium}

This is a very particular and severe presentation of critical aortic stenosis. In addition to obstructed left

Table 8.2 - Criteria for technical success (initial criteria) and criteria that indicate potential outcome to postnatal biventricular correction (modified criteria)

\begin{tabular}{|c|c|}
\hline Initial criteria (all of which must be present) & Modified criteria* \\
\hline LV long-axis Z-score > -2 & $\begin{array}{l}\text { Aortic stenosis or atresia } \\
\text { (mandatory) }\end{array}$ \\
\hline $\begin{array}{c}\text { LV dysfunction capable of generating } \geq 10 \mathrm{mmHg} \text { pressure gradient across aortic } \\
\text { valve or } \geq 15 \mathrm{mmHg} \text { mitral regurgitation jet gradient }\end{array}$ & $\begin{array}{l}\text { LV long-axis Z-score > }-2 \\
\text { (mandatory) }\end{array}$ \\
\hline Mitral annulus Z-score $>-3$ & $\begin{array}{l}\begin{array}{l}\text { Meet, at least, } 4 \text { of the following } 5 \text { parameters: } \\
\cdot \text { LV long-axis Z-score }>0 ; \\
\cdot \text { LV short-axis Z-score }>0 ; \\
\cdot \text { Aortic annulus Z-score }>-3,5 ; \\
\cdot \text { Mitral annulus Z-score }>-2 ;\end{array} \\
\cdot \text { - Aortic valve systolic gradient and/or LV-LA mitral regurgitation } \geq 20 \mathrm{mmHg}\end{array}$ \\
\hline
\end{tabular}

LA: left atrium; LV: left ventricle. * Source: adapted from McElhinney et al. ${ }^{195}$ 
ventricular outflow tract, the mitral valve is significantly abnormal, with annular dilation, resulting in severe mitral regurgitation and LA dilation. The foramen ovale is usually quite restrictive, or the interatrial septum is intact, and there is left ventricular endocardial fibroelastosis, which also compromises the subvalvular apparatus of the mitral valve. Most fetuses with this anatomical presentation have some degree of fetal hydrops, with a high risk of death in utero or of triggering premature labor with immediate neonatal death. This disease appears to be the worst spectrum of the mitral valve arcade, where the chordae tendineae are fused and shortened.

It is believed that this anatomical complex primarily compromises the mitral and aortic valves, associated with endocardial fibroelastosis, leading to dilation of left chambers. Restricted left to right flow at the atrial level contributes to significant LA dilation which compresses the right chambers and increases central venous pressure. This seems to be the physiopathology of fetal hydrops, which is present in $70-80 \%$ of cases, with polyhydramnios being observed in $100 \%$ of cases described by Vogel et al. ${ }^{44}$

Aortic valve opening, in these cases, may reduce the degree of mitral regurgitation and LA pressure, and may treat or improve fetal hydrops and bring the gestation closer to term. ${ }^{201}$ Opening of the atrial septum may be considered for the same procedure, potentializing the effects of aortic valvuloplasty. Besides the intervention, this is a very severe clinical condition, which has a significant impact on fetal and neonatal mortality.

\subsection{Fetal Pulmonary Valvuloplasty}

PAIVS is associated with variable hypoplasia of the right ventricle, tricuspid valve, and right ventricular outflow. The disease's most severe spectrum presents fibromuscular atresia of the infundibulum and pulmonary valve, with significant hypoplasia of the right ventricular cavity and the tricuspid valve, associated with abnormal coronary circulation. Contrastingly, in the more favorable spectrum, the pulmonary valve atresia is membranous; the tricuspid valve annulus diameter and the right ventricular volume are close to normal, and there is an absence of abnormalities in the coronary arteries. Some cases of critical pulmonary stenosis observed during fetal life may evolve to total flow interruption between the right ventricle and the pulmonary artery, with consequent hypoplasia of the right ventricular chamber. These cases behave similarly to PAIVS with mild to moderate hypoplasia of the right ventricle. ${ }^{214}$

The goal of fetal intervention in cases of PAIVS and critical pulmonary stenosis is to promote growth and functional development of the right ventricle and to increase the chances of biventricular circulation during the postnatal period. The identification of potential candidates for the procedure should be based on the risks of the fetus' evolving to univentricular circulation without fetal intervention and the possibility of changing this progression. ${ }^{198}$ The selection of candidates for intervention should follow the criteria previously described in the "Indications" section. Another important criterion in this decision is the presence of signs of fetal heart failure characterized by reverse "a" wave in the ductus venosus flow, which denotes increased right atrium pressure and possible fetal hydrops development. This hemodynamic condition is observed in fetuses who have significant tricuspid regurgitation and very reduced right ventricular compliance. ${ }^{215}$

From the technical point of view, this intervention is more difficult and challenging than aortic valvuloplasty. Due to the reduced dimensions and hypertrophy of the right ventricle, associated with its anatomical characteristics (outflow located anterior and far away from inflow), the positioning of the needle below the pulmonary valve requires very experienced and skilled fetal specialist. The RV puncture should be performed as far as possible from the outflow. In cases with valve atresia, the guidewire utilized should have a slightly firmer tip, in order to allow the interventionist to perforate the valve. ${ }^{201}$ Some authors prefer to introduce a thinner needle through the first one to perforate the valve or proceed the valve perforation with the $17 \mathrm{G}$ needle itself. ${ }^{200}$ After reaching the pulmonary artery, the guide is positioned in one of the pulmonary branches or across the ductus arteriosus, to provide balloon support. For this intervention, the same balloon:annulus ratio as fetal aortic valvuloplasty is employed. The result of the intervention is evaluated by observing the anterograde flow through the pulmonary valve, the reduction of reverse flow through the ductus arteriosus, and the presence of pulmonary insufficiency. Pulmonary insufficiency is a marker of success, and it decreases as gestation advances. Restenosis during fetal life is commonly observed. Most cases will require a new valvuloplasty during the neonatal period. ${ }^{200,216,217}$

In many cases, total recovery of the right ventricle does not occur at birth, making accessory pulmonary flow necessary, either with ductus arteriosus stenting or surgical confection of a systemic to pulmonary shunt (modified Blalock-Taussig). ${ }^{201}$

\subsection{Fetal Atrial Septostomy}

Although HLHS neonatal survival continues to improve worldwide and, slowly in Brazil, some anatomical and functional aspects are risk factors for poor clinical outcome and neonatal or postoperative 
death. ${ }^{218}$ The presence of an intact atrial septum or severely restricted foramen ovale represents one of the worst risk factors of neonatal mortality. It causes deep hypoxemia after birth and pulmonary hypertension (venocapillary) triggered by pulmonary vein arterialization. ${ }^{218}$

In this condition, resuscitation maneuvers are usually ineffective. Some hospitals recommend emergency Norwood operation, with mortality affecting $83 \%$ of patients by the sixth month of life. Even in those who underwent immediate neonatal atrial septostomy, mortality exceeds $48 \% .^{218,219}$ These deaths are usually not directly related to the procedure and end up occurring after the first week of life. ${ }^{196}$ It is believed that, in addition to deep neonatal hypoxemia, anatomical abnormalities secondary to in utero venocapillary hypertension are related to mortality. In these cases, anatomopathological studies have demonstrated arterialization of the pulmonary veins associated with lymphatic vessel dilatation. ${ }^{219-221}$ It is estimated that the incidence of severely restrictive foramen ovale or intact interatrial septum associated with HLHS occur in $6 \%$ of cases, with some degree of restriction affecting, at least, $22 \%$ of patients. ${ }^{219}$

Left atrial decompression during fetal life seems to be essential to the prevent poor immediate neonatal clinical presentation and the remodeling of the pulmonary vascular bed. ${ }^{196}$ The main echocardiographic marker of significantly restricted foramen ovale during fetal life is the presence of high-velocity reverse flow in the pulmonary vein Doppler tracing, which shows an abnormal bidirectional pattern. ${ }^{45}$ This finding indicates that blood is returning to the lungs during atrial contraction, because the LA cannot decompress to the left ventricle or the right atrium. ${ }^{189}$

It is very important to examine at least one pulmonary vein with pulsed-wave Doppler during the echocardiogram of a fetus with HLHS. ${ }^{222}$ The echocardiographer must have in mind that this piece of information may significantly change these patients' outcome and the pre- and postnatal management. Other important features in this condition are pulmonary vein and LA dilation, atrial septum bulging into the right atrium, absent or minimal high-velocity flow across the interatrial septum. ${ }^{189}$

The ideal moment to perform atrial septostomy is discussed. ${ }^{196,223}$ Intending to prevent definitive damage to the pulmonary circulation, the intervention should ideally be performed immediately after the diagnosis. On the other hand, from the technical point of view, it is rather difficult to create an orifice in the interatrial septum that lasts for multiple weeks and prevent severe neonatal hypoxemia. It appears to be consensual that the ideal moment is between the $28^{\text {th }}$ to the $33^{\text {rd }}$ weeks of gestation when the fetus is of good size. During this period, it is feasible to use larger balloons with greater capacity to open wider orifices in the interatrial septum. ${ }^{190,197}$

The use of stents in the interatrial septum has also been considered by some authors. ${ }^{224,225}$ This procedure appears to be more challenging than atrial septostomy, mainly due to the difficulty of optimally positioning the stent in the septum. One of the main problems is to visualize the stent inside the metallic needle via ultrasound. Stent implantation is particularly interesting when the interatrial septum is very thick and, thus, does not allow for the opening of an orifice that is wide enough to alleviate pressure in the LA. Due to the profile of needles available for fetal interventions, the largest stent used is $3 \mathrm{~mm}$, which may, in some cases, reach an internal diameter of $3.5 \mathrm{~mm} \cdot{ }^{39,40}$ The rate of poor positioning and embolization is high, according to recent publications. In cases of embolization, the stent is buried in the atrium, without further complications, and the procedure may be completed with the septostomy. ${ }^{224,225}$

\subsection{Final Considerations of Fetal Cardiac Interventions}

With the development of fetal cardiac interventions, several important principles have been recognized. Technical success of the procedure does not always translate to clinical success after birth. Understanding the natural history of the malformation and continuously refining the criteria for patient selection are absolutely critical when one consider the creation of an invasive fetal cardiology program which includes potentially risky procedures. It is important to recognize that the majority of $\mathrm{CHD}$ are not fatal, and classic palliative treatment during the neonatal period is an option in many situations. However, for some anomalies whose natural history may be changed for the better, or for those with extremely severe prognoses, fetal intervention may be a therapeutic option. Table 8.3 indicates the class of recommendation and level of evidence for the different fetal cardiac interventions adapted form the Fetal Cardiology guidelines published by the AHA in 2014. ${ }^{17}$

\section{Acknowledgments}

These guidelines are the result of the work of many people whose intellectual, creative, "informatic," and executive efforts, combined with those of the authors, constitute the basis of this document. Unfortunately, because of editorial reasons, it is not possible for all of them to appear among the authors who represent each group. The authors thank them here formally for their 


\section{Guideline}

Table 8.3 - Aim and effects of fetal interventions

\begin{tabular}{cccc}
\hline Anomaly & Intervention aim & GOR/LOE \\
\hline CAS with impending HLHS & $\begin{array}{c}\text { Open the Ao valve to promote anterograde flow, stimulate left structure } \\
\text { growth, create possibility of biventricular correction }\end{array}$ & Disease modifying \\
\hline HLHS with intact IAS or restrictive FO & $\begin{array}{c}\text { Open IAS to alleviate left atrial hypertension, prevent pulmonary } \\
\text { vasculopathy, improve oxygenation at birth }\end{array}$ & Lifb/C \\
\hline $\begin{array}{c}\text { CAS with significant mitral regurgitation } \\
\text { and giant LA }\end{array}$ & $\begin{array}{c}\text { Open Ao valve and/or IAS, alleviate left atrial hypertension and prevent } \\
\text { pulmonary vasculopathy, improve oxygenation at birth }\end{array}$ & IIb/C Lifesaving \\
\hline $\begin{array}{c}\text { PAIVS or CPS with evolving RV } \\
\text { hypoplasia }\end{array}$ & $\begin{array}{c}\text { Open pulmonary valve to promote right structure growth and lead to } \\
\text { possible biventricular repair; treat fetal hydrops in cases of severe } \\
\text { tricuspid regurgitation }\end{array}$ & Disease modifying and/or lifesaving \\
IIb/C
\end{tabular}

Ao: aortic; CAS: critical aortic stenosis; CPS: critical pulmonary stenosis; FO: foramen ovale; GOR: grade of recommendation; HLHS: hypoplastic left heart syndrome; IAS: interatrial septum; LA: left atrium; LOE: level of evidence; PAIVS: pulmonary atresia with intact interventricular septum; RV: right ventricle. Source: Adapted from Donofrio et al. ${ }^{17}$

invaluable contributions and consider them co-authors. Their names, in alphabetical sequence, are:

Ana Maria Arregui Zilio, Antonio Luiz Piccoli Jr., Camila Ritter, Carlos Augusto Cardoso Pedra, Cleisson Fabio
Peralta, Giovana Baldissera, Kenya Venusa Lampert, Luiza Van der Sand, Natássia Miranda Sulis, Stefano Boemler Busato, and Victoria de Bittencourt Antunes.

\section{References}

1. Allan LD, Sharland GK, Milburn A, Lockhart SM, Groves AM, Anderson $\mathrm{RH}$, et al. Prospective diagnosis of 1006 consecutive cases of congenital heart disease in the fetus. J Am Coll Cardiol. 1994;23(6):1452-8.

2. Brick DH, Allan LD. Outcome of prenatally diagnosed congenital heart disease: an update. Pediatr Cardiol. 2002;23(4):449-53.

3. Nomura RM, Brizot ML, Liao AW, Hernandez WR, Zugaib M. Conjoined twins and legal authorization for abortion. Rev Assoc Med Bras (1992). 2011;57(2):205-10.

4. Ewigman BG, Crane JP, Frigoletto FD, LeFevre ML, Bain RP, McNellisD. Effect of prenatal ultrasound screening on perinatal outcome: RADIUS Study Group. N Engl J Med. 1993;329(12):821-7.

5. Tegnander E, Eik-Nes SH, Johansen OJ, Linker DT. Prenatal detectionof heart defects at the routine fetal examination at 18 weeks in a nonselectedpopulation. Ultrasound Obstet Gynecol. 1995;5(6):372-80.

6. Fermont L, De Geeter B, Aubry MC, Kachaner J, Sidi D. A close collaboration between obstetricians and pediatric cardiologists allows antenatal detection of severe cardiac malformation by $2 \mathrm{D}$ echocardiography. In: Doyle EF, Engle ME, Gersony WM, Rashkind WJ, Talner NS. (editors). Pediatric cardiology: proceedings of the secong World Congress. New York: Springer-Verlag; 1986. p. 34-7.

7. Garne E, Stoll C, Clementi M; Euroscan Group. Evaluation of prenatal diagnosis of congenital heart diseases by ultrasound: experience from 20 European registries. Ultrasound Obstet Gynecol. 2001;17(5):386-91.

8. Del Bianco A, Russo S, Lacerenza N, Rinaldi M, Rinaldi G, Nappi L, et al. Four chamber view plus three-vessel and trachea view for acomplete evaluation of the fetal heart during the second trimester. J Perinat Med 2006;34(4):309-12. Erratum in: J Perinat Med. 2006;34(6):509.

9. Marek J, Tomek V, Skovranek J, Povysilova V, Samanek M. Prenatal ultrasound screening of congenital heart disease in an unselected national population: a 21-year experience. Heart. 2011;97(2):124-30.

10. Stümpflen I, Stümpflen A, Wimmer M, Bernaschek G. Effect of detailed fetal echocardiography as part of routine prenatal ultrasonographic screening on detection of congenital heart disease. Lancet. 1996;348(9031):854-7.
11. Kleinert, Sabine. Routine prenatal screening for congenital heart disease. Lancet. 1996;348(9031):836.

12. Lopes LM, Damiano AP, Zugaib M. Programa educativo de treinamento em ecocardiografia fetal nível I: impacto na referência e análise de resultados. Rev Bras Ecocardiogr. 2003;16(3):61-8.

13. Wyllie J, Wren C, Hunter S. Screening for fetal cardiac malformations. Brit Heart J. 1994;71(4 Suppl):20-7.

14. Bonnet D, Coltri A, Butera G, Fermont L, Le Bidois J, Kachaner J, et al. Detection of transposition of the great arteries in fetuses reduces neonatal morbidity and mortality. Circulation. 1999;99(7):916-8.

15. Tworetzky W, McElhinney DB, Reddy MV, Brook MM, Hanley FL, Silverman NH. Improved surgical outcome after fetal diagnosis of hypoplastic left heart syndrome. Circulation. 2001;103(9):1269-73.

16. Franklin O, Burch M, Manning N, Sleeman K, Gould S, Archer N. Prenata I diagnosis of coarctation of the aorta improves survival and reduces morbidity. Heart. 2002;87(1):67-9.

17. Donofrio MT, Moon-Grady AJ, Hornberger LK, Copel JA, Sklansky MS, Abuhamad A, et al; American Heart Association Adults With Congenital Heart Disease Joint Committee of the Council on Cardiovascular Disease in the Young and Council on Clinical Cardiology, Council on Cardiovascular Surgery and Anesthesia, and Council on Cardiovascular and Stroke Nursing. Diagnosis and treatment of fetal cardiac disease a scientific statement from the American Heart Association. Circulation. 2014;129(21):2183-242. Erratum in: Circulation. 2014;129(21):e512.

18. American Institute of Ultrasound in Medicine. AIUM practice guideline for the performance of fetal echocardiography. J Ultrasound Med. 2013;32(6):1067-82.

19. Yoo SJ, Lee YH, Cho KS. Abnormal three-vessel view on sonography: a clue to the diagnosis of congenital heart disease in the fetus. Am J Roentgenol. 1999;172(3):825-30.

20. Mavrides E, Cobian-Sanchez F, Tekay A, Moscoso G, Campbell S, Thilaganathan $B$, et al. Limitations of using first-trimester nuchal translucency measurement in routine screening for major congenital heart. Ultrasound Obstet Gynecol. 2001;17(2):106-10. 
21. Clur SA, Ottenkamp J, Bilardo CM. The nuchal translucency and the fetal heart: a literature review. Prenat Diagn. 2009:29(8):739-48.

22. Ghi T, Huggon IC, Zosmer N, Nicolaides KH. Incidence of major structural cardiac defects associated with increased nuchal translucency but normal karyotype. Ultrasound Obstet Gynecol. 2001;18(6):610-4.

23. Simpson LL, Malone FD, Bianchi DW, Ball RH, Nyberg DA, Comstock CH, et al. Nuchal translucency and the risk of congenital heart disease. Obstet Gynecol. 2007;109(2 Pt 1):376-83.

24. Lopes LM, Brizot ML, Lopes MA, Ayello VD, Schultz R, Zugaib M. Structural and functional cardiac abnormalities identified prior to 16 weeks' gestation in fetuses with increased nuchal translucency. Ultrasound Obstet Gynecol. 2003;22(5):470-8.

25. Lopes LM. (editor). Ecocardiografia fetal. Rio de Janeiro: Revinter; 2016. p. 35-65.

26. Hoffman II, Christianson R. Congenital heart disease in a cohort of 19,502 births with long-term follow-up. Am J Cardiol. 1978;42(4):641-7.

27. Hoffman JI, Kaplan S. The incidence of congenital heart disease. J Am Coll Cardiol. 2002;39(12):1890-900.

28. Hoffman JI. The incidence of congenital heart disease: II. Prenatal incidence. Pediatr Cardiol. 1995;16(4):155-65.

29. Ferencz C, Rubin JD, McCarter RJ, Brenner JI, Neill CA, Perry LW, et al. Congenital heart disease: prevalance at livebirth: the BaltimoreWashington Infant Study. Am J Epidemiol. 1985;121(1):31-6.

30. Copel JA, Pilu G, Kleinman CS. Congenital heart disease and extracardiac anomalies: associations and indications for fetal echocardiography. Am J Obstet Gynecol. 1986:154(5):1121-32.

31. Yoon PW, Olney RS, Khoury MJ, Sappenfield WM, Chavez GF, Taylor D. Contribution of birth defects and genetic diseases to pediatric hospitallizations: a population-based study. Arch Pediatr Adolesc Med. 1997;151(11):1096-103

32. Pinto Junior VC, Daher CV, Sallum FS, Jatene MB, Croti UA. The situation of congenital heart surgeries in Brazil. Braz J Cardiovasc Surg. 2004;19(2):III-VI.

33. Brasil. Ministério da Saúde. Sistema de informações hospitalares do SUS (SIH/SUS). Brasília; 2013.

34. Pinto Junior VC, Rodrigues LC, Muniz CR. Reflexions about formulation of politics for attention to cardiovascular pediatrics in Brazil. Braz J Cardiovasc Surg. 2009;24(1):73-80.

35. UNICEF \& United Nations. Child Mortality Report 2015. [Cited in 2017 Jun 15]. Available from: https://www.unicef.org/publications/files/ child_mortality_report_web_8_sep_2015.

36. Brasil. Ministério da Saúde. Sistema de informações de nascidos vi- vos/ MS/SVS/DASIS. Informações de saúde. Nascidos vivos. 2013. [Citado em 2015 Jun 14]. Disponível em: < http://tabnet.datasus.gov.br/cgi/tabcgi. exe?sinasc/cnv/nvuf. def

37. Huggon IC, Ghi T, Cook AC, Zosmer N, Allan LD, Nicolaides KH. Fetal cardiac abnormalities identified prior to 14 weeks' gestation. Ultrasound Obstet Gynecol. 2002;20(1):22-9.

38. Taipale P, Ammälä M, Salonen R, Hiilesmaa V. Two-stage ultrasonography in screening for fetal anomalies at 13-14 and 18-22 weeks of gestation. Acta Obstet Gynecol Scand. 2004;83(12):1141-6.

39. Gembruch U, Geipel A. Indications for fetal ecohocardiography: screening in low- and high-risk populations. In: Yagel S, Silverman NH, Gembruch U. Fetal cardiology. $2^{\text {nd }}$ ed. New York; Informa Healthcare; 2009. p. 111-29.

40. Garne E, Hansen AV, Birkelund AS, Anderson AM. Major congenital anomalies in a Danish region. Dan Med J. 2014;61(6):A4825.

41. Donofrio MT, Levy RJ, Schuette JJ, Skurow-Todd K, Sten MB, Stallings C, et al. Specialized delivery room planning for fetuses with critical congenital heart disease. Am J Cardiol. 2013;111(5):737-47.

42. Roman KS, Fouron JC, Nii M, Smallhorn JF, Chaturvedi R, Jaeggi ET. Determinants of outcome in fetal pulmonary valve stenosis or atresia with intact ventricular septum. Am J Cardiol. 2007;99(5):699-703.
43. Hornberger LK, Sahn DJ, Kleinman CS, Copel JA, Reed KL. Tricuspid valve disease with significant tricuspid insufficiency in the fetus: diagnosis and outcome. J Am Coll Cardiol. 1991;17(1):167-73.

44. Vogel M, McElhinney DB, Wilkins-Haug LE, Marshall AC, Benson CB Juraszek $\mathrm{AL}$, et al. Aortic stenosis and severe mitral regurgitation in the fetus resulting in giant left atrium and hydrops: pathophysiology, outcomes, and preliminary experience with pre-natal cardiac intervention. J Am Coll Cardiol. 2011;57(3):348-55

45. Taketazu M, Barrea C, Smallhorn JF, Wilson GJ, Hornberger LK. Intrauterine pulmonary venous flow and restrictive foramen ovale in fetal hypoplastic left heart syndrome. J Am Coll Cardiol. 2004;43(10):1902-7.

46. Sivasankaran S, Sharland GK, Simpson JM. Dilated cardiomyopathy presenting during fetal life. Cardiol Young. 2005;15(4):409-16.

47. Pedra SR, Smallhorn JF, Ryan G, Chitayat D, Taylor GP, Khan R, et al. Fetal cardiomyopathies: pathogenic mechanisms, hemodynamic findings, and clinical outcome. Circulation. 2002;106(5):585-91.

48. Hornberger LK, Sahn DJ. Rhythm abnormalities of the fetus. Heart. 2007:93(10):1294-300.

49. Strasburger JF. Prenatal diagnosis of fetal arrhytmias. Clin Perinatol 2005;32(4):891-912.

50. Yinon Y, Chitayat D, Blaser S, Seed M, Amsalem H, Yoo S, et al. Fetal cardiac tumors: a single-center experience of 40 cases. Prenat Diagn. 2010;30(10):941-9.

51. Zielinsky P, Busato S. Prenatal effects of maternal consumption of polyphenol-rich foods in late pregnancy upon fetal ductus arteriosus. Birth Defects Res C Embryo Today. 2013;99(4):256-74.

52. Volpe P, Marasini M, Caruso G, Lituania M, Marzullo A, Volpe G, et al Prenatal diagnosis of ductus venosus agenesis and its association with cytogenetic/congenital anomalies. Prenat Diagn. 2002;22(11):995-1000.

53. Uzun O, Babaoglu K, Ayhan YI, Moselhi M, Rushworth F, Morris S, et al. Diagnostic ultrasound features and outcome of restrictive foramen ovale in fetuses with structurally normal hearts. Pediatr Cardiol. 2014;35(6):943-52.

54. Ayed A, Tonks AM, Lander A, Kilby MD. A review of pregnancies complicated by congenital sacrococcygeal teratoma in the West Midlands region over an 18-year period: population-based, cohort study. Prenat Diagn. 2015;35(11):1037-47.

55. Hellmund A, Berg C, Bryan C, Schneider M, Hraška V, Gembruch U. Large fetal pulmonary arteriovenous malformation detected at midtrimester scan with subsequent high cardiac output syndrome and favorable postnatal outcome. Fetal Diagn Ther. 2014;35(2):133-6.

56. Huhta JC. Fetal congestive heart failure. Semin Fetal Neonatal Med. 2005;10(6):542-52.

57. Berkley EM, Goens MB, Karr S, Rappaport V. Utility of feta echocardiography in postnatal management of infants with prenatally diagnosed congenital heart disease. Prenat Diagn. 2009;29(7):654-8.

58. Johnson BA, Ades A. Delivery room and early postnatal management of neonates who have prenatally diagnosed congenital heart disease. Clin Perinatol. 2005;32(4):921-46.

59. Davey BT, Donofrio MT, Moon-Grady AJ, Fifer CG, Cuneo BF Falkensammer CB, et al. Development and validation of a fetal cardiovascular disease severity scale. Pediatr Cardiol. 2014;35(7):1174-80

60. Trevett TN Jr, Cotton J. Idiopathic constriction of the fetal ductus arteriosus. Ultrasound Obstet Gynecol. 2004;23(5):517-9.

61. Ho SY, Anderson RH. Anatomical closure of the ductus arteriosus: a study in 35 specimens. J Anat. 1979;128(Pt 4):829-36.

62. Tarcan A, Gurakan B, Yildirim S, Ozkiraz S, Bilezikci B. Persistent pulmonary hypertension in a premature newborn after 16 hours of antenatal indomethacin exposure. J Perinat Med. 2004;32(1):98-9.

63. Babaoglu K, Cakiroglu Y, Altun G, Doger E, Oguz D. Intrauterine idiopathic severe ductal constriction diagnosed by fetal echocardiography: a cause of hydrops fetalis. Anadolu Kardiyol Derg. 2013;13(5):496-7. 
64. Abdel Mohsen AH, Amin AS. Risk factors and outcomes of persistent pulmonary hypertension of the newborn in neonatal intensive care unit of Al-Minya University Hospital in Egypt. J Clin Neonatol. 2013;2(2):78-82.

65. Toyoshima K, Takeda A, Imamura S, Nakanishi T, Momma K. Constriction of the ductus arteriosus by selective inhibition of cyclooxygenase- 1 and -2 in near-term and preterm fetal rats. Prostaglandins Other Lipid Mediators. $2006 ; 79(1-2): 34-42$.

66. Koren G, Florescu A, Costei AM, Boskovic R, Moretti ME. Nonsteroidal antiinflammatory drugs during third trimester and the risk of premature closure of the ductus arteriosus: a meta-analysis. Ann Pharmacother. 2006;40(5):824-9.

67. Takami T, Momma K, Imamura S. Increased constriction of the ductus arteriosus by dexamethasone, indomethacin, and rofecoxib in fetal rats. Circ J. 2005;69(3):354-8

68. Shima Y, Ishikawa H, Matsumura Y, Yashiro K, Nakajima M, Migita M. Idiopathic severe constriction of the fetal ductus arteriosus: a possible underestimated pathophysiology. Euro J Pediatr. 2011;170(2):237-40.

69. Di Paola R, Mazzon E, Muia C, Genovese T, Menegazzi M, Zaffini R, et al. Green tea polyphenol extract attenuates lung injury in experimental model of carrageenan-induced pleurisy in mice. Respir Res. 2005;6:66.

70. Martinez I, Moreno JJ. Effect of resveratrol, a natural polyphenolic compound, on reactive oxygen species and prostaglandin production. Biochem Pharmacol. 2000;59(7):865-70.

71. Vian I, Zielinsky P, Zilio AM, Mello A, Lazzeri B, Oliveira A, et al. Development and validation of a food frequency questionnaire for consumption of polyphenol-rich foods in pregnant women. Matern Child Nutr. 2015;11(4):511-24

72. Kapadia V, Embers D, Wells E, Lemler M, Rosenfeld CR. Prenatal closure of the ductus arteriosus and maternal ingestion of anthocyanins. J Perinatol. 2010;30(4):291-4

73. Sridharan S, Archer N, Manning N. Premature constriction of the fetal ductus arteriosus following the maternal consumption of camomile herbal tea. Ultrasound Obstet Gynecol. 2009;34(3):358-9.

74. Zielinsky P, Manica JL, Piccoli AL Jr, Nicoloso LH, Barra M, Alievi MM, et al. Fetal ductal constriction caused by maternal ingestion of green tea in late pregnancy: an experimental study. Prenat Diagn. 2012;32(10):921-6

75. Zielinsky P, Piccoli AL Jr, Manica JL, Nicoloso LH. New insights on fetal ductal constriction: role of maternal ingestion of polyphenol-rich foods. Expert Rev Cardiovasc Ther. 2010;8(2):291-8.

76. Zielinsky P, Piccoli AL Jr, Manica JL, Nicoloso LH, Menezes H, Busato A, et al. Maternal consumption of polyphenol-rich foods in late pregnancy and fetal ductus arteriosus flow dynamics. J Perinatol. 2010;30(1):17-21

77. Zielinsky P, Piccoli AL Jr, Vian I, Zilio AM, Naujorks AA, Nicoloso LH, et al Maternal restriction of polyphenols and fetal ductal dynamics in norma pregnancy: an open clinical trial. Arq Bras Cardiol. 2013;101(3):217-25.

78. Zielinsky P, Piccoli AL Jr, Manica JL, Nicoloso LH, Vian I, Bender L, et al. Reversal of fetal ductal constriction after maternal restriction of polyphenol-rich foods: an open clinical trial. J Perinatol. 2012;32(8):5749.

79. Sulis N, Zielinsky P, Nicoloso LH, Piccoli AL Jr, Vian I, Zilio AM, et al. Prevalência da constrição ductal no terceiro trimestre de vida fetal. Arq Bras Cardiol. 2015;105(3 supl. 1):1-150

80. Levin DL, Hyman AI, Heymann MA, Rudolph AM. Fetal hypertension and the development of increased pulmonary vascular smooth muscle: a possible mechanism for persistent pulmonary hypertension of the newborn infant. J Pediatr. 1978;92(2):265-9.

81. Levin DL, Mills LJ, Weinberg AG. Hemodynamic, pulmonary vascular, and myocardial abnormalities secondary to pharmacologic constriction of the fetal ductus arteriosus. A possible mechanism for persistent pulmonary hypertension and transient tricuspid insufficiency in the newborn infant. Circulation. 1979;60(2):360-4.

82. Harada K, Rice MJ, McDonald RW, Shiota T, Ishii M, Reller MD, et al. Doppler echocardiographic evaluation of ventricular diastolic filling in fetuses with ductal constriction. Am J Cardiol. 1997;79(4):442-6.
83. Moise $\mathrm{KJ} J$ r. Effect of advancing gestational age on the frequency of fetal ductal constriction in association with maternal indomethacin use. Am J Obstet Gynecol. 1993;168(5):1350-3.

84. Levin DL, Rudolph AM, Heymann MA, Phibbs RH. Morphological development of the pulmonary vascular bed in fetal lambs. Circulation. 1976;53(1):144-51.

85. Macones GA, Robinson CA. Is there justification for using indomethacin in preterm labor? An analysis of neonatal risks and benefits. Am J Obstet Gynecol. 1997;177(4):819-24

86. Hofstadler G, Tulzer G, Altmann R, Schmitt K, Danford D, Huhta JC. Spontaneous closure of the human fetal ductus arteriosus--A cause of fetal congestive heart failure. Am J Obstet Gynecol. 1996;174(3):879-83.

87. Huhta JC, Moise KJ, Fisher DJ, Sharif DS, Wasserstrum N, Martin C. Detection and quantitation of constriction of the fetal ductus arteriosus by Doppler echocardiography. Circulation. 1987;75(2):406-12.

88. Mielke G, Benda N. Blood flow velocity waveforms of the fetal pulmonary artery and the ductus arteriosus: reference ranges from 13 weeks to term. Ultrasound Obstet Gynecol. 2000;15(3):213-8.

89. Rasanen J, Jouppila P. Fetal cardiac function and ductus arteriosus during indomethacin and sulindac therapy for threatened preterm labor: a randomized study. Am J Obstet Gynecol. 1995;173(1):20-5.

90. van den Hoff MJ, Deprez RH, Ruijter JM, de Boer PA, Tesink-Taekema $\mathrm{S}$, Buffing AA, et al. Increased cardiac workload by closure of the ductus arteriosus leads to hypertrophy and apoptosis rather than to hyperplasia in the late fetal period. Naunyn-Schmiedeberg's Arch Pharmacol. 2004;370(3):193-202.

91. Momma K, Hagiwara H, Konishi T. Constriction of fetal ductus arteriosus by non-steroidal anti-inflammatory drugs: study of additional 34 drugs. Prostaglandins. 1984;28(4):527-36.

92. Moise KJ Jr, Huhta JC, Sharif DS, Ou CN, Kirshon B, Wasserstrum N, et al. Indomethacin in the treatment of premature labor. Effects on the fetal ductus arteriosus. N Engl J Med. 1988;319(6):327-31.

93. Mari G, Moise KJ Jr, Deter RL, Kirshon B, Huhta JC, Carpenter RJ Jr, et al. Doppler assessment of the pulsatility index of the middle cerebral artery during constriction of the fetal ductus arteriosus after indomethacin therapy. Am J Obstet Gynecol. 1989;161(6 Pt 1):1528-31.

94. Respondek M, Weil SR, Huhta JC. Fetal echocardiography during indomethacin treatment. Ultrasound Obstet Gynecol. 1995;5(2):86-9.

95. Rudolph AM. The effects of nonsteroidal antiinflammatory compounds on fetal circulation and pulmonary function. Obstet Gynecol. 1981;58(5 Suppl):63S-7S

96. Majed BH, Kalil RA. Molecular mechanisms regulating the vascular prostacyclin pathways and their adaptation during pregnancy and in the newborn. Pharmacol Rev. 2012;64(3):540-82.

97. Norton ME. Teratogen update: fetal effects of indomethacin administration during pregnancy. Teratology. 1997;56(4):282-92.

98. Sharpe GL, Larsson KS, Thalme B. Studies on closure of the ductus arteriosus. XII. In utero effect of indomethacin and sodium salicylate in rats and rabbits. Prostaglandins. 1975;9(4):585-96.

99. Gordon MC, Samuels P. Indomethacin. Clin Obstet Gynecol. 1995;38(4):697-705

100. Vogel M, Wilkins-Haug LE, McElhinney DB, Marshall AC, Benson CB, Silva $V$, et al. Reversible ductus arteriosus constriction due to maternal indomethacin after fetal intervention for hypoplastic left heart syndrome with intact/restrictive atrial septum. Fetal Diagn Ther. 2010;27(1):40-5.

101. Moise KJ Jr, Ou CN, Kirshon B, Cano LE, Rognerud C, Carpenter RJ Jr. Placental transfer of indomethacin in the human pregnancy. Am J Obstet Gynecol. 1990;162(2):549-54

102. Hallak M, Reiter AA, Ayres NA, Moise KJ Jr. Indomethacin for preterm labor: fetal toxicity in a dizygotic twin gestation. Obstet Gynecol. 1991;78(5 Pt 2):911-3.

103. Paladini D, Marasini M, Volpe P. Severe ductal constriction in the thirdtrimester fetus following maternal self-medication with nimesulide. Ultrasound Obstet Gynecol. 2005;25(4):357-61. 
104. Auer M, Brezinka C, Eller P, Luze K, Schweigmann U, Schwarzler P. Prenatal diagnosis of intrauterine premature closure of the ductus arteriosus following maternal diclofenac application. Ultrasound Obstet Gynecol. 2004;23(5):513-6.

105. Schiess B, Schneider KT, Zimmermann A, Kainer F, Friese K, Oberhoffer $R$. Prenatal constriction of the fetal ductus arteriosus--related to maternal pain medication? Z Geburtshilfe Neonatol. 2005;209(2):65-8.

106. Hanson MA, Bardsley A, De-Regil LM, Moore SE, Oken E, Poston L, et al. The International Federation of Gynecology and Obstetrics (FIGO) recommendations on adolescent, preconception, and maternal nutrition: "Think Nutrition First". Int J Gynaecol Obstet. 2015;131 Suppl 4:S213-53.

107. Lopes LM, Carrilho MC, Francisco RP, Lopes MA, Krebs VL, Zugaib M. Fetal ductus arteriosus constriction and closure: analysis of the causes and perinatal outcome related to 45 consecutive cases. J Matern Fetal Neonatal Med. 2016;29(4):638-45.

108. Ishida H, Inamura N, Kamazu Y, Kayatani F. Clinical features of the complete closure of the ductus arteriosus prenatally. Congenit Heart Dis. 2011;6(1):51-6.

109. Hooper CW, Delaney C, Streeter T, Yarboro MT, Poole SD, Brown N, et al. Selective serotonin reuptake inhibitor (SSRI) exposure constricts the mouse ductus arteriosus in utero. Am J Physiol Heart Circ Physiol. 2016;311(3):H572-81

110. Weintraub A, Mankuta D. Dipyrone-induced oligohydramnios and ductus arteriosus restriction. Isr Med Assoc J. 2006;8(10):722-3.

111. Delaney C, Gien J, Roe G, Isenberg N, Kailey J, Abman SH. Serotonin contributes to high pulmonary vascular tone in a sheep model of persistent pulmonary hypertension of the newborn. Am J Physiol Lung Cell Mol Physiol. 2013;304(12):L894-901

112. Momma K, Nishihara S, Ota Y. Constriction of the fetal ductus arteriosus by glucocorticoid hormones. Pediatr Res. 1981;15(1):19-21.

113. Hassid A. Regulation of prostaglandin biosynthesis in cultured cells. Am J Physiol. 1982;243(5):C205-11.

114. Wasserstrum N, Huhta JC, Mari G, Sharif DS, Willis R, Neal NK. Betamethasone and the human fetal ductus arteriosus. Obstet Gynecol. 1989;74(6):897-900.

115. Faller AL, Fialho E. Polyphenol content and antioxidant capacity in organic and conventional plant foods. J Food Comp Anal. 2010;23(6):561-68.

116. Nijveldt RJ, van Nood E, van Hoorn DE, Boelens PG, van Norren K, van Leeuwen PA. Flavonoids: a review of probable mechanisms of action and potential applications. Am J Clin Nutr. 2001;74(4):418-25.

117. Wollgast J, Anklam E. Polyphenols in chocolate: Is there a contribution to human health? Food Res Int. 2000;33(6):449-59.

118. Rios-Hoyo A, Cortes MJ, Rios-Ontiveros H, Meaney E, Ceballos G, Gutierrez-Salmean G. Obesity, metabolic syndrome, and dietary therapeutical approaches with a special focus on nutraceuticals (Polyphenols): a mini-review. Int J Vitam Nutr Res. 2014;84(3-4):113-23.

119. Efraim P, Alves AB, Jardim DC. Review: Polyphenols in cocoa and derivatives: factors of variation and health effects. Braz J Food Technol. 2011;14(3):181-201.

120. Halliwell B. How to characterize a biological antioxidant. Free Radic Res Commun. 1990:9(1):1-32.

121. Zielinsky PM, Manica JL, Piccoli Jr A, Areias JC, Nicoloso LH, Menezes $\mathrm{HS}$, et al. Experimental study of the role of maternal consumption of green tea, mate tea and grape juice on fetal ductal constriction. $17^{\text {th }}$ World Congress on Ultrasound in Obstetrics and Gynecology, 2007 - Ultrasound in Obstetrics and Gynecology. 2007;30(4):515.

122. Bubols GB, Zielinsky P, Piccoli AL Jr, Nicoloso LH, Vian I, Moro AM, et al. Nitric oxide and reactive species are modulated in the polyphenolinduced ductus arteriosus constriction in pregnant sheep. Prenat Diagn. 2014;34(13):1268-76.

123. Zielinsky P, Martignoni FV, Vian I. Deleterious effects of maternal ingestion of cocoa upon fetal ductus arteriosus in late pregnancy. Front Pharmacol. $2014 ; 5: 281$
124. Zílio AM, Zielinsky P, Vian I, Schaun MI, Markoski M, Lampert K, et al. Polyphenol supplementation inhibits physiological increase of prostaglandin E2 during reproductive period - a randomized clinica trial. Prostaglandins Leukot Essent Fatty Acids. 2017 Apr 5. [Epub ahead of print].

125. Vian I, Zielinsky P, Zilio AM, Schaun M, Brum C, Lampert KV, et al. Increase of Prostaglandin E2 in the Reversal of Ductal Constriction After Polypheno Restriction. Ultrasound Obstet Gynecol. 2018 Nov;52(5):617-622.

126. Khan HY, Zubair H, Ullah MF, Ahmad A, Hadi SM. A prooxidant mechanism for the anticancer and chemopreventive properties of plant polyphenols. Curr Drug Targets. 2012;13(14):1738-49.

127. Arnt A. Quantificação do conteúdo de polifenóis totais em alimentos consumidos no sul do Brasil. 2015. Dissertação de mestrado. Instituto de Cardiologia do Rio Grande do Sul, Porto Alegre, 2015.

128. Kleinman CS, Nehgme RA. Cardiac arrhythmias in the human fetus. Pediatr Cardiol. 2004;25(3):234-51

129. Zielinsky P. [Fetal heart rhythm disorders. Detection and prenatal management]. Arq Bras Cardiol. 1996;66(2):83-6.

130. Kleinman CS, Donnerstein RL, Jaffe CC, DeVore GR, Weinstein EM, Lynch DC, et al. Fetal echocardiography: a tool for evaluation of in utero cardiac arrhythmias and monitoring of in utero therapy: analysis of 71 patients. Am J Cardiol 1983;51(2):237-43.

131. Zielinsky P, Dillenburg RF, de Lima GG, Zimmer LP. [Fetal supraventricula tachyarrhythmias. Experience of a fetal cardiology referral center]. Arq Bras Cardiol 1998;70(5):337-40.

132. Fouron JC, Proulx F, Miro J, Gosselin J. Doppler and M-mode ultrasonography to time fetal atrial and ventricular contractions. Obstet Gynecol. 2000;96(5 Pt 1):732-6.

133. Fouron JC, Fournier A, Proulx F, Lamarche J, Bigras JL, Boutin C, et al. Management of fetal tachyarrhytmia based on superior vena cava/aorta Doppler flow recordings. Heart. 2003;89(10):1211-6.

134. Hornberger LK. Echocardiographic assessment of fetal arrhythmias. Heart. 2007;93(11):1331-3.

135. Carvalho JS, Prefumo F, Ciardelli V, Sairam S, Bhide A, Shinebourne EA Evaluation of fetal arrhythmias from simultaneous puldes wave Dopple in pulmonary artery and vein. Heart. 2007;93(11):1448-53.

136. Dancea A, Fouron JC, Miró J, Skoll A, Lessard M. Correlation between electrocardiographic and ultrassonographic time-interval measurements in fetal lamb heart. Pediatr Res. 2000;47(3):324-8.

137. Wacker-Gussmann A, Strasburger JF, Cuneo BF, Wakai RT. Diagnosis and treatment of fetal arrhythmia: Am J Peronatol. 2014;31(7):617-28.

138. Strasburger JF, Wakai, RT. Fetal cardiac arrhythmia detection and in utero therapy: Nat Rev Cardiol. 2010;7(5):277-90.

139. Copel JA, Liang RI, Demasio K, Ozeren S, Kleinman CS. The clinica significance of the irregular fetal heart rhythm. Am J Obstet Gynecol. $2000 ; 182(4): 813-7$

140. Fouron JC. Fetal arrhythmias: the Saint-justine hospital experience. Prenat Diagn. 2004;24(13):1068-80.

141. Srinivasan S, Strasburger J. Overview of fetal arrhythmias. Curr Opin Pediatr. 2008;20(5):522-31.

142. Eliasson H, Wahren-Herlenius M, Sonesson SE. Mechanisms in fetal bradyarrhythmia: 65 cases in a single center analyzed by Dopple flow echocardiographic techniques. Ultrasound Obstet Gynecol. 2011;37(2):172-8.

143. Breur JM, Oudijk MA, Stoutenbeek P, Visser GH, Meijboom EJ. Transient non-autoimmune fetal heart block. Fetal Diagn Ther. 2005;20(2):81-5.

144. Machado MV, Tynan MJ, Curry PV, Allan LD. Fetal complete heart block. Br Heart J. 1988;60(6):512-5.

145. Schmidt KG, Ulmer HE, Silverman NH, Kleinmann CS, Copel JA Perinatal outcome of fetal complete atrioventricular block: a multicenter experience. J Am Coll Cardiol. 1991;17(6):1360-6. 
146. Cuneo BF, Zhao H, Strasburger JF, Ovadia M, Huhta JC, Wakai RT. Atrial and ventricular rate response and patterns of heart rate acceleration during maternal-fetal terbutaline treatment of fetal complete heart block. Am J Cardiol. 2007;100(4):661-5.

147. Sonesson SE, Salomonsson S, Jacobsson LA, Bremme K, Wahren-Herlenius M. Signs of first-degree heart block occur in one-third of fetuses of pregnant women with anti-SSA/Ro 52-kd antibodies. Arthritis Rheum. 2004;50(4):1253-61.

148. Rein AJ, Mevorach D, Perles Z, Gavri S, Nadjari M, Nir A, et al. Early Diagnosis and treatment of atrioventricular block in the fetus exposed to maternal anti-SSA/Ro-SSB/La antibodies: a prospective, observational, fetal kinetocardiogram-based study. Circulation. 2009;119(14):1867-72.

149. Aoki H, Inamura N, Kawazu Y, Nakayama M, Kayatani F. Fetal echocardiographic assessment of endocardial fibroelastosis in maternal anti-SSA antibody-associated complete heart block. Circ J. $2011 ; 75(5): 1215-21$.

150. Krishnan A, Pike JI, Donofrio MT. Prenatal evaluation and management of fetuses exposed to anti SSA/Ro antibodies. Pediatr Cardiol. 2012;33(8):1245-52.

151. Ambrosi A, Wahren-Herlenius M. Congenital heart block: evidence for pathogenic role of maternal autoantibodies. Arthritis Res Ther. $2012 ; 14(2): 208$.

152. Eliasson H, Sonesson SE, Sharland G, Granath F, Simpson J, Carvalho JS, et al; Fetal Working Group of the European Association of Pediatric Cardiology. Isolated atrioventricular block in the fetus. A retrospective, multinational, multicenter study of 175 patients. Circulation. 2011;124(18):1919-26.

153. Clancy RM, Buyon JP, Ikeda K, Nozawa K, Argyle DA, Friedman DM, et al. Maternal antibody responses to the 52-kd SSA/RO p200 peptide and development of fetal conduction defects. Arthritis Rheum. 2005;52(10):3079-86.

154. Bergman G, Eliasson H, Bremme K, Wahren-Herlenius M, Sonesson SE. Anti-Ro52/SSA antibody-exposed fetuses with prolonged atrioventricular time intervals show signs of decreased cardiac performance. Ultrasound Obstet Gynecol. 2009;34(5):543-9.

155. Rosenthal D, Druzin M, Chin C, Dubin A. A new therapeutic approach to the fetus with congenital complete heart block: preemptive, targeted therapy with dexamethasone. Obstet Gynecol. 1998;92(4 Pt 2):689-91.

156. Trucco SM, Jaeggi E, Cuneo B, Moon-Grady AJ, Silverman E, Silverman $\mathrm{N}$, et al. Use of intravenous gamma globulin and corticosteroids in the treatment of maternal autoantibody-mediated cardiomyopathy. J Am Coll Cardiol. 2011;57(6):715-23.

157. Jaeggi ET, Fouron JC, Silverman ED, Ryan G, Smallhorn J, Hornberger LK. Transplacental fetal treatment improves the outcome of prenatally diagnosed complete atrioventricular block without structural heart disease. Circulation. 2004;110(12):1542-8.

158. Cuneo BF, Lee M, Roberson D, Niksch A, Ovadia M, Parilla BV, et al. A management strategy for fetal immune-mediated atrioventricular block. J Matern Fetal Neonatal Med. 2010;23(12):1400-5

159. Friedman DM, Kim MY, Copel JA, Llanos C, Davis C, Buyon JP. Prospective evaluation of fetuses with autoimmune-associated congenital heart block followed in the PR Interval and Dexamethasone Evaluation (PRIDE) Study. Am J Cardiol. 2009;103(8):1102-6.

160. Buyon JP, Clancy RM, Friedman DM. Cardiac manifestations of neonatal lupus erythematosus: guidelines to management, integrating clues from the bench and bedside. Nat Clin Pract Rheumatol. 2009;5(3):139-48.

161. Raboisson MJ, Fouron JC, Sonesson SE, Nyman M, Proulx F Gamache S. Fetal Doppler echocardiographic diagnosis and successful steroid therapy of Luciani-Wenckebach phenomenon and endocardial fibroelastosis related to maternal anti-Ro and anti-La antibodies. Am Soc Echocardiogr. $2005 ; 18(4): 375-80$.

162. Lopes LM, Tavares GM, Damiano AP, Lopes MA, Aiello VD, Schultz R, et al. Perinatal outcome of fetal atrioventricular block: one-hundred sixteen cases from a single institution. Circulation. 2008;118(12):1268-75. Erratum in: Circulation. 2008;118(16): e671.
163. Mitchell J, Cuneo B, Etheridge SP, Horigome H, Weng H, Benson W. Fetal heart rate predictors of long QT syndrome. Circulation. 2012:126(23):2688-95.

164. Carpenter RJ Jr, Strasburger JF, Garson A Jr, Smith RT, Deter RL, Engelhardt HT Jr. Fetal ventricular pacing for hydrops secondary to complete atrioventricular block. J Am Coll Cardiol. 1986;8(6):1434-6.

165. Scagliotti D, Shimokocil DD, Pringle KC. Permanent cardiac pacemaker implant in the fetal lamb. Pacing Clin Electrophysiol. 1987;10(6):1253-6.

166. Assad RS, Jatene MB, Moreira LF, Sales PC, Costa R, Hanley FL, et al. Fetal heart block: a new experimental model to assess fetal pacing. Pacing Clin Eletrophysiol. 1994;17(7):1256-63.

167. Assad RS, Zielinsky P, Kalil R, Lima G, Aramayo A, Santos A, et al. New lead for in utero pacing for fetal congenital heart block. J Thorac Cardiovasc Surg. 2003;126(1):300-2.

168. Assad RS, Zielinsky P, Kalil R, Lima G, Aramayo A, Santos A, et al. New electrode for pacing fetuses with complete heart block. Rev Bras Cir Cardiovasc. 2003;18(1):40-4.

169. Lulic Jurjevic R, Podnar T, Vesel S. Diagnosis, clinical features, management, and post-natal follow-up of fetal tachycardias. Cardiol Young. 2009;19(5):486-93.

170. Ekman-Joelson BM, Mellander M, Lagnefeldt L, Sonesson SE. Foetal tachyarrhythmia treatment remains challenging even if the vast majority of cases have a favourable outcome. Acta Paediatr. 2015;104(11):1090-7.

171. Cuneo BF, Strasburger JF. Management strategy for fetal tachycardia. Obstet Gynecol. 2000;96(4):575-81.

172. Simpson JM, Maxwell D, Rosenthal E, Gill H. Fetal ventricular tachycardia secondary to long QT syndrome treated with maternal intravenous magnesium: case report and rewiew of the literature. Ultrasound Obstet Gynecol. 2009;34(4):475-80.

173. Merriman JB, Gonzalez JM, Rychil J, Ural SH. Can digoxin and sotalol therapy for fetal supraventricular tachycardia and hydrops be successful? A case report. J Reprod Med. 2008;53(5):357-9.

174. Zhou K, Hua Y, Zhu Q, Liu H, Yang S, Zhou R, et al. Transplacental digoxin therapy for fetal tachyarrhythmia with multiple ecaluation systems. J Matern Fetal Neonatal Med. 2011;24(11):1378-83.

175. Rebelo M, Macedo, AJ, Nogueira G, Trigo C, Kaku S. Sotalol in the treatment of fetal tachyarrhythmia. Rev Port Cardiol. 2006;25(5):477-81.

176. van der Heijden LB, Oudijk MA, Manten GT, ter Heide H, Pistorius L, Freund MW. Sotalol as first-line treatment dor fetal tachycardia and neonatal follow-up. Ultrasound Obstet Gynecol. 2013;42(3):285-93.

177. Shah A, Moon-Grady A, Bhogal N, Collins KK, Tacy T, Brook M, et al. Effectiveness of sotalol as first-line therapy for supraventricular tachyarrhythmias. Am J Cardiol. 2012;109(11):1614-8.

178. Pézard PG, Boussion F, Sentilhes L, Lépinard C, Couvreur MH, Victor J, et al. Fetal tachycardia: a role for amiodarone as first-or second-line therapy? Arch Cardiovasc Dis. 2008;101(10): 619-27.

179. Kang SL, Howe D, Coleman M, Roman K, Gnanapragasam J. Foetal supraventricular tachycardia with hydrops fetalis: a role for direct intraperitoneal amiodarone. Cardiol Young. 2015;25(3):447-53.

180. Bartalena L, Bogazzi F, Braverman LE, Martino E. Effects of amiodarone administration during pregnancy on neonatal thyroid function and subsequent neurodevelopment. J Endocrinol Invest. 2001;24(2):116-30.

181. Parilla BV, Strasburger JF, Socol ML. Fetal supraventricular tachycardia complicated by hydrops fetalis: a role for direct fetal intramuscular therapy. Am J Perinatol. 1996;13(8):483-6.

182. Hansmann M, Gembruch U, Bald R, Manz M, Redel DA. Fetal tachyarrhythmias: transplacental and direct treatment of the fetus: a report of 60 cases. Ultrasound Obstet Gynecol. 1991;1(3):162-8.

183. Vigneswaran TV, Callaghan N, Andrews RE, Miller O, Rosenthal E, Sharland GK, et al. Correlation of maternal flecainide concentrations and therapeutic effect in fetal supraventricular tachycardia. Heart Rhythm. 2014;11(11):2047-53. 
184. Uzun O, Babaoglu K, Sinha A, Massias S, Beattie B. Rapid control of foetal supraventricular tachycardia with digoxin and flecainide combination treatment. Cardiol Young. 2012;22(4):372-80. Erratum in: Cardiol Young. 2012;22(4):488

185. Naheed ZJ, Strasburger JF, Deal BJ, Benson DW Jr, Gidding SS. Fetal tachycardia: mechanisms and predictors of hydrops fetalis. J Am Coll Cardiol. 1996;27(7):1736-40.

186. Horigome $H$, Nagashima $M$, Sumitomo $N$, Yoshinaga $M$, Ushinohama $\mathrm{H}$, Iwamoto $\mathrm{M}$, et al. Clinical characteristics and genetic background of congenital long-QT syndrome diagnosed in fetal, neonatal, and infantile life: a nationwide questionnaire survey in Japan. Circ Arrhythm Electrophysiol. 2010;3(1):10-7. Erratum in: Circ Arrhythm Electrophysiol. 2012;5(6):e120-2.

187. Cuneo BF, Ovadia M, Strasburger JF, Zhao H, Petropulos T, Schneider $\mathrm{J}$, et al. Prenatal diagnosis and in utero treatment of torsades de pointes associated with congenital long QT syndrome. Am J Cardiol. 2003;91(11):1395-8.

188. Kohl T, Sharland G, Allan LD, Gembruch U, Chaoui R, Lopes LM, et al. World experience of percutaneous ultrasound-guided balloon valvuloplasty in humam fetuses with severe aortic valve obstruction. Am J Cardiol. 2000;85(10):1230-3

189. Pedra CA, Peralta C, Pedra SF. Intervenções terapêuticas no coração fetal. Rev Soc Cardiol Estado de Sao Paulo. 2011;21(4):64-70.

190. McElhinney DB, Tworetzky W, Lock JE. Current status of fetal cardiac intervention Circulation. 2010;121(10):1256-63.

191. Tworetzky W, Marshal AC. Balloon vavuloplasty for congenital heart disease in the fetus. Clin Perinatol. 2003:30(3):541-50.

192. Artz W, Werttaschnigg D, Veit I, Klement F, Gitter R, Tulzer G. Intrauterine aortic valvuloplasty in fetus with critical aortic stenosis: experience and results of 24 procedures. Ultrasound Obstet Gynecol. 2011;37(6):689-95.

193. Mäkikallio K, McElhinney DB, Levine JC, Marx GR, Colan SD, Marshall $\mathrm{AC}$, et al. Fetal aortic valve stenosis and the evolution of hypoplastic left heart syndrome: patient selection for fetal intervention. Circulation. 2006;113(11):1401-5.

194. Marshall AC, Tworetzky W, Bergersen L, McElhinney DB, Benson $\mathrm{CB}$, Jennings RW, et al. Aortic valvuloplasty in the fetus: technical characteristics of successful balloon dilation. J Pediatr. 2005;147(4):535-9.

195. McElhinney DB, Marshall AC, Wilkins-Haug LE, Brown DW, Benson CB, Silva $\mathrm{V}$, et al. Predictors of technical success and postnatal biventricular outcome after in utero aortic valvuloplasty for aortic stenosis with evolving hypoplastic left heart syndrome. Circulation. 2009;120(15):1482-90.

196. Marshall AC, van der Velde ME, Tworetzky W, Gomez CA, Wilkins-Haug $\mathrm{L}$, Benson CB, et al. Creation of an atrial septal defect in utero for fetuses with hypoplastic left heart syndrome and intact or highly restrictive atrial septum. Circulation. 2004;110(3):253-8.

197. Marshall AC, Levine J, Morash D, Silva V, LockJE, Benson CB, et al. Results of in utero atrial septoplasty in fetuses with hypoplastic left heart syndrome. Prenat Diagn. 2008;28(11):1023-8.

198. Gardiner HM, Belmar C, Tulzer G, Barlow A, Pasquini L, Carvalho JS, et al. Morphologic and functional predictors of eventual circulation in the fetus with pulmonary atresia or critical pulmonary stenosis with intact septum. J Am Coll Cardiol. 2008;51(13):1299-308.

199. Tulzer G, Artz W, Franklin RC, Loughna PV, Mair R, Gardiner HM. Fetal pulmonary valvuloplasty for critical pulmonary stenosis or atresia with intact septum. Lancet. 2002;360(9345):1567-8.

200. Tworetzky W, McElhinney DB, Marx GR, Benson CB, Brusseau R, Morash $D$, et al. In utero valvuloplasty for pulmonary atresia with hypoplastic right ventricule: techniques and outcomes. Pediatrics. 2009;124(3):e510-8.

201. Pedra SR, Peralta CF, Crema L, Jatene IB, da Costa RN, Pedra CA. Fetal interventions for congenital heart disease in Brazil. Pediatr Cardiol. 2014;35(3):399-405.

202. Gardiner H. In-utero intervention for severe congenital heart disease. Best Pract Res Clin Obstet Gynaecol. 2008;22(1):49-61.
203. Matsui H, Gardiner H. Fetal intervention for cardiac disease: the cutting edge of perinatal care. Semin Fetal Neonatal Med. 2007:12(6):482 9. 204. Fishman NH, Hof RB, Rudolph AM, Heymann MA. Models of congenital heart disease in fetal lambs. Circulation. 1978;58(2):354-64.

205. Levin DL, Perkin RM, Parkey M, Mayhew E, Hartwig R. Experimental aortic stenosis in fetal lambs. Circulation. 1980;62(6):1159-64.

206. Sedmera D, Hu N, Weiss KM, Keller BB, Denslow S, Thompson RP Cellular changes in experimental left heart hypoplasia. Anat Rec. 2002;267(2):137-45

207. Miller CE, Wong CL, Sedmera D. Pressure overload alters stress-strain properties of the developing chick heart. Am J Physiol Heart Circ Physiol. 2003;285(5):H1849-56.

208. Samson F, Bonnet N, Heimburger M, Rücker-Martin C, Levitsky DO Mazmanian GM, et al. Left ventricular alterations in a model of fetal left ventricular overload. Pediatr Res. 2000;48(1):43-9.

209. Eghtesady P, Michelfelder E, Altaye M, Ballard E, Hirsh R, Beekman RH $3^{\text {rd }}$. Revisiting animal models of aortic stenosis in the early gestation fetus. Ann Thorac Surg. 2007;83(2):631-9.

210. Tworetzky W, Wilkins-Haug L, Jennings RW, van der Velde ME, Marshal AC, Marx GR, et al. Balloon Dilation of severe aortic stenosis in the fetus: potential for prevention of hypoplastic left heart syndrome: candidate selection, technique, and results of successful intervention. Circulation. 2004:110(15):2125-31.

211. Emani SM, McElhinney DB, Tworetzky W, Myers PO, Schroeder B Zurakowski D, et al. Staged left ventricular recruitment after singleventricle palliation in patients with borderline left heart hypoplasia. J Am Coll Cardiol. 2012:60(19):1966-74.

212. Friedman KG, Freud L, Escobar-Diaz M, Banka P, Emani S, Tworetzky $W$. Left ventricular remodeling and function in children with biventricular circulation after fetal aortic valvuloplasty. Pediatr Cardiol. 2015;36(7):1502-9

213. Friedman KG, Margossian R, Graham DA, Harrild DM, Emani SM, WilkinsHaug LE, et al. Postnatal left ventricular diastolic function after fetal aortic valvuloplasty. Am J Cardiol. 2011;108(4):556-60.

214. Todros T, Paladini D, Chiappa E, Russo MG, Gaglioti P, Pacileo G, et al. Pulmonary stenosis and atresia with intact ventricular septum during prenatal life. Ultrasound Obstet Gynecol. 2003;21(3):228-33.

215. Gardiner HM. Progression of fetal heart disease and rationale of fetal intracardiac interventions. Semin Fetal Neonatal Med. $2005 ; 10(6): 578-85$.

216. Salvin JW, MacElhinney DB, Colan SD, Gauvreau K, del Nido PJ Jenkins KJ, et al. Fetal tricuspid valve size and growth as predictor of outcome in pulmonary atresia with intact ventriuclar septum. Pediatrics. 2006;118(2):e415-20.

217. Tworestzky W, Marshall AC. Fetal interventions for cardiac defects. Pediat Clin North Am. 2004;51(6):1503-13.

218. Vlahos AP, Lock JE, McElhinney DB, van der Velde ME. Hypoplastic left heart syndrome with intact or highly restrictive atrium septum: outcome after neonatal transcatheter atrial septostomy. Circulation. 2004;109(19):2326-30.

219. Rychik J, Rome Jl, Collins MH, DeCampli WM, Spray TL. The hypoplastic left heart syndrome with intact atrial septum: atrial morphology, pulmonary vascular histopathology and outcome. J Am Coll Cardiol. 1999;34(2):554-60.

220. Moerman PL, Van Dijck H, Lauweryns JM, Eggermont E, Van der Hauwaert LG. Premature closure of the foramen ovale and congenital pulmonary cystic lymphangiectasis in aortic valve atresia or in severe aortic valve stenosis. Am J Cardiol. 1986;57(8):703-5.

221. Graziano JN, Heidelberger KP, Ensing GJ, Gomez CA, Ludomirsky A The influence of a restrictive atrial septal defect on pulmonary vascular morphology in patients with hypoplastic left heart syndrome. Pediatr Cardiol. 2002;23(2):146-51

222. Sekar $\mathrm{P}$, Hornberger LK. The role of fetal echocardiography in fetal intervention: a symbiotic relationship. Clin Perinatol. 2009;36(2):301-27. 


\section{Guideline}

223. Wilkins-Haug LE, Benson CB, Tworetzky W, Marshall AC, Jennings RW, Lock JE. In-utero intervention for hypoplastic left heart syndrome - a perinatologist's perspective. Ultrasound Obstet Gynecol. $2005 ; 26(5): 481-6$.

224. Chaturvedi RR, Ryan G, Seed M, Van Arsdell G, Jaeggi ET. Fetal stenting of the atrial septum: technique and initial results in cardiac lesions with left atrial hypertension. Int J Cardiol. 2013;168(3):2029-36.
225. Kalish BT, Tworetzky W, Benson CB, Wilkins-Haug L, Mizrahi-Arnaud A, McElhinney DB, et al. Technical challenges of atrial septal stent placement in fetuses with hypoplastic left heart syndrome and intact atrial septum. Catheter Cardiovasc Interv. 2014;84(1):77-85. 
